\title{
Historia geológica de Colombia
}

\section{Hans Bürgl}

Rev. Acad. Colomb. Cienc. Ex. Fis. Nat. 1961, 11 (43): 138-191.

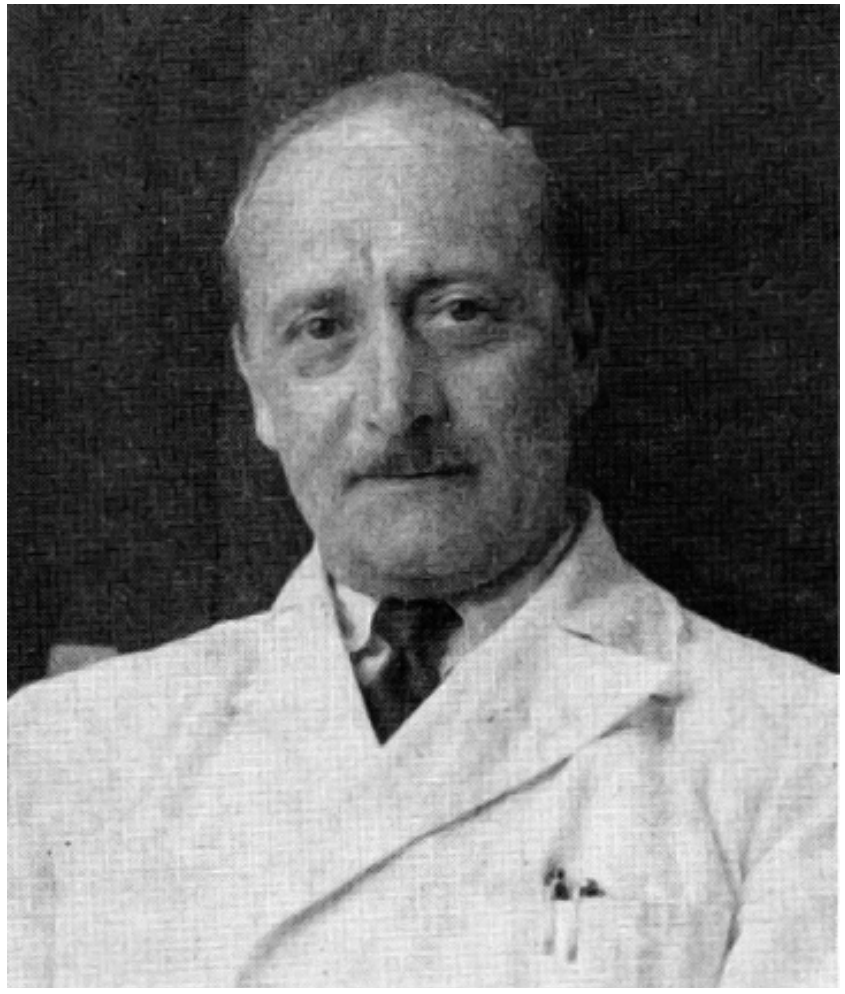

\section{Hans Bürgl (1907-1966)}

Bürgl nació en Viena(Austria). Allí mismo estudió Ciencias Naturales con especialización en Paleontología y Biología. En 1933 obtuvo el doctorado en la Universidad de Viena, bajo la dirección del profesor Eduard Suess. De 1931 a 1939 trabajó con la compañía Standard Oil en Egipto y Alemania. Luego prestó sus servicios a la Kontinentale Erdol Gessels Schaft en Rumania. En 1942 regresó a trabajar en Austria. En 1951 llegó a Colombia como Jefe de Paleontología del Servicio Geológico Nacional en donde inició el estudio y contribuyó al conocimiento geológico del país. En 1957 se vinculó como profesor de la Universidad Nacional de Colombia en Bogotá, allí y de manera muy importante, trabajó en la formación y orientación de las primeras promociones de geólogos colombianos a través de las cátedras de Paleontología, Geología Histórica, Geología Regional, Geología General y Física. Unos años antes de su muerte, ocurrida en la ciudad de Bogotá en 1966, creó una compañía de consultoría para asesorar a las compañías petroleras.

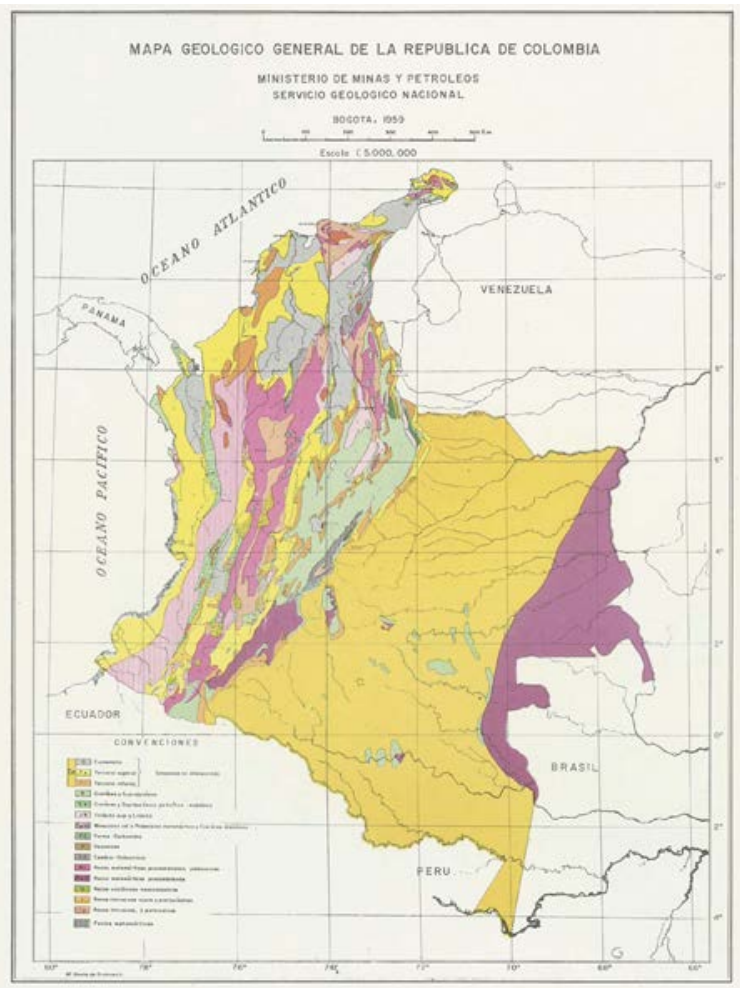

En este artículo, el autor lleva a cabo una síntesis muy informativa del conocimiento geológico del país existente al momento de la publicación, la que ofrece una visión personal permeada y enriquecida por su formación y por el trabajo de campo que realizara a lo largo y ancho de nuestro país. Desde su aparición en la Revista de la Academia, esta publicación se convirtió en una obra de consulta obligada para los interesados en la evolución de corteza terrestre de nuestra Colombia en el marco de los procesos exógenos y endógenos de carácter regional y global.

José A. Lozano

Miembro Honorario

Jorge A. Brieva

Biblioteca de la Acadeamia Colombiana de Ciencias Exactas, Físicas y Naturales 


\title{
HISTORIA GEOLOGICA DE COLOMBIA
}

\author{
HANS BÜRGL \\ de la Academia Colombiana de Ciencias \\ y del Instituto de Ciencias de la Univer- \\ sidad Nacional de Colombia.
}

\section{P R O L O G O \\ de LUIS GUILLERMO DURAN S. \\ Profesor del Departamento de Geología y Geofísica de la Universidad Nacional de Colombia.}

"...La Terre - ma sceur la Terre, aurait dit saint François d'Assisem'est apparue, dès ma jeunesse, comme infiniment belle; digne d'être parcourue, étudiée, expliquée et chantée; capable de nous consoler dans les pires douleurs et, quoique périssable elle-même, de nous farler d'éternité... Quand les sciences dont elle est l'objet m'eurent définitivement séduit, enchainé et conquis, mon admiration devint une sorte de passion ardente et je tâchai de communiquer cette flamme aux âmes qui s'approchaient de la mienne..."

Pierre Termier ("A la Gloire de la Terre", 1922).

\begin{abstract}
Unicamente nuestro gran aprecio personal por el Dr. Hans Bürgl, y nuestra común vinculación a la tarea de la docencia universitaria en una facultad que ambos hemos visto nacer y crecer con el cariño más entrañable, nos han decidido a aceptar la gentil invitación de la Dirección de la Revista de la Academia Colombiana de Ciencias, a prologar una obra cuyos indiscutibles méritos sobrepasan, con mucho, nuestros modestos conocimientos y capacidades. Nos resultaba muy difícil, además, debemos confesarlo, rehusar como profesores de Geología de la Universidad Nacional, a la oportunidad de destacar la labor científica y didáctica de un distinguido miembro de nuestra Facultad de Geología y Geofísica que ha perpetuado entre nosotros la escuela geológiea de un maestro por quien siempre hemos sentido la más grande admiración y profundo respeto: Eduard Suess. Testimonio de ello es el retrato que en la/ galería del Instituto de Ciencias preside Suess, por iniciativa y obra nuestra que nos enorgullecen. Con ell culto a este eminentísimo precursor de las ciencias de la Tierra hemos querido exteriorizar allí nuestra íntima y angustiosa preocupación, tantas veces expresada, por que la Universidad no corte sus nexos con las fuentes europeas de nuestra cultura clásica, en su afán aparentemente creciente por una orientación excesivamente pragmática 1 . Nada podía, pues, satisfacer mejor nuestros anhelos en este sentido, que la exaltación de los méritos y la labor de tan digno representante de la escuela vienesa de Suess en nuestra Universidad, como lo es el Profesor Bürgl.
\end{abstract}

Escribir un bosquejo extenso de la geología de cualquier país es labor de una complejidad difícilmente imaginable, y para hacerlo con verdadera competencia y claridad se requieren dotes excepcionales, entre otras razones porque la Geología hoy día es una disciplina científica y técnica que se subdivide en un sinnúmero de ramas y especialidades, cualquiera de las cuales demanda toda una vida para su dominio, y se necesitan conocimientos y experiencia en sus múltiples facetas para alcanzar con algún éxito el objetivo. En la geología colombiana, los problemas de la Paleontología, la Estratigrafía, la Petrografía, la Tectónica, la Volcanologia, la Glaciología, la Geofísica, etc., ofrecen complicaciones y peculiaridades que son verdaderos retos para cualquier investigador, y no serán definitivamente resueltos sino mediante una intensificación consciente de estos estudios. Antes de la presente obra se han publicade en diversas épocas resúmenes sobre la geología de Colombia, ya sean generales o desde puntos de vista especializados, y es jusțo consignar para ellos aquí el testimonio de la admiración que su esfuerzo calidad nos merecen; sin ellos no habría podido el Dr. Bürgl presentarnos hoy una obra tan extensa, completa y acertada como la suya. En su minuciosa bibliografía al final del trabajo, él da crédito a sus predecesores, pero nosotros quisiéramos recordar aquí, con su carácter de resúmenes o bosquejos generales o especiales muy meritorios, las obras de Karsten (1886), Hettner (1887), Tulio Ospina (1911), Schuchert (1935), Stille (1940), Schaufelberger (1944), Anderson (1945), R. Hno. Daniel (1948), Gerth (1955) y Jenks-Olsson (1956). Aun cuando de carácter mucho más especializado en lo referente a las minas, debemos mencionar también la obra del Dr. Roberto Wokittel, publicada por el Servicio Geológico Nacional en Mayo de 1960, como una valiosísima contribución a la literatura geológica y minera colombiana.

El Dr. Bürgl es suficientemente conocido entre nosotros y en el extranjero por sus numerosos trabajos y publicaciones sobre la geología de Colombia. Después de doctorarse en Paleontología y Geología en 1933 en su patria, en la Universidad de Viena, trabajó como geólogo en la exploración petrolífera para varias compañías en diversos países europeos y en Egipto. Vino a Colombia como paleontólogo jefe, del Servicio Geológico Nacional en 1951, y desde 1957 se vinculó a la docencia en la Universidad Nacional, con carácter de profesor de tiempo completo desde el presente año. Posee, pues, el autor de esta Historia Geológica, además de sus vastas disciplinas académicas y docentes, una gran experiencia de campo.

1 L. G. Durán S., "Programa de Investigación Científica Sistemática para la Facultad de Geología y Geofísica de la Universidad Nacional", Revista del Petróleo, N 66, Bogotá, 1956. 
En esta "Historia Geológica de Colombia" ha realizado su autor una formidable labor de síntesis, a la cual ha aportado gran cantidad de datos, obtenidos en sus propios estudios e investigaciones. a todo lo largo y ancho de nuestro suelo colombiano. Con mente y mano maestras ha trazado en ella el desarrollo geológico de nuestro país, describiendo, analizando y cartografiando sus vicisitudes a través de la noche cósmica de las eras y períodos geológicos, hasta el amanecer de nuestra era Psicozoica, explicándonos los paroxismos tectónicos que solevantaron las cordilleras; los procesos sedimentarios de sus geosinclinales; los fenómenos erosivos, que con los ríos y los glaciares pugnan, como factores exógenos, por reducir el continente al nivel del mar, en lucha contra los procesos endógenos del volcanismo, que han amojonado con sus picos enhiestos y nevados las cimas de nuestros Andes. Con todo ello nos hace asistir, simultáneamente, a los fenómenos que plasmaron, en las profundidades de nuestro suelo, los depósitos de hierro, oro, esmeraldas, hidrocarburos y demás minerales de nuestra riqueza patria. Los geólogos profesionales y los estudiantes de las ciencias de la Tierra tendrán de hoy en adelante una magnífica y autorizada obra de estudio y de consulta sobre la geología de Colombia, absolutamente al día, de indiscutible utilidad práctica y científica.

Esta "Historia Geológica de Colombia" es una obra cuya necesidad se hacía sentir ya imperiosamente, y son probablemente no pocos los geólogos colombianos que habrán acariciado el proyecto de llevarla a cabo algún día. Le ha correspondido el privilegio de adelantarse en el camino, no obstante, a un destacado representante de la ciencia europea, quien de esta manera lleva a su culminación, al menos en esta muy urgente y significativa etapa, tan preciada labor. Advirtamos una vez más, sin embargo, que los fundamentos de ésta fueron establecidos en forma esporádica por sus predecesores alemanes y franceses en el siglo pasado; luégo acrecentados brillantemente en forma sistemática por los Dres. Scheibe y Lleras Codazzi, y demás miembros de la Comisión Científica Nacional (1917-1931: Stutzer, Grosse, Scheibe hijo, Hubach, etc.), y han sido multiplicados y enriquecidos con denuedo y éxito encomiables por competentes geólogos colombianos y extranjeros, principalmente miembros del Servicio Geológico Nacional y de las compañías petroleras.

No es un mero recurso retórico nuestra alusión al gran Suess, hecha al principio, en relación con la obra del Dr. Bürgl. El insigne maestro austriaco creó indudablemente una escuela, cuyas características imprimió en forma indeleble en su monumental obra "La Faz de la Tierra", en donde el criterio eminentemente histórico y paleontológico no desplaza, sin embargo, al analítico y físico, precursor de la propia tectónica y de la geodinámica. A su vez, ambos criterios, según nuestro punto de vista, se destacan sobre un maravilloso fondo universalista y humanístico que alcanza quizá su máxima expresión al abordar científicamente el fascinante tema histórico-religioso del diluvio universal. Pocas veces nos es dado rastrear con tanta facilidad y precisión, en la obra de un hombre de ciencia, las componentes helénicas de la cultura de Occidente, particularizadas en la antítesis de praxis y teoría, protagonizada por Eudoxos y Arquimedes, frente a Platón y Aristóteles ${ }^{1}$.

En su obra, el Dr. Bürgl analiza la evolución geológica de nuestro país, también con un marcado énfasis histórico, como queriendo asignar, con la mayor precisión y meticulosidad posibles, a base de sus vastos conocimientos paleontológicos, cada episodio al capítulo o página correspondiente en el gran libro de las rocas del planeta; en éste, los fósiles representan signos y caracteres de paginación que el autor se especializa en leer con exactitud, ya se trate de organismos minúsculos, o microfósiles, o de vertebrados gigantes.

Otras características que llaman poderosamente nuestra atención en este trabajo, para no mencionar sino algunas más, se relacionan con los cortes estructurales, la interpretación de la sedimentación cíclica del Cretáceo, y las isopacas del Senoniano en Cundinamarca. En el corte longitudinal de los sedimentos Cretáceos y pre-Cretáceos en la Cordillera Oriental (fig. 18), el autor ha introducido, como sugerencia muy valiosa, el factor de la curvatura terrestre, que sólo recientemente parece haber sido tenido en cuenta, en conexión con los procesos de las cuencas sedimentarias, por K. F. Dallmus ${ }^{2}$. En su análisis de la sedimentación cíclica del Cretáceo llega el Dr. Bürgl a conclusiones de sumo interés sobre el valor real de las subdivisiones cronoestratigráficas y su aparente sujeción a ciclos de seis millones de años, con sendas cuotas de sedimentación de 20 a 26 centímetros por milenio. La explicación de estos ciclos, en función de las oscilaciones rítmicas de la corteza terrestre podría ser, a su vez, un valioso argumento adicional en favor de esta hipótesis. En cuanto a las isopacas del Senoniano en la región de Cundinamarca (fig. 25), nos parece un magnífico ejemplo de estratigrafía analítica y cuantitativa, cuyas aplicaciones ofrecen hoy mayores perspectivas en diversos campos, tanto de la geología pura como de la práctica, según opinión del propio Levorsen ${ }^{3}$. Leyendo, o auncuando sólo sea simplemente examinando, la obra del Dr. Bürgl, encuentra uno perfectamente justificada la afirmación de estratígrafos modernos como J. M. Weller, de Chicago (1960), de que "la Estratigrafía es el núcleo y el corazón de la geología".

Al lado de esta gran competencia de historiador de la Tierra, nos sorprende también en el autor, sin embargo, su aguda percepción y análisis del problema físico, tectónico. En este aspecto, la comparación que él hace de nuestro sistema andino con otras cadenas montañosas del globo, como los Alpes, y la manera como contrasta y correlaciona los tipos de estructuras de plegamiento y de dislocación de nuestras tres cordilleras, para concluir con la síntesis geodinámica del capítulo sobre los "Terremotos" y su figura 36, son a nuestro modo de ver, una excelente contribución a la geología de Colombia y del continente sudamericano. Más aún, en este particular, el Dr. Bürgl se orienta con asombrosa seguridad por entre el laberinto de las teorías tectónicas y geotectónicas modernas, como experto conocedor y crítico de las contribuciones de europeos y americanos en tan intrincado campo, y concluye dentro del marco general de la tectonofísica de C. F. Richter y J. T. Wilson. Este último es el adalid que en auestro Nuevo Mundo orienta, en su Instituto de Ciencias de la Tierra, de la Universidad de Toronto, una nueva escuela inspirada en una más estrecha e íntima cooperación entre Física (Geofísica) y Geología, cuyos elementos acaba de sintetizar en su obra más reciente ${ }^{4}$, y sobre la cual se basa en gran parte, digámoslo de paso, la concepción de nuestro programa de Geología y Geofísica en la Universidad Nacional.

I A. Lalande, "Las Teorías de la Inducción y la Experimentación", Losada, S. A., Buenos Aires, 1944 .

2 K. F. Dallmus, "Mechanics of Basin Evolution, etc.", en "The Habitat of Oil", Amer. Assoc. of Petr. Geologists, Tulsa, 1958.

3 A. I. Levorsen, comunicación personal, 1961.

4 J. T. Wilson, et al., "Physics and Geology", McGraw-Hill Book Co., N. York, 1959. 
En su estilo analítico y crítico, el autor nos ofrece en general, como conclusiones e interpretaciones seguras, sólo aquellas plenamente respaldadas por los hechos, y plantea los problemas por resolver, por otra parte, en forma positivamente estimulante para los investigadores y estudiosos de estas disciplinas. Y en cuanto a su filosofía científica, su aseveración de que los problemas geológicos, y en particular los estructurales, se tornan más complicados cuando se los investiga con mayor detalle, sugiriendo así una elevada complejidad en ellos, que lógicamente se resiste o se opone a hipótesis o interpretaciones simplistas, nos satisface personalmente mucho más que la filosofía preconizada por algunos eminentes geólogos petroleros americanos, con quienes hemos discutido el punto. Estos se acogen al postulado newtoniano de que "la naturaleza obra según los caminos más fáciles", prefieren desechar las posibles complicaciones y optan por interpretaciones demasiado esquemáticas, que con frecuencia no se ajustan a la realidad. No quisiéramos que nuestra crítica en este sentido, a dichos científicos americanos, fuera tildada de irreverente, pues sólo nos impulsa a ella la convicción sincera de que en nuestro siglo XX la concepción newtoniana del mundo físico es sólo una simplificación, particularizada, del universo einsteiniano, un tanto más complejo, entre otras razones por el hecho de haber introducido una cuarta dimensión en el problema. Además, en las posiciones de avanzada de las ramas más modernas de la Geología, autoridades también americanas se han pronunciado enfáticamente en favor de este criterio, como lo hacen, por ejemplo, los Profesores Thornbury ${ }^{1}$, de Indiana y Nevin ${ }^{2}$, de Cornell.

El tercer elemento de la escuela vienesa de Suess nos parece que se manifiesta con mayor claridad en la historia geológica del Dr. Bürgl, en su capítulo sobre el "Cuaternario". En él describe y discute cuidadosamente los datos aportados por otros investigadores, como Royo y Gómez, Stirton y Van der Hammen, para concluir haciendo hincapié sobre su propia opinión, basada en los hallazgos de implementos humanos y huesos de Megaterio y de Mastodonte en una terraza de Garzón, de que el Homo Sapiens tuvo en Sudamérica un precursor contemporáneo de aquellos gigantes extinguidos. En su breve pero concisa discusión sobre el problema, se advierten las muy poco comunes inquietudes y aficiones antropológicas del geólogo que no se contenta con inquirir sobre el destino de la "Nave Tierra", que dijera Termier, despreocupándose de sus "emigrantes", los hombres. He aquí, pues, una calidad humana en un investigador científico, de la cual se sentirían satisfechos Cajal o Unamuno.

La última componente de la obra del Dr. Bürgl que nos resta parangonar con la de Suess, en esta nuestra apreciación de su historia, y no por última menos importante, es la de su mérito didáctico. Compilar el enorme acervo de datos geológicos aportados sobre Colombia desde Humboldt, Von Buch y Hettner hasta nuestro días, sin dejar escapar lo substancial, es ya de suyo labor ímproba de paciencia y pericia. Pero hacerlo, además, en forma adecuada y sistemática, analizando y seleccionando los datos para no incurrir en repeticiones inoficiosas o en omisiones lamentables, para ofrecer una interpretación final correcta y atractiva, como lo hace este autor, requiere, además, dotes de expositor que él posed en alto grado, y que ejercita y refina diariamente en su cátedra universitaria y en las discusiones y seminarios académicos que promueve con entusiasmo. Y esta es, precisamente, la característica en la obra del autor que, por la razón muy personal aducida al principio de este prólogo, quisiéramos nosotros realzar con mayor énfasis.

El Profesor Bürgl se asoció a la Facultad de Geología y Geofísica desde sus albores (1957), y ha venido desde entonces ejerciendo su magisterio docente con un celo y una eficiencia que honran a nuestra institución. En sus cátedras de Paleontología, Geología Histórica, Geología Regional, Geología General y Geología Física, puede él estar seguro de haber formado verdaderos discípulos, y de haber inculcado en ellos, con la inspiración que emana de una vocación científica como la que se trasluce en el epígrafe de Termier que encabeza estas notas, el cariño y el interés por las disciplinas geológicas, concebidas en esta forma polifacética y elevada que perpetuará entre nosotros la esencia de la escuela de Suess. Por lo demás, sentimos la profunda satisfacción de que la labor cotidiana en la cátedra, estimulada por el interés inquisitivo de sus estudiantes del Instituto de Ciencias, ha debido contribuír poderosamente a que el Profesor Bürgl se hubiera decidido a escribir esta estupenda monografía, en donde campea el espíritu de investigación universitario que Ortega y Gasset definió como "la verdadera dignidad de la universidad" 3.

No queremos terminar sin aludir en forma francamente elogiosa a la labor editorial del Director de la Revista de la Academia, Dr. Luis María Murillo, a cuyo esmero, devoción y habilidad, se debe el hecho de que los mapas y las figuras del trabajo, además de cumplir su natural cometido, hagan de él, junto con el texto, una pulcra y bella publicación, por la cual podemos felicitar muy de veras tanto a la Academia Colombiana de Ciencias, como al Dr. Murillo.

1 w. D. Thornbury, "Principles of Geomorphology", John Wiley \& Sons, N. York, 1954.

2 C. M. Nevin, comunicación personal, 1960.

3 J. Ortega y Gasset, "Misión de la Universidad", Obras Completas, Rev. de Occidente, Madrid, 1930. 


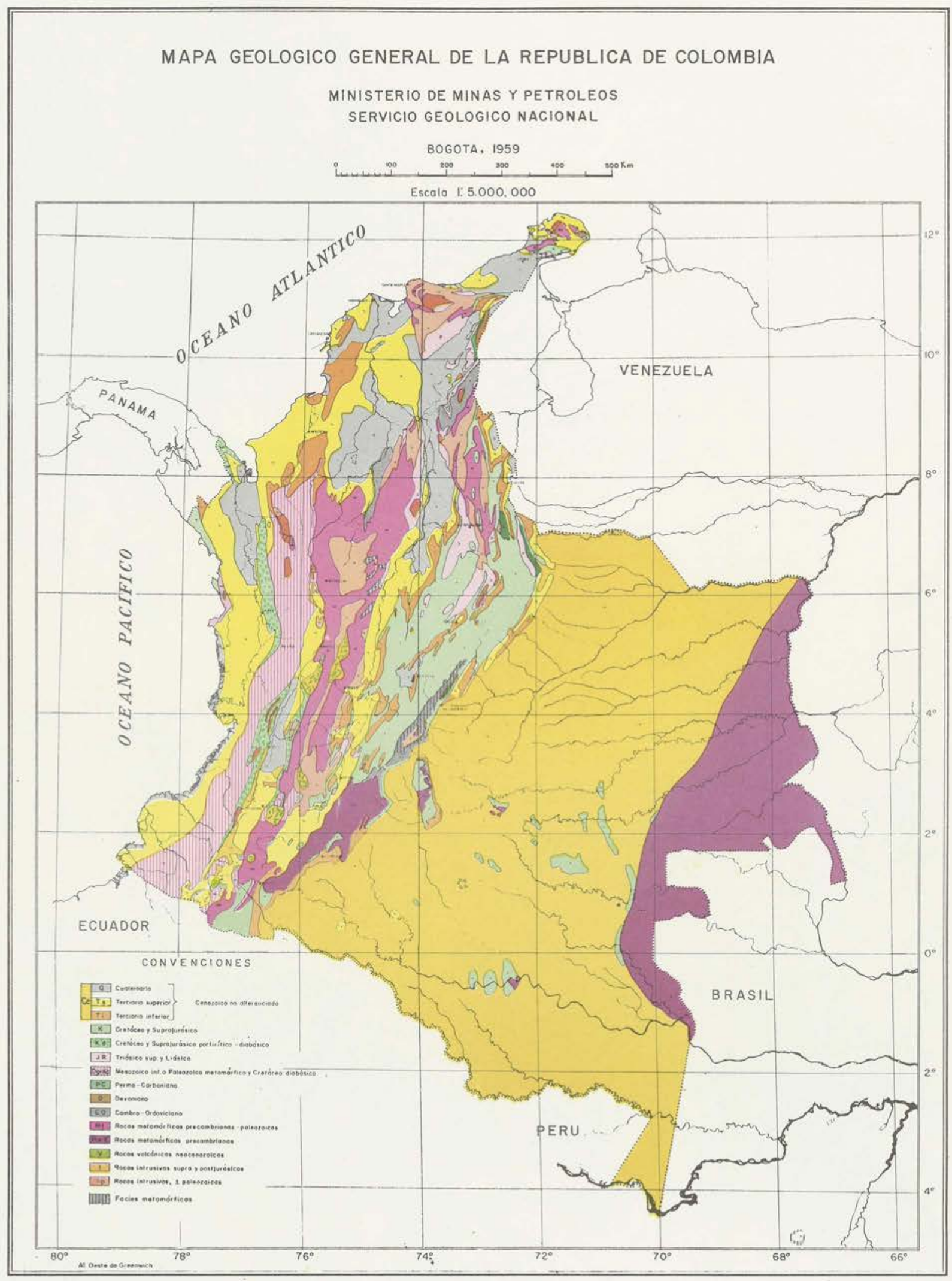

Al hacer la reproducción facsimil de este mapa modificado por el doctor Hans Bürgl, se conservó el indice de la escala original. El de la reducción es de 1: 9.626 .000 (N. de la D.) 


\section{INTRODUCCION}

Según sus rocas, Colombia se divide en dos regiones principales:

A. Los Llanos Orientales, [F13-L9] ${ }^{1}$ en los cuales un basamento muy antiguo (Precambriano) está cubierto por capas marinas y terrestres mesozoicas y cenozoicas, relativamente planas y delgadas.

B. La Región geosinclinal Andina, la cual desde el Cambriano estuvo por largos períodos bajo el nivel del mar y donde se acumularon sedimentos marinos, continentales y volcánicos de muchos miles de metros de potencia. En varias de las fases de movimientos tectónicos, estas capas fueron plegadas o dislocadas, intruídas por magmas y solevantadas hasta formar cordilleras expuestas a la erosión.

Esta región de composición litológica, muy compleja se puede subdividir en:

1. La Cordillera Central [C12-E5], llamada por TULIO OSPINA (1911) la columna vertebral de los Andes colombianos, que está constituída en primer lugar, por rocas cristalinas e ígneas del Paleozoico antiguo. Su extensión septentrional forman la Sierra Nevada de Santa Marta [F3] y los núcleos antiguos de la Alta Guajira [H1-2].

2. La Cordillera Occidental [B12-D5] y la Serranía de Baudó [C9-B6] (o Cordillera Costanera) al oeste de la Cordillera Central, que constan predominantemente de rocas marinas y volcánicas del Mesozoico.

3. La Cordillera Oriental [C12-G2] que en primer lugar consta de sedimentos mesozoicos, pero que en sus "núcleos antiguos" (GERTH 1957) tiene también series de rocas paleozoicas y precambrianas de considerable potencia.

Las cordilleras andinas están separadas una de otra por depresiones morfológicas muy largas y angostas; entre las Cordilleras Costanera y Occidental se extienden las depresiones de los ríos San Juan [C9] y Atrato [C7-B6]. La Cordillera Central está limitada al oeste por las fosas del Patía [B12] y del Cauca [D8-E5] y al este por los valles de los ríos Magdalena [D11-E2] y César [F3]. Todas estas unidades morfológicas de los Andes colombianos tienen un rumbo general SSWNNE.

\section{PRECAMBRIANO}

El basamento de los Llanos Orientales consta de neises (arcaicos?), que fueron intruídos y en gran parte reemplazados por magmas granosieníticas durante el Algonquiano. Según A. GANSSER (1954 y en D. TRUMPY 1943), todas las partes orientales de las Intendencias de Vaupés [112] y Vichada [J9] y los alrededores de San José del Guaviare [G11] tienen un basamento de sienitas, caracterizadas por su contenido en microclina y cuarzo azul. A veces son abundantes en magnetita y los cristales de este mineral alcanzan hasta $20 \mathrm{~cm}$. de diámetro, especialmente en las pegmatitas. En el Río Isaná [L12], en el límite entre Colombia y

1 Las letras y cifras entre corchetes se refieren a las coordenadas en el mapa de la figura 41 .
Brasil, afloran cuarcitas y esquistos sericíticos con magnetita, los cuales corresponden tal vez a las itabiritas del Cuadrilátero Ferrífero (base del Algonquiano Superior) en la provincia de Minas Gerais del Brasil.

El basamento cristalino de la Serranía de La Macarena [F11] comprende esquistos micáceos, paraneises, anfibolitas y ortoneises en parte granosieníticos, rocas seguramente de edad precambriana (A. GANSSER en D. TRUMPY 1943).

Los movimientos tectónicos que formaron las cordilleras andinas, solevantaron hasta la superficie rocas precambrianas en numerosos sitios. En Colombia, este es el caso particularmente en los "macizos antiguos" (H. GERTH 1957) de la Cordillera Oriental, que son (fig. 1): el Macizo de Garzón [D11], el Macizo de Quetame [F9], el Macizo de Guantiva [G8], el Macizo de Santander [G6] y el núcleo de la Serranía de Perijá [G3]. Como Arcaico se consideran los neises anfibólicos y micáceo-hornbléndicos del flanco occidental del Macizo de Garzón (E. GROSSE 1935, G. KEHRER 1935 y 1939, V. OPPENHEIM 1941, J. ROYO Y GOMEZ 1942, O. RENZ en D. TRUMPY 1943) y el neis al este de la línea Ocaña-Bucaramanga [F5-F6] en el Macizo de Santander.

El Algonquiano está representado en el interior del Macizo de Garzón por neis con intrusiones graníticas y dioríticas (G. KEHRER 1935, 1939); en el Macizo de Quetame por las filitas y cuarcitas de la "Serie de Quetame” (A. HETTNER 1892, E. A. SCHEIBE 1938, H. BƯRGL 1960 b); en el Macizo de Guantiva por neis cordierítico silimanítico y esquistos micáceos con cuarzo (G. BOTERO RESTREPO 1950) y en el Macizo de Santander por esquistos micáceos con moscovita (E. A. SCHEIBE 1938).

En la Sierra Nevada de Santa Marta [F3] (G. GANSSER 1955) y en la Alta Guajira [H1-2] (O. STUTZER 1937, H. BÜRGL 1960 a) se encuentran esquistos hornblendo-biotíticos y augito-anfibolíticos, que cambian lateralmente a neis con anfíbol y plagioclasa, probablemente de edad arcáica. Sobre estas series descansan esquistos micáceo-cuarcíticos algonquianos, los cuales también cambian a neises. La Cordillera Central probablemente contiene también rocas precambrianas pero allí es difícil distinguirlas de rocas metamórficas de menor edad.

Las rocas precambrianas de la región andina experimentaron variados cambios por movimientos tectónicos e intrusiones posteriores. El Escudo de Las Guayanas, como también los del Brasil y Patagonia en contraste, han sido poco disturbados desde el principio del $\mathrm{Pa}$ leozoico (fig. 2).

Durante todo el "tiempo histórico" de la tierra, es decir, desde el Cambriano, dichos escudos formaron el antepaís de la región andina, cuyas depresiones marinas o terrestres se rellenaron con el detritos de la erosión de estos escudos.

\section{CAMBRIANO Y ORDOVICIANO}

\section{Rocas y series}

En varios lugares de La Macarena [F11] y en el camino que atraviesa la Cordillera Oriental al noroeste de Uribe [E10], afloran argilitas arenosas, micáceas, de 


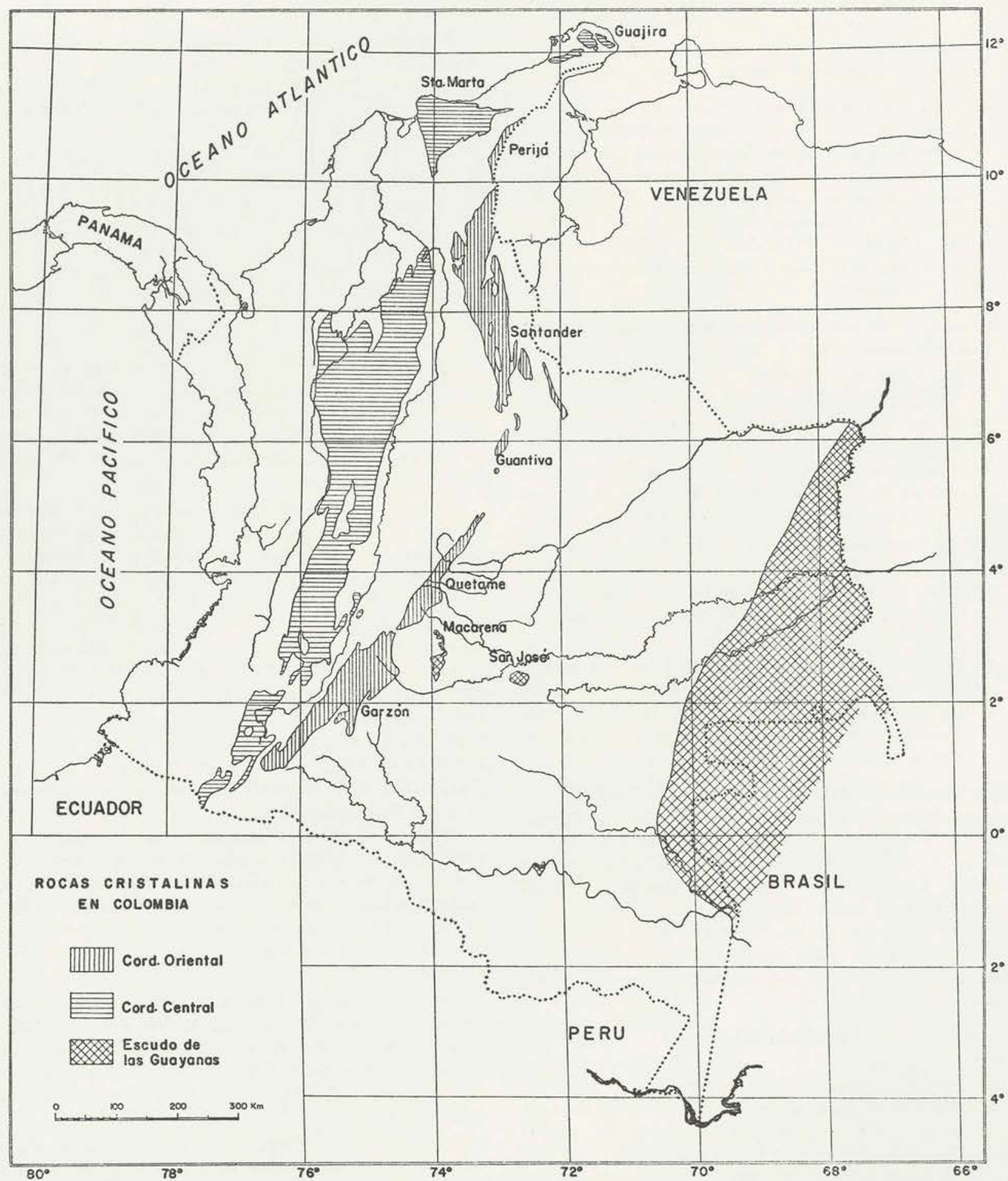

Fig. 1 - Distribución de rocas cristalinas del Precambriano y Paleozoico antiguo en Colombia; están situadas en la Cordillera Central, la Sierra Nevada de Santa Marta y la Alta Guajira, en los Macizos antiguos de la Cordillera Oriental (Garzón, Quetame, Guantiva, Santander, Perijá), en La Macarena y en el Escudo de Las Guayanas. 


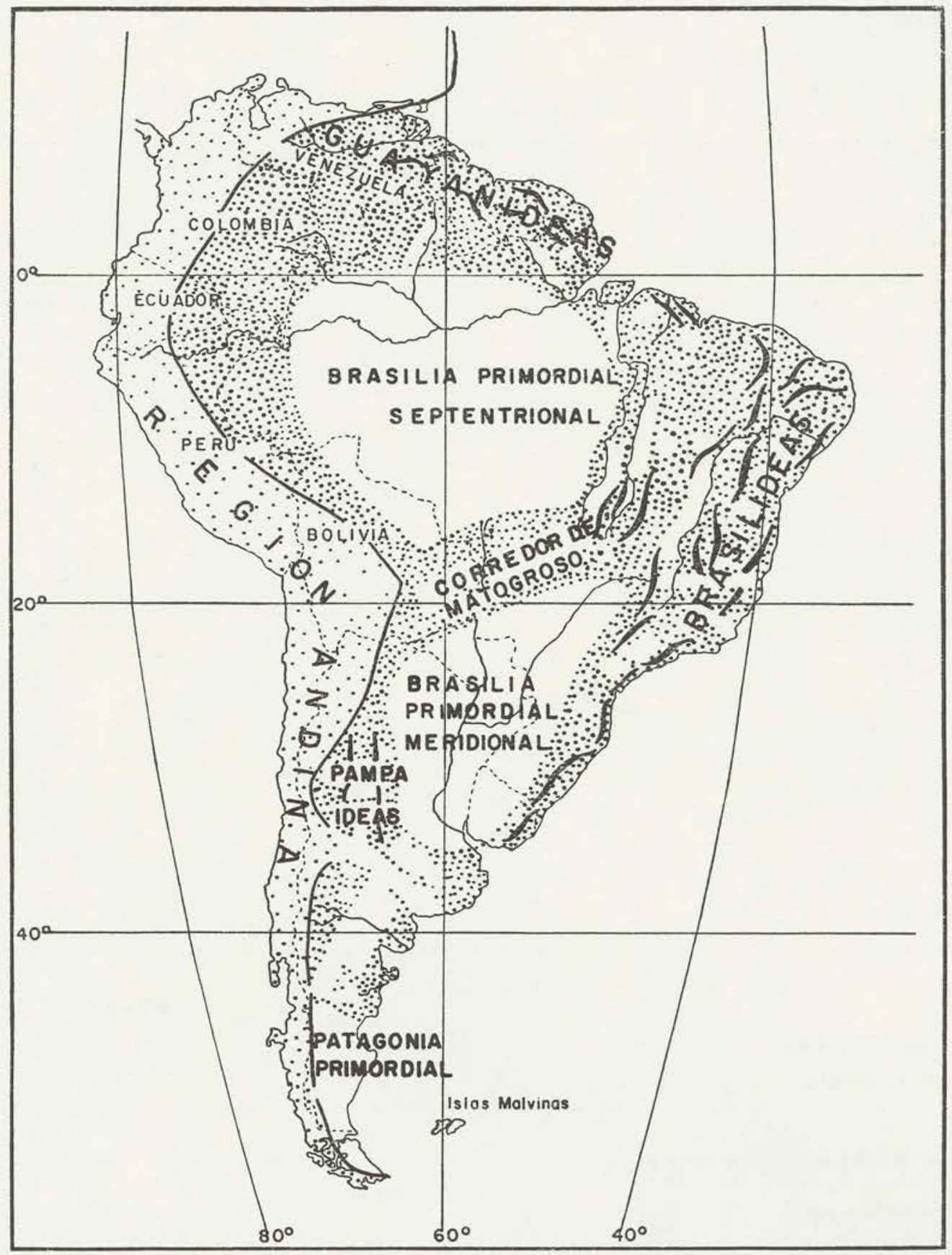

Fig. 2 - Las partes de Suramérica consolidadas antes del Cambriano según H. STILLE 1958 (modificado). En blanco dentro del continente: Suramérica primordial, consolidada antes del NeoAlgonquiano; puntos gruesos: regiones consolidadas por los plegamientos asínticos, es decir durante el Neo-Algonquiano; puntos finos: Región andina. 


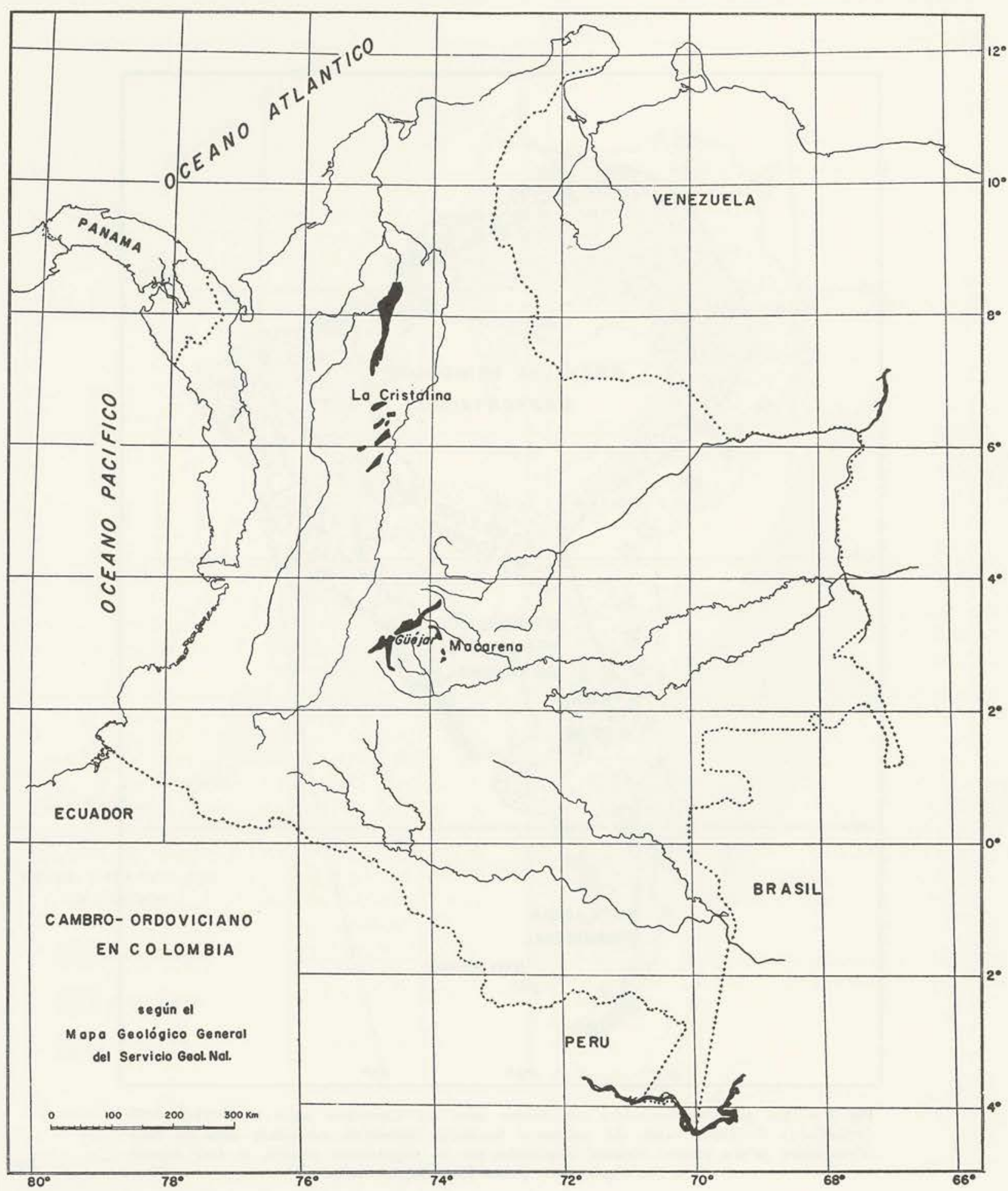

Fig. 3 - Afloramientos fosilíferos del Cambro-Ordoviciano en Colombia. 
color gris oscuro y areniscas cuarcíticas pardas con fajas delgadas de caliza arenosa, a las cuales D. TRUMPY (1943) dio el nombre de "Serie de Güéjar" (fig. 3). Los fósiles colectados por A. Gansser, E. Hubach y O. Renz y estudiados por H. J. HARRINGTON \& M. KAY (1951) indican que estos estratos fueron sedimentados en el Cambriano medio, Ordoviciano inferior (Tremadoquiano y Arenigiano) y Ordoviciano medio bajo (Llanvirniano). Cambro-Ordoviciano se encontró también en la perforación La Heliera 1 [HJ7] de la Mobil Oil Company, la cual alcanzó una profundidad de $2940 \mathrm{~m}$. (O. SHOCKLEY 1960).

Otros sitios con fósiles (Graptolites) del Ordoviciano inferior se hallan situados en el flanco oriental de la Cordillera Central, cerca a Puerto Berrío [E7] y a Las Cristalinas (J. V. HARRISON 1930, G. BOTERO ARANGO 1940). Las capas que los contienen son también argilitas un poco arenosas, pero ligeramente metamórficas lo que quizá fue causado por la intrusión del batolito de Antioquia durante la fase orogénica caledónica, la cual se comentará más adelante.

En Colombia, además de estas series fosilíferas hay otras sin fósiles, que se consideran de edad cambroordoviciana. Esto se refiere particularmente al Grupo de Cajamarca [D9] (H. W. NELSON 1957). Su sucesión típica se encuentra entre Ibagué y Armenia [D9] en donde consta predominantemente de esquistos verdes (prasinitas), esquistos grafíticos, filitas cuarcíticas con intercalaciones de calizas cristalinas, a veces un poco cuarcíticas y grafíticas, y diabasas cristalinas. Esquistos de este tipo constituyen la mayor parte de la Cordillera Central en todo su curso desde El Banco [F4] hasta la frontera con Ecuador y parece que se encuentran también esporádicamente en la parte sur de la Cordillera Occidental.

Muy semejantes son los Esquistos de Santa Marta [E2]. A. GANSSER (1955) los describe como filitas arcillo-arenosas, esquistos verdes y diabasas doleríticas cristalinas, que forman la zona metamórfica externa de la Sierra Nevada de Santa Marta. Su equivalente es aparentemente la "Serie semimetamórfica" en la Alta Guajira [H1-2] (H. BƯRGL 1960 a). En el núcleo de la Serranía de Perijá [G3] se encuentran esquistos filíticos y verdes y en el Macizo de Santander [G6] esquistos arcillo-arenosos que pertenecen aparentemente al mismo conjunto.

D. TRUMPY (1943) supone que la Serie de Quetame sea la facies metamórfica de la Serie de Güéjar; pero anteriormente ya mencionamos que la opinión de A. HETTNER (1892) y E. A. SCHEIBE (1938) de que representan el Precambriano alto es más probable. Además, de ninguna manera se descarta que todas o algunas de las series no fosilíferas citadas en este capítulo sean de edad precambriana; la ausencia de fósiles en estratos con un grado muy bajo de metamorfismo merece especial atención.

E. HUBACH (1957 a) considera el Grupo de Cajamarca en su totalidad como mesozoico metamórfico y lo correlaciona con el Triásico de Payandé [D10], el Grupo de Dagua [C10] y el Grupo Diabásico. Es posible que la Cordillera Central contenga pequeñas manchas de Mesozoico metamórfico que son difíciles de separar del Grupo de Cajamarca; pero ésta no es una razón para considerar todo este conjunto como demasiado moderno. Además, se descarta por completo la posibilidad de edad mesozoica para los Esquistos de Santa Marta, la Serie semimetamórfica de la Alta Guajira y los esquistos filíticos de la Cordillera Oriental que se tratan en este conjunto, por su posición debajo de la Formación Girón.

\section{Fauna}

En Colombia, al igual que en otras partes de la tierra, los fósiles más importantes del Paleozoico inferior son los Trilobites, los Braquiópodos y los Graptolites.

Los restos de Trilobites, hallados en Colombia no son tan perfectos ni tan numerosos como en algunos lugares de Canadá, Escandinavia o Bohemia. Pero en su mayoría se pueden identificar con géneros ya conocidos en otras regiones. Del Cambriano medio H. J. HARRINGTON \& KAY (1951) determinaron dos nuevas especies de Ehmania; del Tremadoquiano y Arenigiano (Ordoviciano Inferior) Geragnostus, Kainella, Pseudokainella?, Megalaspis, Raphiophorus?, Symphysurus, Tropidopys y varios otros.

En la Macarena se hallaron los Braquiópodos Obolus, Lingulella, Acrotreta y Nanorthis (?) y los Graptolites Dichograptus, Didymograptus y Tetragraptus. Didymograptus y Dichograptus se hallaron también entre Las Cristalinas y Puerto Berrío en la Cordillera Central (J. V. HARRISON 1930).

\section{Paleogeografía}

HARRINGTON \& KAY (1951) suponen que la Serie de Güéjar fue depositada en el margen de un miogeosinclinal que recibió sus sedimentos de una tierra firme situada al oeste del Escudo de Las Guayanas. Las capas de Las Cristalinas en la Cordillera Central se distinguen litológicamente poco de las de La Macarena. La Serie de Cajamarca y los Esquistos de Santa Marta, para los cuales A. GANSSER (1955) y H. W. NELSON (1957) suponen una edad cambro-ordoviciana, también fueron depositados en un mar de poca profundidad en forma de arcillas, arenas finas, margas dolomíticas y derrames diabásicos. La gran extensión de estos sedimentos parecidos indica que existió en el Cambro-Ordoviciano un mar somero, cuyo fondo hundió muy lentamente permitiendo la acumulación de estas series uniformes. Según HARRINGTON \& KAY (1951), la fauna indica conexiones de este mar con el Perú oriental, Bolivia y Argentina por un lado y con Canadá, Gales y Escandinavia por otro.

\section{Movimientos tectónicos pre-devonianos}

El Ordoviciano superior y el Siluriano (Gotlandiano en la terminología europea) no están representados en Colombia, al menos no por capas fosilíferas. Durante este interespacio tuvieron lugar movimientos tectónicos bastante intensos, acompañados en la Cordillera Oriental por intrusiones de granito. A esta fase pertenecen el granito biotítico de San Sebastián (Sierra Nevada de Santa Marta, A. GANSSER 1955), el granito biotítico de la Serranía de Macuira (Alta Guajira, O. STUTZER 1928, H. BÜRGL 1960 a), del Macizo de Santander (HETTNER 1892, H. STILLE 1907, E. A. SCHEIBE 1938) y las granodioritas del Macizo de Garzón (G. KEHRER 1935, las considera como terciarias). Es muy probable que con estas intrusiones en la Cordillera 


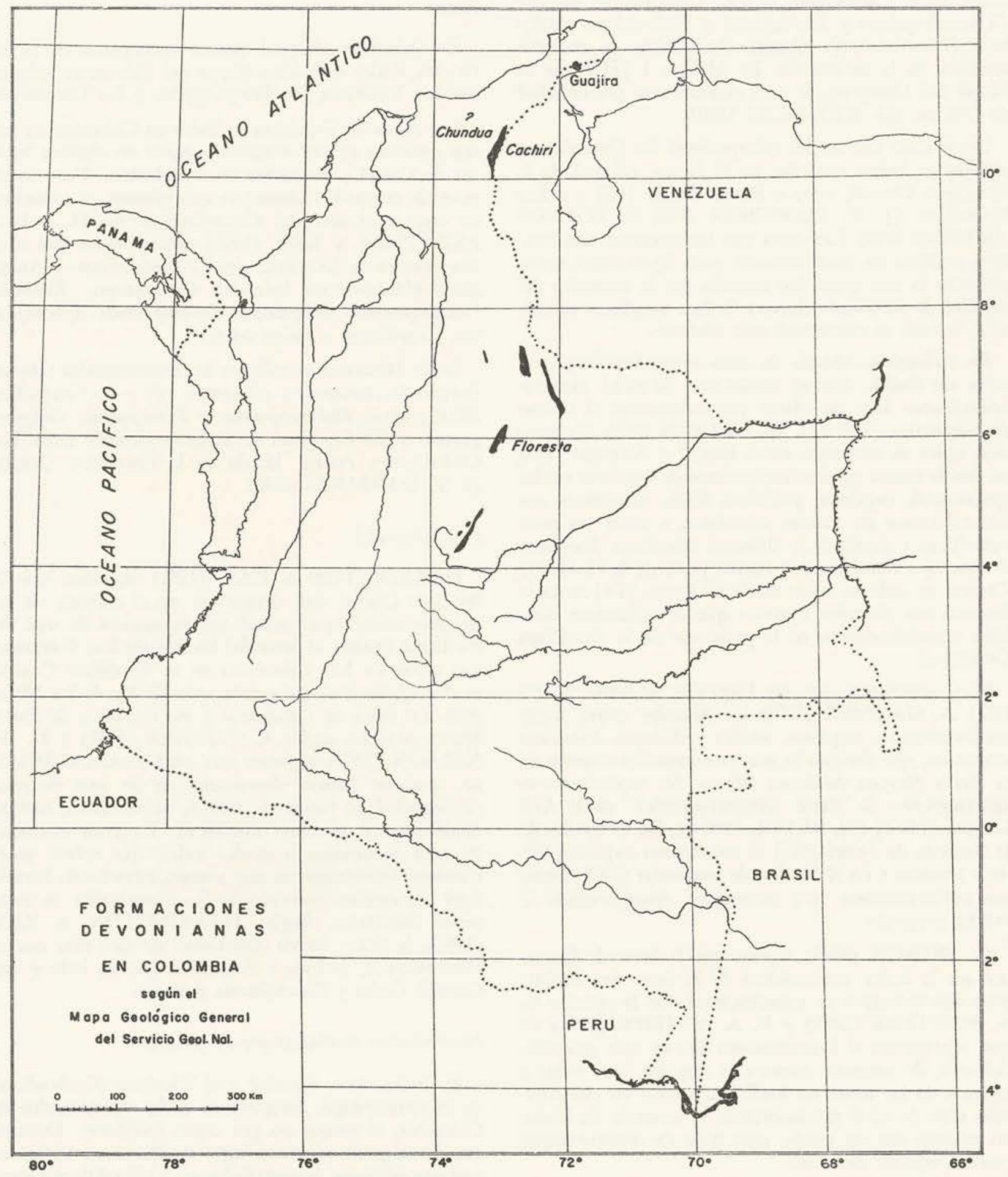

Fig. 4 - Afloramientos del Devoniano Medio en Colombia. 
Oriental se correlacionen las granodioríticas de Antioquia [D7], Ibagué [D9] y otros extensos batolitos granodioríticos en la Cordillera Central. Aparentemente, las intrusiones no afectaron solamente la región andina sino también el Escudo de Las Guayanas. Prueba de esto es la muestra de una pegmatita colectada por José Manuel Carvajal en los alrededores de San José de Guaviare [G11], cuya edad fue determinada en 436 millones de años, lo que corresponde al Ordoviciano superior (U. S. ATOMIC ENERGY COMMISSION 1958).

Las dislocaciones e intrusiones predevonianas se correlacionan con las fases caledónicas en Europa.

\section{DEVONIANO}

\section{Generalidades}

Las cordilleras andinas caledónicas habían sido erodadas y aplanadas, cuando el mar entró nuevamente a la tierra colombıana y depositó nuevos sedimentos sobre los anteriores. Este avance marino tuvo lugar al principio del Devoniano Medio y sus depósitos comprenden las formaciones Floresta [G8] y Río Cachirí [G3] (fig. 4).

El Devoniano se descubrió primero en el territorio venezolano de la Serranía de Perijá (Formación Río Cachirí). Después Scholl y Remington lo hallaron también en el flanco colombiano de esta serranía ${ }^{1}$. Talvez a las mismas regiones (Curumaní-Santa Isabel y al este de Manaure [F3]) se refiere D. TRUMPY 1943. Según E. Hubach (en D. TRUMPY 1943) su presencia en el Macizo de Santander (Labateca [G6]) es por lo menos probable. El sitio más típico del Devoniano colombiano lo descubrieron A. A. Olsson y P. Dickey en Floresta [G8] en el Macizo de Guantiva (A. A. OLSSON \& K. E. CASTER 1937, G. BOTERO RESTREPO 1950). Después fue encontrado en el Macizo de Quetame (E. A. SCHEIBE 1938, D. TRUMPY 1943, BƯRGL 1957 y 1960 b) y por último en la Alta Guajira (H. BÜRGL 1960 a). Parece por lo tanto, que el Devoniano forma una capa casi continua en el subsuelo de la Cordillera Oriental desde el Río Ariari [EF10] hasta la Península de la Guajira [H1], mientras que se desconoce en otras partes de Colombia. TULIO OSPINA (1911) y R. SCHEIBE (1926) suponen, que el Occidente Andino era tierra firme durante el Paleozoico moderno. En estas opiniones se basan aparentemente los mapas paleogeográficos de H. \& G. TERMIER (1952, cartes XVI y XVII), que muestran en el Carboniano y Permiano una "Tierra Caribe", que comprende el Occidente Andino de Colombia, América Central y las Islas Antillas.

\section{Rocas}

La Formación Río Cachirí tiene casi $2500 \mathrm{~m}$. de potencia, mientras que en Curamaní-Santa Isabel [G3] se midieron 620 y en Floresta [G8] $710 \mathrm{~m}$. El Devoniano siempre descansa discordantemente sobre los estratos más antiguos. Su base consta de conglomerados finos y guijosos de pocos metros de espesor, mientras que la mayor parte comprende una serie irregular de pizarras arcillosas y lutitas negras, grises o rojas y areniscas grises, micáceas y cuarcíticas. Entre éstas están intercalados

\footnotetext{
1 No en la Península de la Guajira en sentido estricto como lo cita CH. SCHUCHERT 1935, p. 672.
}

bancos de calizas gris azulosas hasta negruzcas o marrones, con frecuencia fosilíferas. Estos estratos se depositaron en un mar bastante uniforme de no más de $100 \mathrm{~m}$. de profundidad, que también recibió sus sedimentos del Escudo de Las Guayanas. Su costa occidental no se conoce hasta el momento.

\section{Fauna}

En las formaciones devonianas los fósiles están restringidos a algunos pocos horizontes arcillosos y calcáreos, pero en éstos se encuentran a veces en gran abundancia. Los más frecuentes en Colombia son los Braquiópodos, los cuales alcanzan su máximo desarrollo en el Devoniano. Particularmente característicos son los Espiriferáceos, los cuales se distinguen claramente de los Braquiópodos cambro-ordovicianos por sus alas alargadas y sus costillas fuertes (figs. 5 y 6). En la fauna de Floresta, K. E. CASTER (1939) distinguió 41 especies de Braquiópodos y las correlacionó con el Devoniano Medio (Onondagiano y Hamiltoniano) de la región atlántica de Norteamérica.

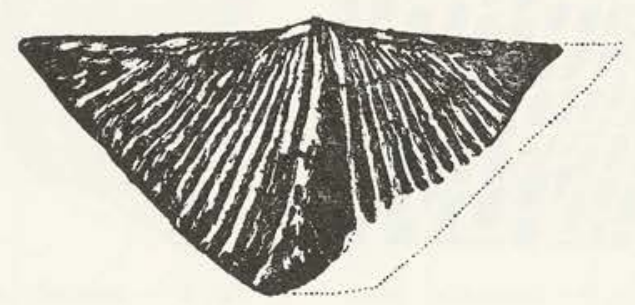

Fig. 5 - Brachyspirifer (?) palmerae CASTER del Devoniano Medio de Floresta, según K. E. CASTER 1939.

En gran abundancia se encuentran también los restos de Briozoos. A. A. MCNAIR (1940) describió 10 géneros con 24 especies de la Formación Floresta. Todas las especies son nuevas (figs. 7 y 8 ); sin embargo, nueve de éstas presentan afinidades con Briozoos del Devoniano Medio de Norteamérica oriental, particularmente del Hamiltoniano.

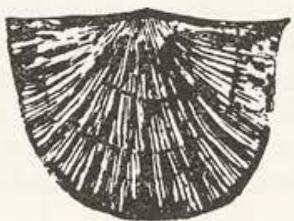

Fig. 6 - Stropheodonta kozlowskii CASTER del Devoniano Medio de Floresta, según K. E. CASTER 1939.

Los Trilobites son muy escasos; A. A. Olsson y P. Dickey hallaron en Floresta solamente tres especies (A. A. OLSSON \& K. E. CASTER 1937, K. E. CASTER 1939). Entre los fósiles devonianos, que R. Wokittel colectó en los Farallones de Medina [F9] y de Sumapaz (Gutiérrez) [EF9] del Macizo de Quetame existen fragmentos de un Trilobites gigante del género Coronura (?), que probablemente alcanzó $35-40 \mathrm{~cm}$. de largo (BƯRGL 1957). Este no es el más grande del mundo, porque la especie Uralichas riberoi hallado en Portugal alcanza $70 \mathrm{~cm}$. de largo. Sin embargo, comparado con la mayoría de los Trilobites, este gigante, que se conserva en el Museo Geológico Nacional de Bogotá, merece especial atención. 
En 1917, en la Quebrada Honda al norte de Villavicencio [F9], Roberto Scheibe halló un guijarro de unos diez centímetros de diámetro, compuesto de grauvacka areniscosa gris negra, dura, de grano fino y rica en mi$\mathrm{ca}$, que contiene restos relativamente completos de un Crinoideo. Este fue estudiado por W. E. SCHMIDT (1938) y recibió el nombre de Bogotacrinus scheibei E. W. SCHMIDT (fig. 9). Este autor pensó que se trataba de un fósil del Devoniano inferior. Pero la concordancia litológica del guijarro con las capas del Devoniano medio, descubiertas posteriormente, hace suponer que también este Crinoideo pertenezca a la parte media del Devoniano.

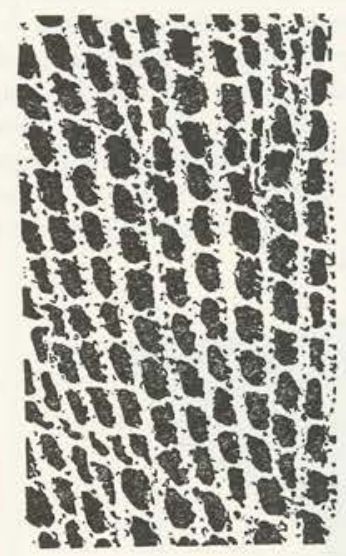

Fig. 7-Fenestellina colombiana McNAIL del Devoniano medio de Floresta, Boyacá. Según McNAIL, 1940.

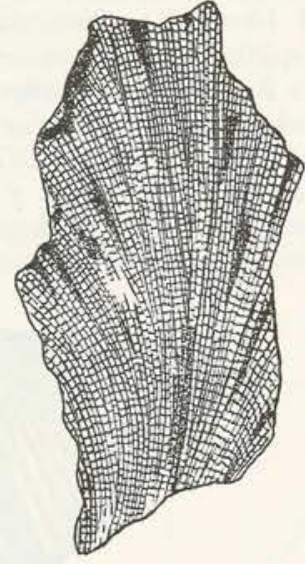

Fig. 8 - Fenestella vene zuelensis WEISBORD del Devoniano medio del Río Cachirí; según WEISBORD 1926.
Los paleontólogos que estudiaron los fósiles devonianos de Colombia y la parte oriental de la Serranía de Perijá (N. E. WEISBORD 1926, Galloway en SCHU. CHERT 1935, K. E. CASTER 1939, A. H. MCNAIR 1940, J. ROYO Y GOMEZ 1942, Emeis y J. S. Williams en D. TRUMPY 1943, BƯRGL 1957) con la excepción de W. E. SCHMIDT (1938) llegaron al resultado de que el Devoniano fosilífero de Colombia corresponde al Devoniano medio, es decir, al Onondagiano y Hamiltoniano. Sin embargo, es muy posible que las partes altas no fosilíferas se sedimentaran en el Devoniano superior. Casi con seguridad podemos suponer pues, que el Devoniano inferior falta en Colombia; su límite sep- tentrional queda por lo tanto, más al sur que lo indicado por L. G. WEEKS (1947).

\section{Movimientos tectónicos}

En todos los sitios donde su base está expuesta, se observa que el Devoniano medio descansa discordantemente sobre los estratos más antiguos (fig. 10). Esta discordancia se correlaciona tal vez con la fase acádica en Norteamérica o con otras más antiguas del ciclo caledónico (R. C. MOORE 1958, p. 192). Por su parte en lo general está concordantemente superpuesto por el Carboniano, solamente en el Macizo de Guantiva (Floresta), G. BOTERO RESTREPO (1950, pp. 265 y 276) observó discordancias locales y suaves entre ambos pisos en la carretera Santa Rosa de Viterbo [FG8]-Floresta [G8]. Sin embargo, este autor no está seguro, de si se trata más bien de inconformidades causadas por fallas o plegamientos disarmónicos posteriores. En la misma región, el Devoniano y los esquistos y neises infrayacentes están intruídos por granitos; no se ha podido comprobar si estas rocas ígneas intruyeron también al Carboniano y Rético-Liásico. Se podría pensar que las discordancias entre el Devoniano y Carboniano y las

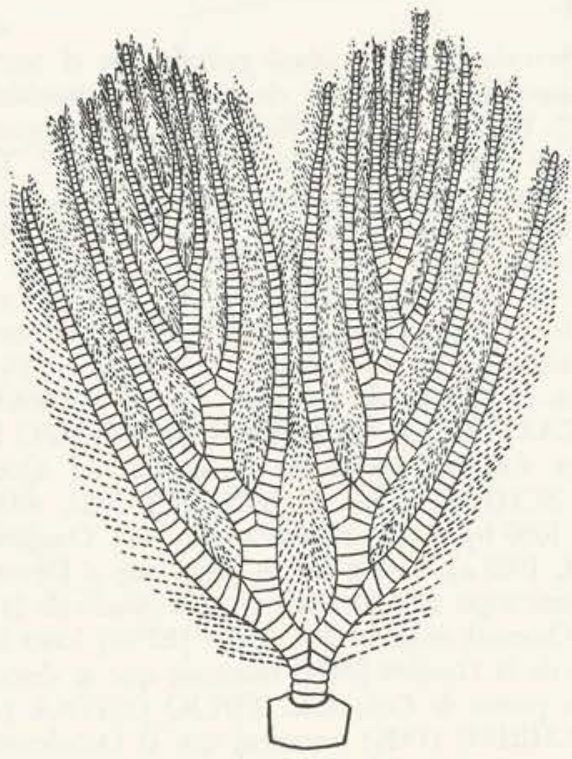

Fig. 9 - Bogotacrinus scheibei W. E. SCHMIDT; reconstrucción de los brazos de un radio, según W. E. SCHMIDT 1938.

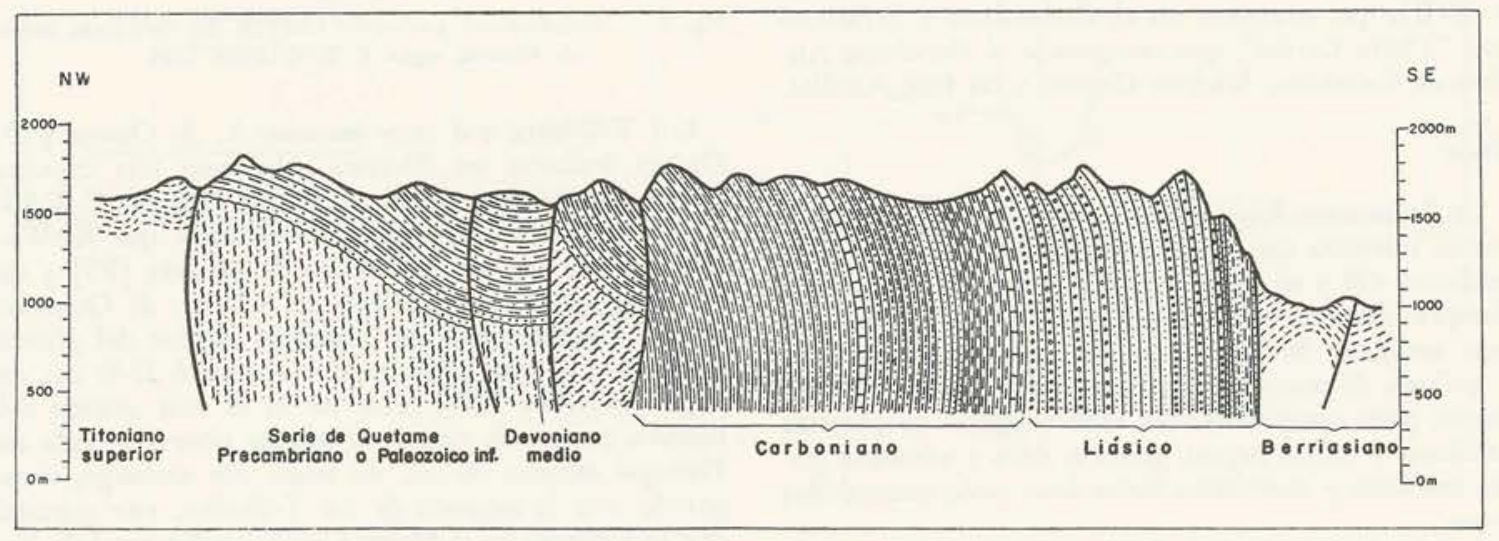

Fig. 10 - Corte a través del Precretáceo del río Batá en el Macizo de Quetame. 


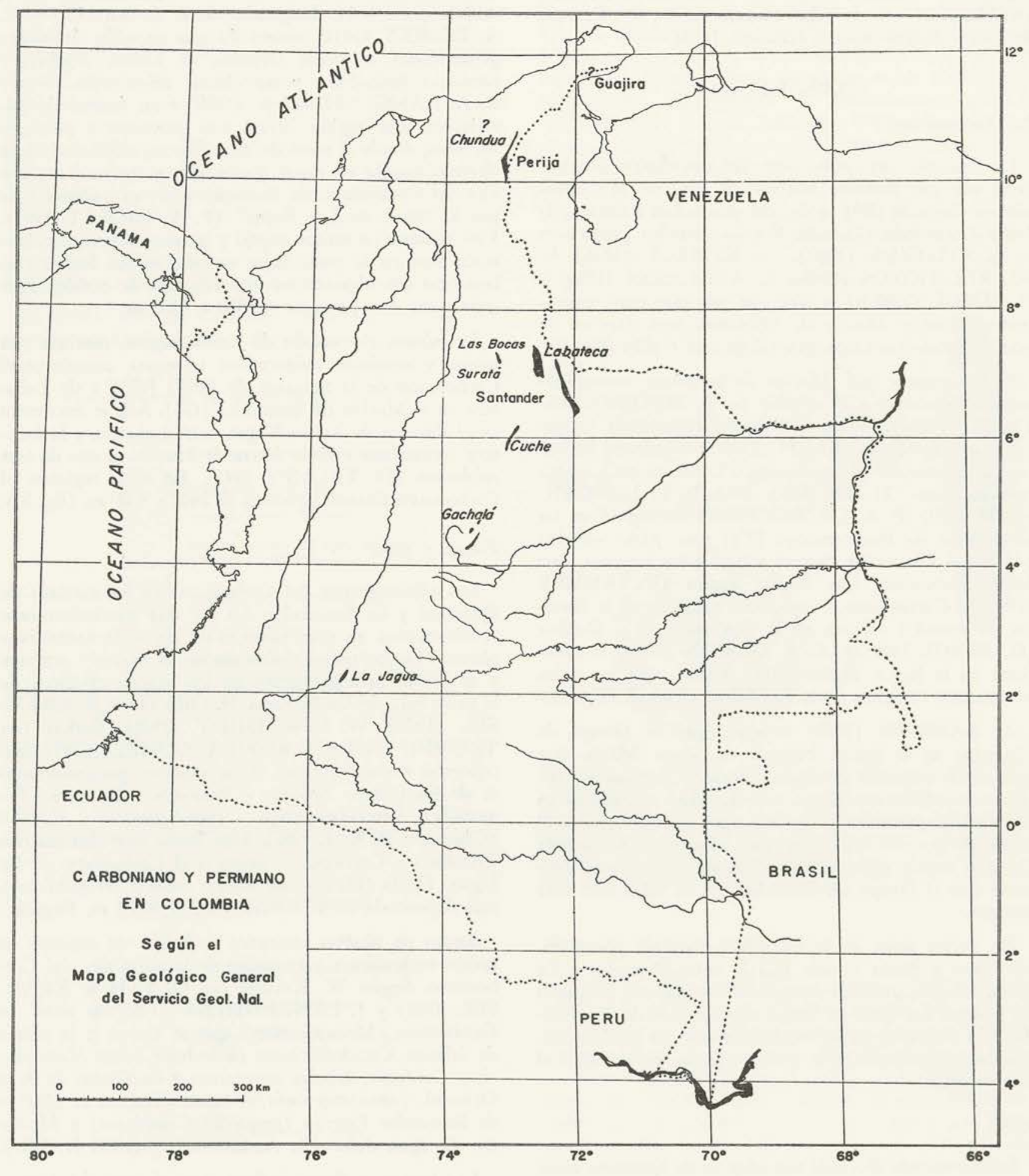

Fig. 11 - Afloramientos del Carboniano y Permiano en Colombia. 
intrusiones graníticas fueron causadas por movimientos tectónicos al final del Devoniano (fase bretónica?), pero G. BOTERO RESTREPO (1950) está más inclinado a considerarlas como productos de movimientos posteriores.

También TRUMPY (1943) menciona intrusiones graníticas, tal vez de edad precarboniana, del Páramo de Tierra Negra cerca a Labateca [G6].

\section{CARBONIANO}

Las formaciones

En Colombia, el Carboniano fue descubierto por primera vez por Roberto Scheibe en 1917 en el camino Medina-Gachalá [F9] arriba del punto Las Palmas y lo llamó Formación Gachalá. Por los estudios posteriores de O. STUTZER (1927), G. KEHRER (1933), V. SUAREZ HOYOS (1945), A. A. OLSSON (1956) y H. BÜRGL (1960 b) se sabe que este piso tiene amplia extensión en el Macizo de Quetame, pero aún no ha sido elaborado un mapa general de esta región (fig. 10).

El Carboniano del Macizo de Guantiva conocemos particularmente por el estudio de G. BOTERO RESTREPO (1950), quien lo designó Formación Cuche (=? Soapaga E. HUBACH 1933). También en el Macizo de Santander (Bucaramanga, Labateca etc.), ocupa extensas áreas (D. TRUMPY 1943, R. L. LANGENHEIM 1959). P. A. DICKEY (1941) distinguió en los alrededores de Bucaramanga [F6] una parte inferior que llamó Formación Suratá y una parte superior, que llamó Formación Las Bocas. Según D. TRUMPY (1943) el Carboniano se encuentra también en la Serranía de Perijá y tal vez en la Península de la Guajira (H. BÜRGL 1960 a). A. A. OLSSON (1956) lo menciona en la Jagua, Huila [D11]. Existe pues, en todos los macizos antiguos de la Cordillera Oriental (fig. 11).

A. GANSSER (1955) supone, que el Grupo de Chundua en la Sierra Nevada de Santa Marta, que consiste de esquistos grafíticos, dioríticos, areniscas cuarcíticas y calizas cristalinas, sea de edad neopaleozoica (carboniana-permiana). Sin embargo, si consideramos el hecho de que los estratos de esta edad en la Cordillera Oriental nunca están metamorfizados, parece más probable que el Grupo de Chundua sea de edad aún más antigua.

En varios sitios de la Cordillera Central, por ejemplo cerca a Santa Leticia [C11], entre Popayán y La Plata, afloran areniscas compactas con láminas delgadas de grafito. En éstos se hallan impresiones de Equisetidae (?) y esporas no determinadas aún. Es posible aunque no comprobado, que estas areniscas pertenezcan al Carboniano.

\section{Rocas}

La Formación Gachalá del Macizo de Quetame tiene una potencia de más de $2.000 \mathrm{~m}$. y consta de areniscas un poco cuarcíticas y argilitas duras de colores brillantes rojo y verde. Estas contienen algunos bancos de 1-3 m. de calizas compactas, las cuales contienen ocasionalmente abundantes Braquiópodos, Corales tabulados (Chaetetes) y troncos de Crinoideos (fig. 10).

Litológicamente muy semejantes son las argilitas y arcillas pizarrosas de color amarillo hasta rojo-violáceo de la Formación Cuche en el Macizo de Guantiva. Pero faltan allí las intercalaciones calcáreas fosilíferas y la edad carboniana está indicada por un solo hallazgo del Lamelibranquio Palaeoneilo sulcatina (CONRAD).

Magníficos afloramientos del Carboniano se encuentran inmediatamente al norte de Bucaramanga [F6]. Allí la parte baja, designada "Serie de Suratá" por P. A. DICKEY (1941) consta de una sucesión de lutitas grises duras, en parte arenosas, de lutitas, argilitas y areniscas limoníticas y cuarcíticas abigarradas. Según R. A. LANGENHEIM Jr. (1959) éstas fueron depositadas en una región litoral con pantanos y planicies fluviales, donde el nivel del mar fluctuó sedimentándose alternadamente en capas marinas y terrestres. La parte alta del Carboniano de Bucaramanga está representada por la "Serie de Las Bocas" (P. A. DICKEY 1941). Esta consiste en lutitas negras y pardas oscuras, con arenisca fina en la parte baja; encima siguen lutitas carbonáceas con algunos mantos delgados de carbón. Esta serie tiene una potencia de 500 a $1000 \mathrm{~m}$.

La misma alternación de lutitas negras, marinas con lutitas y areniscas abigarradas terrestres constituye el Carboniano de la Serranía de Perijá [G3] y de Labateca en el Macizo de Santander [G6]. Allí se encuentra en el Páramo de Tierra Negra entre Labateca y la frontera venezolana y en la Sierra de Murillo al este de esta población (D. TRUMPY 1943). En estas regiones el Carboniano alcanza espesores de 2400 y 4000 m. (fig. 12).

\section{Fauna y flora}

Los afloramientos del Carboniano en los macizos de Quetame y de Santander son los que particularmente suministraron un gran número de restos de animales y plantas. Los animales fósiles son en su mayoría marinos y se hallan principalmente en los bancos calcáreos de la parte baja del Carboniano. H. GERTH \& R. KR ÄUSEL (1931), W. E. SCHMIDT (1938), Barker (en TRUMPY 1943) y J. ROYO Y GOMEZ (1945) describieron o determinaron Braquiópodos, particularmente de los grupos Spirifer y Productus, Briozoos ( $F e$ nestella), Lamelibranquios (Aviculopecten) y Corales (Chaetetes, BÜRGL 1957). Una fauna muy distinta con Trilobites y Cefalópodos presenta el Carboniano de La Jagua, Huila [D11]. Esta fauna, todavía no publicada, está depositada en la colección de la Shell en Bogotá ${ }^{1}$.

Restos de plantas terrestres se hallan en especial en lutitas carbonáceas y areniscas de la parte alta del Carboniano. Según W. Kräusel (en GERTH \& KRÄUSEL 1931) y J. LANGENHEIM (1959) se trata de Equisetinae (Mesocalamites) que se elevan a la altura de árboles, Cicadofilicíneas (helechos) como Neuropteris y Cordaites, árboles semejantes a las Ginko de Asia Oriental. Junto con éstos se encuentran en el Macizo de Santander Esterias (pequeños Crustáceos) y Moluscos de agua dulce (R. A. LANGENHEIM Jr. 1959).

Las faunas y floras indican que el mar del Carboniano inferior (Misisipiano) avanzó rápidamente sobre la parte oriental de la Región Andina, y después se llenó con sedimentos. Durante el Carboniano Superior (Pensilvaniano) regresó paulatinamente y extensas sel-

1 El autor expresa su agradecimiento al Dr. A. Maurenbrecher estratígrafo-jefe de la Compañía Shell-Cóndor S. A., por haberle permitido observar tan interesante fauna. 
vas en parte pantanosas avanzaron sobre el fondo anteriormente marino.

\section{PERMIANO}

\section{Rocas y faunas}

En los macizos de Santander, Guantiva y Quetame siguen encima de la capa más alta con fósiles carbonianos varios cientos de metros de areniscas no fosilíferas con marcas de oleaje, que fueron depositadas en aguas de solo $10 \mathrm{~m}$. de profundidad. Estas areniscas litorales pertenecen tal vez ya al Permiano, como lo indica el hallazgo de un Mooreoceras al norte del Río Blanco en el municipio de Guayabetal [F9]. A base de lagunas en la sedimentación y ligeras discordancias locales, G. BOTERO RESTREPO (1950) cree poder subdividir la Formación Cuche en tres partes, correspondientes al Carboniano inferior (Misisipiano), al Carboniano superior (Pensilvaniano) y al Permiano.

El único sitio en Colombia donde se han hallado abundantes fósiles marinos del Permiano, es la Serranía

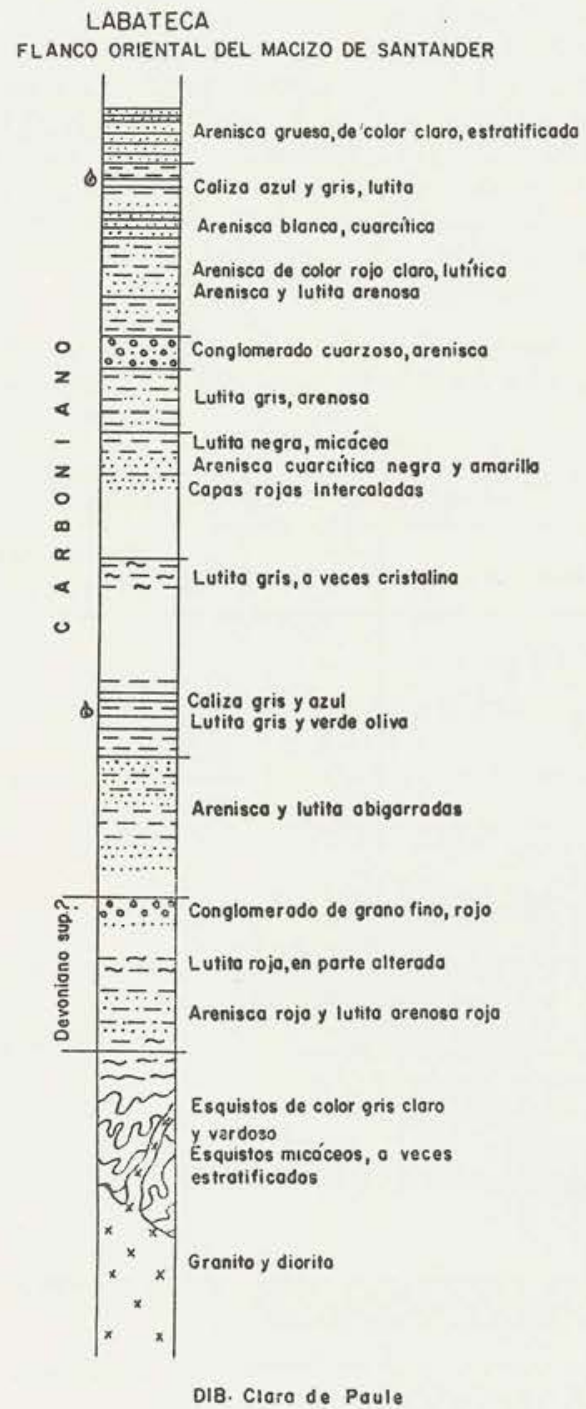

Fig. 12 - Columna estratigráfica del Pre-Girón de Labateca en el flanco oriental del Macizo de Santander, según E. Hubach en TRUMPY 1943. de Perijá. Según O. Renz (en TRUMPY 1943) se hallan en una caliza ligeramente dolomítica con láminas y nódulos de lidita negra.

Los fósiles son abundantes y consisten en restos de esponjas, Crinoideos, muchos Braquiópodos, Gasterópodos y los géneros Medlicottia y Perrinites de los Cefalópodos amonoideos y Tinacoceras de los nautiloideos (A. K. MILLER \& V. ST. WILLIAMS 1945). Cerca a Manaure también J. Wyatt Durham y O. L. Haught colectaron Medlicottia y Perrinites y los Cefalópodos nautiloideos Mooreoceras y Domatoceras (M. L. THOMPSON \& A. K. MILLER 1949). Las capas contienen también los Foraminíferos Stafella, Schubertella, Pseudoschwagerina (fig. 13), Parafusulina (fig. 14) y otros. Son formas con una concha calcárea robusta que vivieron en aguas agitadas cerca a la costa y a arrecifes. Los fósiles de Manaure indican la presencia del Permiano inferior (Wolfcampiano), medio (Leonardiano y Guadalupiano) y tal vez superior.

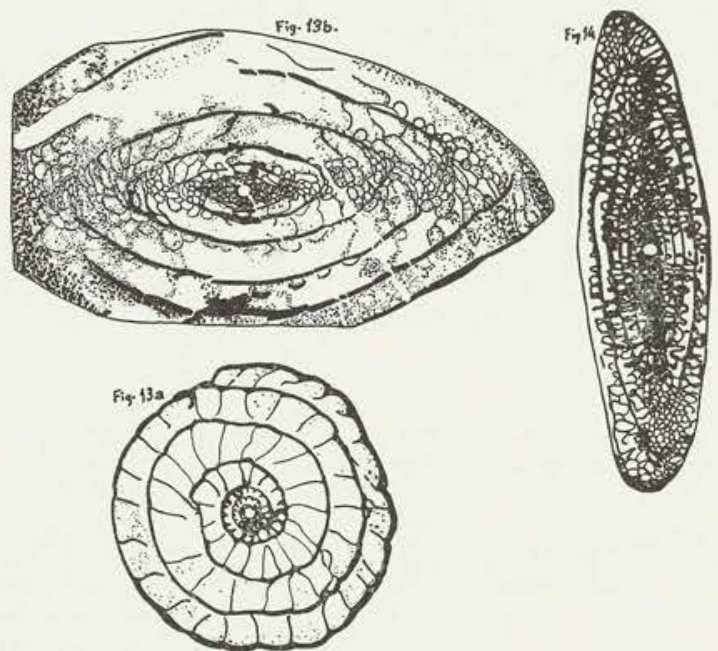

Fig. 13 - Secciones sagitales y axiliales del Foraminífero Pseudoschwagerina dallmusi THOMPSON MILLER? del Permiano de la quebrada Manaure, $4.5 \mathrm{~km}$. E Manaure, Departamento de Magdalena. Aumento 10x. Según THOMPSON \& MILLER 1949. Fig. 14 - Sección axial de Parafusulina trumpyi THOMPSON \& MILlER, del Permiano del río Molino, $6 \mathrm{~km}$. aguas arriba de la población de Molino, Magdalena. Aumento 10x. Según THOMPSON \& MILLER 1949.

\section{El limite Paleozoico-Mesozoico}

La figura 15 muestra de una manera gráfica la sucesión pre-titoniana de los macizos antiguos de la Cordillera Oriental. Si consideramos los estratos paleozoicos conjuntamente, llama nuestra atención en primer lugar, su facies uniforme en una distancia total de $700 \mathrm{~km}$. de agua baja (litoral y epinerítica) en todas las series. Esto indica que son depósitos de mares sucesivos, que fueron muy amplios pero uniformes y en los cuales el mar nunca alcanzó gran profundidad. La cuota de sedimentación era de máximo $5 \mathrm{~cm}$. en mil años, velocidad muy baja comparada con la de la sedimentación en el Mesozoico y Terciario de la misma región.

En el Perú, por contraste, se conocen depósitos paleozoicos de aguas más profundas y de gran espesor; solamente el Permo-Carboniano tiene allí un espesor de $10.000 \mathrm{~m}$. (NEWELL, CHRONIC \& ROBERTS 1953). Parece por lo tanto, que el territorio andino co- 
lombiano formó durante el Paleozoico una estribación de poco hundimiento de un extenso geosinclinal, que tuvo su centro en el Perú.

La uniformidad del mar del Oriente Andino se termina al final del Paleozoico. Los sedimentos mesozoicos indican irregularidades del basamento, islas solevantadas y regiones unas de mayor y otras de menor hundimiento. Las capas mesozoicas casi siempre reposan discordantemente sobre las más antiguas. H. W. NELSON (1957) describe rocas extrusivas riodacíticas de edad permo-triásica en la región al sur de Ibagué [D9]. Todos estos fenómenos indican, que al final del Paleozoico tuvieron lugar movimientos tectónicos, pero no tanto a manera de plegamientos sino más bien de movimientos de bloques a lo largo de fallas, como se observan también en otras partes de los Andes ( $H$. GERTH 1955). Estas dislocaciones se correlacionan con fases tardías del ciclo varíscico.

En Colombia, el resultado más importante de estos movimientos fue la separación de la región andina en dos partes: la occidental y la oriental, separadas por lo menos temporalmente por una barrera que llamamos el Umbral Interandino. Del Triásico en adelante, el Occidente y el Oriente andinos se manifiestan como distintas provincias sedimentarias, magmáticas y tectónicas.

\section{TRIASICO Y LIASICO}

a) Oriente Andino

\section{Grupo de Payandé}

Las rocas mesozoicas más antiguas las encontramos en los alrededores de Payandé y Chaparral [D10] (E.
JAWORSKI 1922, O. RENZ en D. TRUMPY 1943, H. W. NELSON 1957). Consisten de una sucesión de capas rojas continentales, con una caliza marina lidítica de $600 \mathrm{~m}$. en su parte media. D. TRUMPY (1943) designó este horizonte calcáreo como Formación Payandé. H. W. NELSON (1957) distinguió además, una Formación Pre-Payandé y otra Post-Payandé.

El Pre-Payandé consta de 300 a $400 \mathrm{~m}$. de conglomerados, areniscas arcósicas y argilitas abigarradas. Los componentes que constituyen estas rocas son fragmentos de granodioritas, dacitas, riolitas y porfiritas, las cuales después del solevantamiento de la Cordillera Central a lo largo de fallas, fueron transportados por torrentes y depositados en las planicies en su pie oriental (H. W. NELSON 1957). Sobre estos sedimentos continentales transgredió el mar y depositó $600 \mathrm{~m}$. de calizas arenosas desde gris azulosas hasta negras, con algunas intercalaciones de areniscas, lutitas pizarrosas, lidita negra y brechas calcáreas, que constituyen la Formación Payandé. En su parte inferior, algunos bancos o lentejones contienen fósiles de edad carniana (Triásico superior basal) como Equínidos, Crinoideos (Pentacrinus), Gasterópodos y el Lamelibranquio Myophoria jaworskii. En su parte alta se hallaron Amonitas ( $\mathrm{Ne}$ vadites, Anolcites) y el Lamelibranquio Pseudomonotis ochotica, fósiles guía del Noriano (JAWORSKI 1922, TRUMPY 1943). La Formación Payandé fue intruída posteriormente por diques granodioríticos (L. TRUMPY las clasifica como porfiríticos) que transformaron en sus contactos las calizas en mármol y las areniscas en hornfels verdoso.

Sin límite preciso, las capas marinas de Payandé transgreden hacia arriba a estratos volcánicos continen-

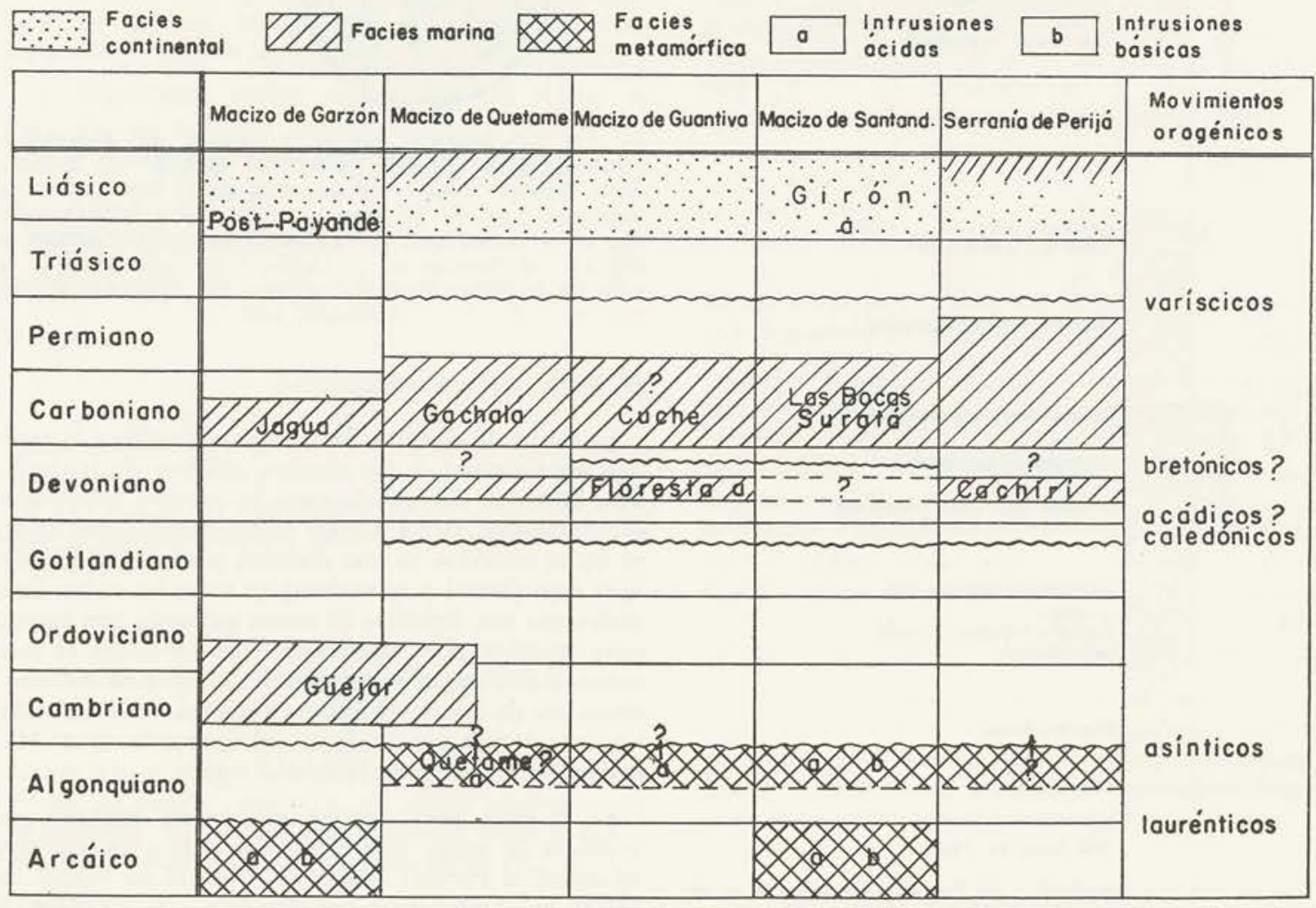

Fig. 15 - Estratos pre-titonianos en los macizos antiguos de la Cordillera Oriental. 
tales que constituyen la parte baja del Post-Payandé. Son aglomerados piroclásticos, tobas y derrames volcánicos de composición riolítica hasta andesítica. Cerca a Payandé tienen una potencia de 500 a $600 \mathrm{~m}$. (H. W. NELSON 1957). Hacia el sur se conectan probablemente con las cuarzo-porfiritas del Río Páez [D11]. La parte alta del Post-Payandé, bien expuesta en el Río Saldaña entre Coyaima y Ataco [D10] y al este del Río Magdalena entre Prado y Dolores [E10], comprende conglomerados y areniscas arcósicas abigarradas con troncos silicificados de árboles (Coníferas). Estos sedimentos del Post-Payandé fueron depositados en un ambiente continental y se correlacionan con el Grupo de Girón (Rético-Liásico) de las partes septentrionales de la Cordillera Oriental.

\section{Grupo de Girón}

Desde su creación por A. HETTNER en 1892, el término Girón fue aplicado a estratos de muy distinta edad, desde Carboniano hasta Neocomiano. Hoy se restringe el nombre Formación o Grupo de Girón a los sedimentos, predominantemente continentales, de edad reticoliásica de la Cordillera Oriental. En la región típica, los alrededores de la población de Girón al suroeste de Bucaramanga [F6], fue estudiado detalladamente por R. L. LANGENHEIM (1959). Consiste allí en su parte inferior $(750 \mathrm{~m}$.) de areniscas grises, cuarcíticas, feldespáticas, con frecuencia conglomeráticas y de argilitas abigarradas. En la parte media, de $1250 \mathrm{~m}$. de espesor, predominan limolitas y argilitas de color gris oscuro, rojo y verde. En la parte alta $(1500 \mathrm{~m}$.) se encuentran nuevamente en primer lugar, areniscas arcósicas (feldespáticas) de color gris pardo, con pocas intercalaciones delgadas de lutita y limolita gris verdosa. Con pocos cambios litológicos esenciales, la Formación Girón se extiende de ahí hacia el interior del Macizo de Santander, donde reduce pronto su espesor y desaparece por completo cerca a la población de California [G6] (M. JULIVERT 1959). Hacia el suroeste se continúa en la Cordillera de Los Cobardes al norte de Vélez. La Formación Girón ocupa amplias áreas en las vertientes del valle del Río Magdalena entre Puerto Wilches [F6] y El Banco [F4-5], en el Valle César [F3] y en la Alta Guajira [H1-2].

En las zonas occidentales de la Cordillera Oriental, el Girón contiene en su parte inferior extensas intercalaciones de pórfido cuarcítico. Algunos horizontes en los alrededores de Aguachica [F5] pueden alcanzar hasta varios centenares de metros (DICKEY 1941). En el flanco suroriental de la Sierra Nevada de Santa Marta, los pórfidos se vuelven muy macizos y están atravesados por pórfidos con feldespatos alcálicos y granófiros aplíticos, mientras que en el interior de esta sierra se convierten en porfiritas cuarcíticas y pórfidos graníticos, a veces biotíticos y hornbléndicos (G. GANSSER 1955). Un afloramiento muy típico de estos pórfidos en la parte inferior del Girón se presenta en el Cerro de La Teta en la Alta Guajira (O. STUTZER 1928).

En los alrededores de Bucaramanga, el Girón carece de rocas eruptivas; el mismo en el anticlinorio de Arcabuco [F8], que se extiende desde Aratoca hacia el sur hasta Villa de Leiva [F8], y en las lomas entre Soatá y Floresta [G8]. Más al sur, el Girón desaparece debajo del Cretáceo, pero reaparece en el Macizo de Quetame sobre el Carboniano del Río Batá [F9] (H.
BƯRGL 1960 b) con un espesor de $1350 \mathrm{~m}$. Fue encontrado debajo del Cretáceo en la perforación Raspe 1 de la International Petroleum Company [E9]. Llega nuevamene a la superficie en los alrededores de Payandé, extendiéndose ampliamente entre Payandé, Chaparral, en el valle del Río Saldaña [D9] y en los alrededores de Prado y Dolores [E10] (Formación Post-Payandé). En el Río Páez [D11] se presenta en forma de pórfidos cuarcíticos y areniscas abigarradas macizas. Puede decirse que el Girón se extiende casi continuamente por toda la Cordillera Oriental desde la Guajira en el norte, hasta La Plata, Huila [D11], en el sur (fig. 16).

Con muy pocas excepciones, el Grupo de Girón se depositó en un ambiente desértico y un clima árido. Las areniscas abigarradas conglomeráticas, feldespáticas y de granos de diferentes tamaños son depósitos de torrentes, que se formaron, al igual que en los desiertos actuales a veces con intervalos de muchos años de sequía (ssel en Africa septentrional). El curso de tales torrentes desérticos cambia con cada tormenta y así se explica la irregularidad de las capas del Girón y su estratificación cruzada. Ciertas areniscas pueden considerarse como dunas consolidadas, pero éstas son relativamente escasas lo mismo que en los desiertos actuales (J. WALTHER 1924).

Sin embargo, en todos los desiertos hay sitios donde el agua dulce sube continuamente a la superficie y los oasis que rodean estas fuentes son tan característicos para el desierto como los ríos secos, las cuencas saladas y las dunas. Tales oasis existieron también en el desierto del Girón. Cerca a Montebel, en la carretera Duitama-Charalá [F8], A. A. OLSSON (en TRUMPY 1943) colectó pequeños Crustáceos (Esterias y Ostrácodos), Gasterópodos y restos de plantas. W. BOCK (1953 a, b) quien estudió la fauna, la considera de edad rética, con alguna reserva (R. L. LANGENHEIM 1959). En los alrededores de Bucaramanga [F6] y en la Serranía de Arcabuco [F8], J. LANGENHEIM (1959) logró hacer una basta colección de restos vegetales, particularmente de Lagenopteris nilssoniana, Elatocladus, Podozamites, Cladophebis, Zamites y Gingko. Dicha flora habla en favor de una edad rético-liásica.

El Girón es la única formación (por lo menos mesozoica) de la Cordillera Oriental, que se formó bajo condiciones que facilitan la acumulación de grandes depósitos de sal. Como los yacimientos de sal de $\mathrm{Zi}$ paquirá, Nemocón y Sesquilé [F8] están actualmente rodeados por estratos del Cretáceo, la mayoría de los geólogos presume, que la sal se formó en el Cretáceo o especialmente en el Cenomaniano, Aptiano? y Valanginiano (R. SCHEIBE 1925, E. HUBACH 1957). Es la opinión del autor, sin embargo, que la sal se formó en un lago sin desagüe en la cuenca continental central del Girón y que debido a su peso menor en comparación con el de las lutitas del Cretáceo, las penetró en forma de tapones salinos.

Pero no todos los depósitos de la Formación Girón son productos de un desierto. Hacia el final del Liásico, el mar invadió la gran planicie y sedimentó capas marinas. Tales capas describe H. W. NELSON (1957) en el Post-Payandé de Prado-Dolores, Huila [E10]; R. L. LANGENHEIM (1959) encontró calizas con Pelecípodos marinos en el miembro superior cerca a Palermo en el Macizo de Arcabuco [F8] y H. BÜRGL (1960 b) 


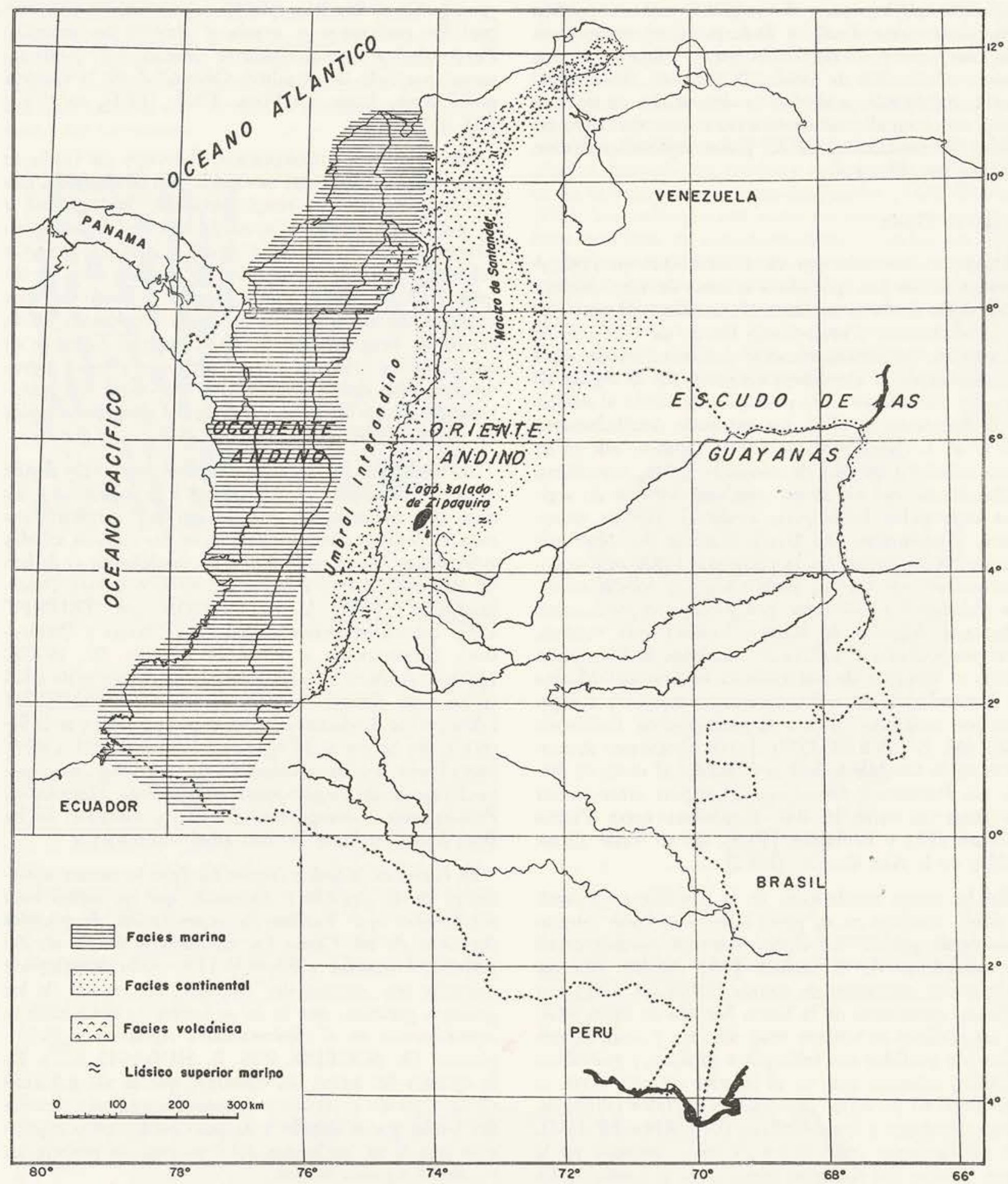

Fig. 16 - Sedimentos del Rético-Liásico en Colombia. 
colectó Trigonias de edad liásica superior en la parte más alta marina del Girón del Macizo de Quetame [F9]. Al suroeste de El Banco, cerca a la Laguna de Morrocoyal [E5], E. Hubach (en D. TRUMPY 1943) colectó algunas Amonitas liásicas (Arietites, Psiloceras?) Lamelibranquios y plantas en lutitas negras y calizas delgadas (estratigráficamente?) debajo de una serie de $2600 \mathrm{~m}$. de argilitas, areniscas y conglomerados rojos con gruesos derrames volcánicos, tobas y piroclásticos. R. Martin y O. Renz (en D. TRUMPY 1943) encontraron Esterias, parecidas a las de Montebel y una impresión de una Amonita en la Quebrada Los Indios, $32 \mathrm{~km}$. al SE de Fundación [E3] en el flanco SW de la Sierra Nevada de Santa Marta. Capas calcáreas marinas, parecidas a las que halló R. L. LANGENHEIM en el Macizo de Arcabuco fueron observadas por Otto Renz (en D. TRUMPY 1943) cerca a Manaure en el Valle César [F3] en la parte alta del Girón. Estos numerosos sitios indican que el mar invadió casi toda la región de la Cordillera Oriental al final del Liásico; pero se retiró después muy pronto y sus depósitos fueron en su mayor parte erodados en el intervalo entre el Liásico superior y la transgresión marina del Kimmeridgiano y Titoniano.

En el mismo intervalo, tuvieron lugar ligeros movimientos tectónicos que se correlacionan con los nevádicos antiguos de las cordilleras norteamericanas, y particularmente con la fase agassízica del Dogger superior. En su curso, magmas graníticas inyectaron en varios sitios la Formación Girón (Jordán [F7] en el Río Sogamoso, R. L. LANGENHEIM 1959, parte SE de la Sierra Nevada de Santa Marta, A. GANSSER 1955). En este período intruyeron los extensos batolitos centrales (tonalita, granito, sienita) de la Sierra Nevada de Santa Marta (A. GANSSER 1955) y aparentemente también algunas granodioritas de la Cordillera Central (H. W. NELSON 1957).

\section{b) Occidente Andino}

Generalidades

No se puede decir con seguridad absoluta sí, y en caso afirmativo, por cuales formaciones el Triásico y Liásico estén representados en el Occidente Andino. En esta región faltan fósiles de todo el intervalo entre el Ordoviciano Inferior (Puerto Berrío-Las Cristalinas) y el Caloviano Superior (Piso del Pesar). La edad de las formaciones intermedias fue, por consiguiente, asignada de diferentes maneras. En este informe seguimos la opinión de TULIO OSPINA (1911) y R. SCHEIBE (1931) quienes atribuyeron una edad triásica-jurásica a las formaciones Dagua y Espinal, las cuales H. W. NELSON (1957) comprendió dentro de una sola unidad estratigráfica que llamó "Grupo de Dagua".

\section{Grupo de Dagua}

Su parte más antigua, la Formación Dagua en el sentido de E. HUBACH \& B. ALVARADO (1934), consta en su parte inferior de esquistos y pizarras filliticos, más o menos grafíticos, de algunos miles de metros de espesor. En donde están en contacto con cuerpos tonalíticos, se han transformado en esquistos micáceos. La parte alta, de $2000 \mathrm{~m}$. metros de espesor, comprende rocas arenosas esquistosas, pizarras silicosas grafíticas, lutitas negras y lutitas calcáreas. Un solo horizonte de caliza silicosa alcanza $350 \mathrm{~m}$. de espesor. En ciertos sitios, las pizarras transgreden a filitas y esquistos compactos de color verde oscuro y violeta. H. W. NELSON (1957) observó que estos grados más altos de metamorfismo están en conexión con intrusiones diabásicas.

La Formación Espinal (E. HUBACH \& B. ALVA. RADO 1934) comprende liditas negras y pizarras silicosas y tiene un espesor máximo de $300 \mathrm{~m}$. Según $\mathrm{H}$. W. NELSON (1957) existe una transición sucesiva entre las Formaciones Dagua y Espinal. La última está concordantemente superpuesta con el Grupo PorfiríticoDiabásico.

El grado de metamorfismo dinámico se reduce paulatinamente desde abajo hacia arriba en el Grupo de Dagua. H. W. NELSON (1957) supone que esto se explica por la posición profunda $(15.000 \mathrm{~m}$.) que dicho grupo ocupó en el Cretáceo Superior debajo del Grupo Porfirítico-Diabásico y no por una fase orogénica especial.

Respecto a su edad el Grupo de Dagua ha sido considerado como Precambriano (E. GROSSE 1926) hasti Suprajurásico e Infracretáceo (H. W. NELSON 1957). En el Ecuador se considera la continuación meridional del Grupo de Dagua como Paleozoico (W. SAUER 1957). E. HUBACH \& B. ALVARADO (1945) acentúan por un lado la semejanza entre las pizarras de Dagua y las del Nórico de Chaparral-Payandé y por el otro con las del Grupo de Cajamarca. En nuestro concepto son en todo caso de edad precaloviana y pueden, por consiguiente, corresponder al Triásico Superior (Payandé) y Rético-Liásico (Girón y Post-Payandé) del Oriente Andino (T. OSPINA 1911, R. SCHEIBE 1931). A base de esta suposición se elaboró el mapa de la figura 16. La edad del Grupo de Dagua y su relación con el Grupo de Cajamarca, es el principal interrogante de la estratigrafía de Colombia.

\section{Grupo de Chita}

En los valles de los ríos Pascual [B12] y Patía [B11], en el flanco este de la Cordillera Occidental, E. GROSSE (1935) distinguió el Grupo de Chita (Nariño), que comprende cuatro formaciones:

La unidad inferior ( $\mathrm{p}^{1}$ en los mapas de E. GROSSE), expuesta entre Rosario y El Peñol, consta de pizarras arcillosas grises, con frecuencia algo metamórficas, con interposiciones locales de areniscas tobáceas y tobas porfiríticas.

La segunda unidad $\left(\mathrm{p}^{2}\right)$, que aflora al E y NE de Chita [B12], consta también de pizarras arcillosas grises, con intercalaciones de pizarra silicea, pizarras y esquistos verdes y violáceos débilmente filíticas. Su parte alta, que forma la loma de Chita, consta de cuarcitas blancas.

La tercera unidad $\left(\mathrm{p}^{3}\right)$ comprende tobas aglomeráceas porfiríticas y melafídicas apizarradas, de color violáceo, sin metamorfismo. Esta unidad aflora en Chita y al oeste del Río Pascual.

La unidad más alta $\left(\mathrm{p}^{4}\right)$ consta de liditas y pizarras siliceas negras, con intercalaciones locales de tobas porfiríticas violáceas y verdes. De esta unidad proviene la muestra con Rzehakina epigona lata CUSHMAN \& JARVIS, que se tratará más adelante y que la determina como Paleoceno (pág. 173). 
E. GROSSE (1935) consideró los estratos del Grupo de Chita como Paleozoico (?) y los separó claramente de la Formación Porfirítica, que colocó tentativamente en el Cretáceo. A su vez, E. HUBACH (1957) los correlaciona de la manera siguiente:

$$
\begin{aligned}
& \left.\mathrm{p}^{4} \ldots \ldots \ldots\right\} \text { Grupo Diabásico en facies porfirítica } \\
& \left.\mathrm{p}^{3} \quad \ldots \ldots \ldots\right\} \text { con muchos sedimentos } \\
& \mathrm{p}^{2} \quad \ldots \ldots \ldots \text { Formación Liberia (J. Keizer) } \\
& \mathrm{p}^{1} \quad \ldots \ldots \text {.... Formación Espinal. }
\end{aligned}
$$

En algunos lugares, por ejemplo en los alrededores del macizo diorítico de Piedrancha, los estratos del Grupo de Chita están metamorfoseados a filitas y cornubianitas. Según E. HUBACH (1957 a) este metamorfismo se explica por las intrusiones tonalíticas del Terciario inferior, que efectaron también la Formación del Cauca.

\section{SUPRAJURASICO Y CRETACEO}

\section{a) Occidente Andino}

\section{El Grupo Porfirítico-Diabásico}

Al final del Doggeriano, en el Calloviano superior, se observa el primer paso del mayor avance marino en la historia de los Andes colombianos; el mar inundó de nuevo partes del Occidente Andino y sedimentó el Piso del Pesar discordantemente sobre los estratos más antiguos. Este hecho resulta de un examen verificado por el autor en las Amonitas que E. Hubach colectó en 1932 en la carretera que va de Popayán a Coconuco [C11], en el flanco occidental de la Cordillera Central. Estas Amonitas fueron consideradas algunas veces como del Albiano (E. HUBACH \& ALVARADO 1934, E. HUBACH 1957) otras como del Liásico (E. HUBACH 1945), pero en realidad representan los géneros Lamberticeras y Quenstedtoceras, fósiles guía del Caloviano superior (fig. 17). Se hallaron en lutitas oscuras, un poco calcáreas, con láminas lidíticas, intercaladas en una serie de derrames volcánicos, de unos $800 \mathrm{~m}$. de potencia, depositados abajo del nivel del mar, y compuestos de porfiritas, atravesadas por diques andesíticos, probablemente cenozoicos.

Con este Piso del Pesar empieza la enorme serie de rocas volcánicas de más de $10.000 \mathrm{~m}$. de espesor, que junto con las formaciones Dagua y Espinal constituye la mayor parte de la Cordillera Occidental y del flanco occidental de la Cordillera Central. Pero no solamente en Colombia se conoce esta formación; es tal vez la más característica de todos los Andes y fue observada primeramente por CHARLES DARWIN en marzo de 1833. En los varios países andinos la formación recibió nombres distintos, pero se trata siempre de la misma unidad. En Colombia, fue distinguida por primera vez por T. OSPINA (1911), después designada por E. GROSSE (1926) como Formación Porfirítica; R. SCHEIBE (1931) la llamó "Grupo de las porfiritas, meláfiros, diabasas y parientes"; E. HUBACH \& B. ALVARADO (1934) la llamaron "Grupo de Faldequera" y H. W. NELSON (1957) le aplicó el nombre de "Grupo Diabásico". Esta unidad consiste principalmente en derrames volcánicos submarinos de composición variada, en la parte inferior relativamente ácidas (porfiritas, metáfiros) y en la superior, casi exclusivamente básicos (diabasas y rocas ultrabásicas). A base de estas diferencias en composición, E. GROSSE (1926) distinguió una "Formación Porfirítica Antigua" y una "Formación Porfirítica Moderna", las cuales corresponden aproximadamente a la "Formación Acida" y a la "Formación Básica" de E. HUBACH y B. ALVARADO (1934).

Entre esta masa de rocas volcánicas se intercalan, a distancias considerables, sedimentos marinos normales tales como lutitas, lutitas silicosas y liditas. En algunas se hallaron fósiles que permiten determinar la edad de este conjunto con bastante precisión. Por su gran importancia estratigráfica citamos estos sitios detalladamente:

a) En la carretera Popayán-Coconuco [C11], $25 \mathrm{~km}$. de Popayán, E. HUBACH colectó en el Piso del Pesar, que forma la base del Grupo PorfiríticoDiabásico, Lamberticeras lamberti (SOWERBY) y Quenstedtoceras cf. leachi (SOWERBY), que determinan la edad de estos estratos como Caloviano superior.

b) En la Loma Hermosa, Antioquia [D7], R. Scheibe halló en calizas negras según E. GROSSE (1926, p. 54) Pulchellia cf. didayana (D’ORBIGNY), Desmoceras? cf. charrierianum (D'ORBIGNY) y Lytoceras? cf. subfimbriatum (D'ORBIGNY). Esta fauna, que fue determinada por G. Steinmann, es de edad barremiana.

c) En Ebéjico, Antioquia, E. GROSSE (1926, p. 53) encontró $4 \mathrm{~km}$. al SSE de la población, en una arenisca ferruginosa intercalada dentro de porfiritas, Exogyra boussingaultii D'ORBIGNY, Cucullaea raulini LEYMERIE, Trigonia hondaana LEA, Protocardium cf. forbesi PICTET \& RENEVIER, Venus cf. silvatica COQUAND, Arcopagia? cf. subconcentrica D'ORBIGNY, Solen? cf. robinaldinus D'ORBIGNY, Pseudoglauconia studeri VILANOVA y Pseudoglauconia helvetica PICTET. G. Steinmann consideró esta fauna como aptiana. Según la experiencia del autor se trata del nivel basal del Albiano.

d) En la región de La Virginia-Balboa, [C10], Caldas, H. W. NELSON (1957, p. 55) colectó una muestra de lidita negra, la que contenía una asociación de los Foraminíferos Guembelina y Globigerina. Esta asociación es típica para el Turoniano superior y Senoniano basal (Coniaciano inferior).

e) En la Quebrada San Marcos, al sur de Vijes [C10], H. W. NELSON (1957, p. 55) colectó en lutitas silicosas Inoceramus cf. peruanus BRÜUGEN y Guembelina, que es también una asociación típica del límite Turoniano-Senoniano.

f) En San Antonio, $30 \mathrm{~km}$. SSW de Cali [C10], Jan Keizer (según H. W. NELSON 1957) colectó Inoceramus peruanus BRÜGGEN y en un horizonte más alto una rica fauna de Foraminíferos de edad Senoniano medio.

g) En 1952, Jesús A. Bueno, entonces Director del Laboratorio Nacional de Fomento Minero de Pasto, entregó al autor una muestra de porfirita arcillosa y arenosa que colectó al sur de Ancuyá, Nariño [B12], en el camino que conduce a Guaitarilla. Esta muestra contenía buenos ejemplares de Rzehakina epigona lata CUSHMAN \& JAR- 
VIS, en Colombia un fósil guía del Paleoceno inferior. Según E. HUBACH (1957), las capas fosilíferas pertenecen a la parte alta del Grupo de Chita de E. GROSSE (1935).

De los datos anteriores se deduce con plena claridad, que el Grupo Porfirítico-Diabásico del Occidente Andino comprende el espacio de tiempo desde el Caloviano superior hasta el Paleoceno. Este resultado está perfectamente de acuerdo con los obtenidos en los demás países andinos. Anteriormente se pensaba, que las rocas efusivas porfiríticas-diabásicas empezaron ya en el Triásico. Hoy se consolida la opinión de que derrames verdaderos de esta composición en todos los Andes comienzan con el Caloviano, es decir, después de la fase agassízica y que donde se presentan rocas de estos tipos en capas más antiguas se trata de intrusiones (HOFFSTETTER, FUENZALIDA \& CECIONI 1957, p. 273).

La gran potencia de más de $10 \mathrm{~km}$. del Grupo Porfirítico-Diabásico se puede explicar solamente por un hundimiento progresivo del fondo del Occidente Andino. Por este hundimiento, los estratos del Dagua y Espinal llegaron a profundidades de 12 a $20 \mathrm{~km}$. y ello explica el metamorfismo que experimentaron las partes inferiores de la Formación Dagua. Durante el Jurásico Superior, el Cretáceo y el Paleoceno, el Occidente Andino era un típico eugeosinclinal en el sentido de $\mathrm{H}$. STILLE (1940), del cual salieron las trangresiones que inundaron el miogeosinclinal del Oriente Andino.

\section{b) Oriente Andino}

\section{Potencia del Cretáceo}

El espesor del Cretáceo varía considerablemente en las distintas partes de la Cordillera Oriental. En la Alta Guajira [H1-2] (O. RENZ 1956, H. BÜRGL 1960 a) es de $2600 \mathrm{~m}$.; al este de El Banco, Magdalena [F4] se reduce un poco; entre Bucaramanga y Barrancabermeja [F6] aumenta a $4400 \mathrm{~m}$. (MORALES ET ALT. 1958). El máximo espesor se observa en la Cuenca de Cundinamarca con $16.000 \mathrm{~m}$. (más $800 \mathrm{~m}$. del Titoniano superior). Hacia el sur se reduce muy rápidamente y en los alrededores de Neiva [D11] no tiene más de $600 \mathrm{~m}$; ; la reducción continúa hacia el sur y en los alrededores de la Cueva de los Guácharos [B12] (J. E. RAMIREZ 1953) se adelgaza en una capa de apenas $100 \mathrm{~m}$. (fig. 18).

\section{Las transgresiones suprajurásicas y cretáceas}

Estas diferencias en potencia han sido causadas en primer lugar por el avance progresivo del mar sobre la tierra firme del Oriente Andino, hasta que en el Cretáceo superior lo cubre por completo y además la parte septentrional del Escudo de las Guayanas. Las etapas principales en este avance son las transgresiones del Kimeridgiano, Titoniano, Hauteriviano y Albiano.

La primera etapa, la del Kimeridgiano inferior, se observa en la Alta Guajira. El mar depositó allí lutitas limolíticas (Formación Cocinas) de $1600 \mathrm{~m}$. de espesor, bien conservadas en la Fosa de la Guajira (O. RENZ 1956, H. BÜRGL 1960 a). El Kimeridgiano y el Cretáceo de la Alta Guajira no contienen rocas eruptivas y se manifiestan de tal manera como elementos típicos del Oriente Andino.

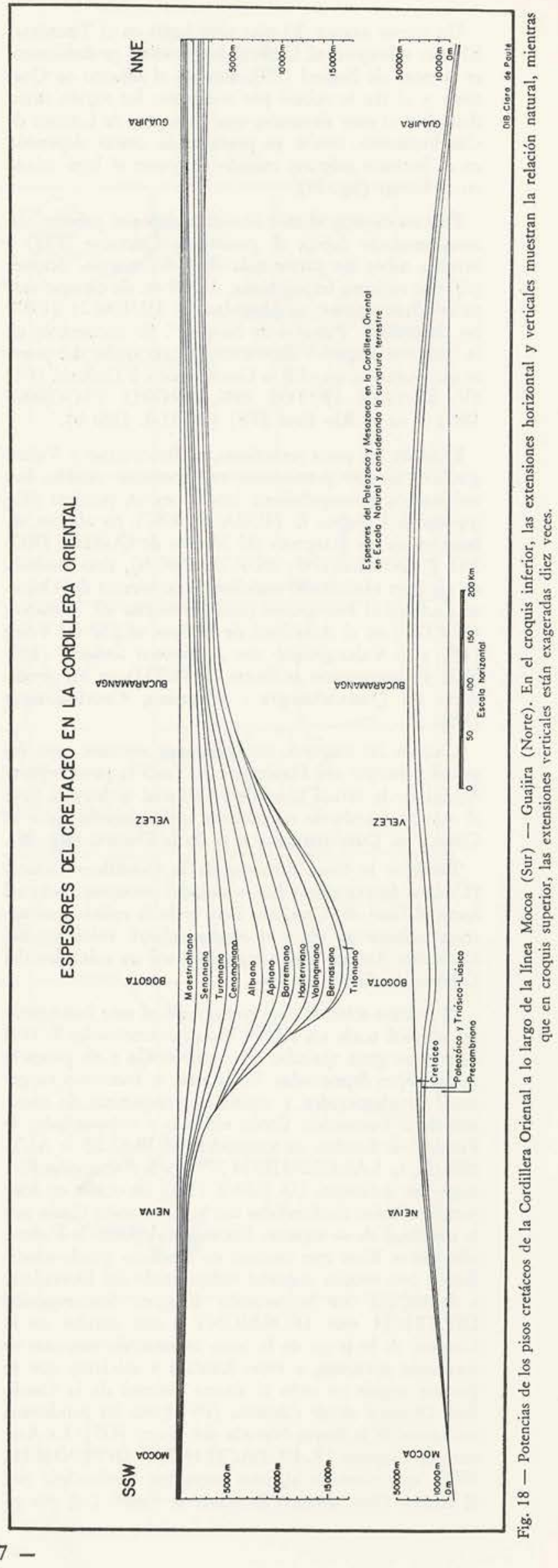


Un nuevo avance del mar tuvo lugar en el Titoniano. El mar sobrepasó el Umbral Interandino probablemente al oeste de Bogotá [E9], alcanzó el Macizo de Quetame y al fin le cubrió por completo. La región inundada por el mar titoniano, que llamamos la Cuenca de Cundinamarca, estaba ya preformada como depresión en el Jurásico inferior, cuando se formó el lago salado en el Girón (fig. 19).

En esta cuenca, el mar titoniano depositó primero un conglomerado (cerca al puente de Quetame [F9]) y brechas sobre las partes más altas del macizo, después pizarras oscuras, ferruginosas, de $800 \mathrm{~m}$. de espesor, que están fuertemente subplegadas. E. HUBACH (1957) las denominó "Pizarras de Sáname". Se encuentran en la carretera Bogotá-Villavicencio, aguas arriba del puente de Quetame, en el Río Guavio cerca a Gachalá [F8] (V. SUAREZ HOYOS 1945, J. ROYO Y GOMEZ 1945) y en el Río Batá [F8] (BÜRGL 1960 b).

Durante los pisos posteriores, el Berriasiano y Valanginiano, el mar permaneció relativamente estable. Sus sedimentos, principalmente lutitas negras, piríticas (Esquistos de Culebra, E. HUBACH 1957), no afloran solamente en las márgenes del Macizo de Quetame (ROYO Y GOMEZ 1945; BÜRGL 1960 b), sino también en algunos vértices del anticlinorio occidental del Oriente Andino; el Berriasiano (con Berriasella aff. spinulosa GERTH) en el Anticlinal de Bolívar, al SW de Vélez [F7] y el Valanginiano con Leptoceras hubachi (ROYO) y Crioceratites andinum (GERTH) en los alrededores de Quebradanegra y Nimaima, Cundinamarca [E8].

Una de las mayores transgresiones marinas tuvo lugar al principio del Hauteriviano. Toda la parte septentrional de la actual Cordillera Oriental se hundió bajo el mar formando de tal manera, una conexión entre la Cuenca de Cundinamarca y la de la Guajira (fig. 20).

También la loma terrestre de la Cordillera Central (Umbral Interandino) fue inundada, permaneciendo así hasta el final del Cretáceo. Pero todavía existía una barrera submarina entre el eugeosinclinal volcánico del Occidente Andino y el miogeosinclinal no volcánico del Oriente Andino.

El terreno sobre el cual transgredió el mar hauteriviano oriental tenía un relieve bastante acentuado, lo cual causó una gran variedad en composición y en potencia de las capas depositadas. En la base se formaron en general conglomerados y areniscas, compuestas de material de la Formación Girón erodado y redepositado: la Formación Tambor en Santander (MORALES \& ALT. 1958, R. L. LANGENHEIM 1959) y la Formación Rionegro en la Guajira (O. RENZ 1956), las cuales en años pasados fueron confundidas con la Formación Girón por la similitud de su aspecto. Encima se depositó la Formación Santa Rosa que consiste en limolitas pardo-amarillentas con mucho material redepositado del Devoniano o de calizas con la pequeña Exogyra boussingaultii DIETRICH non D'ORBIGNY o con corales en la Guajira. A lo largo de la costa oriental de este mar se formaron areniscas, a veces lutíticas y calcáreas que se pueden seguir en todo el flanco oriental de la Cordillera Oriental desde Cáqueza [F9] hasta las pendientes orientales de la Sierra Nevada del Cocuy [G7]: La Arenisca de Cáqueza (E. HUBACH 1945, V. OPPENHEIM 1950), que también algunas veces fue confundida con el Girón. Otro abanico de arena se formó (tal vez ya en el Valanginiano) al suroeste de la cuenca, y se presenta hoy día en el núcleo del anticlinorio de VilletaUtica-La Palma [E8].

En el Barremiano y Aptiano, el mar del Oriente Andino cambió poco su extensión. Se depositaron predominantemente lutitas oscuras (Formación La Paja, MO. RALES \& ALT. 1958) y en la parte septentrional las calizas de la Formación Cogollo (NOTESTEIN, HUBMAN \& BOWLER 1944, O. RENZ 1956). Parece que al final del Aptiano, ligeros plegamientos tuvieron lugar y algunas regiones (Anticlinorio de Arcabuco, flanco oriental de la Cordillera Oriental) fueron solevantados sobre el nivel del mar y expuestos a la erosión.

Al principio del Albiano el mar se extendió de nuevo, esta vez particularmente hacia el sur y el este (fig. 21). En el Huila [D11], el Alto Putumayo [C13], y hasta el Perú (BENAVIDES-CACERES 1956), la suceción continua crétacea empieza tan sólo con este piso. El mar inundó también la Serranía de La Macarena [F11] (F. PABA SILVA \& TH. VAN DER HAMMEN 1960) y muy extensas partes septentrionales del Escudo de las Guayanas, donde se formó durante el Albiano y el Cretáceo superior, la Arenisca de Roraima (A. GANSSER 1954) ${ }^{1}$. En el Albiano, el mar mesozoico alcanzó su máxima extensión y la conservó hasta el final del Cretáceo.

\section{Sedimentación cíclica}

Fuera de estos hundimientos sucesivos del Oriente Andino durante el Jurásico superior y el Cretáceo, $\mathrm{H}$. BÜRGL (1960 c) reconoció movimientos verticales más leves que causaron una sedimentación cíclica, particularmente en la Cuenca de Cundinamarca. Esta se manifiesta de tal manera, que los pisos empiezan con sedimentos de poca profundidad (conglomerados, areniscas, calizas, liditas), y encima se depositan lutitas oscuras, piríticas, sedimentadas en profundidades batiales (200-600 m.). Hacia el final de cada piso, sedimentos epineríticos y litorales avanzan otra vez hacia el centro de la cuenca (fig. 22). Cada piso cronostratigráfico, caracterizado por una distinta fauna de Amonitas, representa por lo tanto un ciclo sedimentario. Como cada piso tiene en la Cuenca de Cundinamarca aproximadamente igual espesor máximo, H. BƯRGL supone que también su duración fue más o menos igual y llega a la conclusión representada en el siguiente esquema:

$\begin{array}{llll}\text { Piso } & \text { Duración } & \text { Espesor } & \text { Cuota de sedimentación } \\ \text { Maestrichtiano } & 6 \text { millones de años } 1450 \mathrm{~m} . & 24 \mathrm{~cm} \text {. en mil años } \\ \text { Senoniano } & 6 \text { millones de años } 1600 \mathrm{~m} . & 26.6 \mathrm{~cm} \text {. en mil años } \\ \text { Turoniano } & 6 \text { millones de años } 1500 \mathrm{~m} . & 25 \mathrm{~cm} \text {. en mil años } \\ \text { Cenomaniano } & 6 \text { millones de años } 1250 \mathrm{~m} .20 .8 \mathrm{~cm} \text {. en mil años } \\ \text { Albiano } & 6 \text { millones de años } 2300 \mathrm{~m} .38 .3 \mathrm{~cm} \text {. en mil años } \\ \text { Aptiano } & 6 \text { millones de años } 1700 \mathrm{~m} .28 .4 \mathrm{~cm} \text {. en mil años } \\ \text { Barremiano } & 6 \text { millones de años } 1500 \mathrm{~m} .25 \mathrm{~cm} \text {. en mil años } \\ \text { Hauteriviano } & 6 \text { millones de años } 1500 \mathrm{~m} .25 \mathrm{~cm} \text {. en mil años } \\ \text { Valanginiano } & 6 \text { millones de años } 1600 \mathrm{~m} .26 .6 \mathrm{~cm} \text {. en mil años } \\ \text { Berriasiano } & 6 \text { millones de años } 1500 \mathrm{~m} .25 \mathrm{~cm} \text {. en mil años }\end{array}$

En el Maestrichtiano (inferior, medio y superior) y en el Senoniano (Coniaciano, Santoniano y Campaniano) se reconocen en cada uno tres subciclos de una duración de dos millones de años aproximadamente.

\footnotetext{
1 Otros geólogos que estudiaron la Arenisca de Roraima la consideran de edad paleozoica.
} 


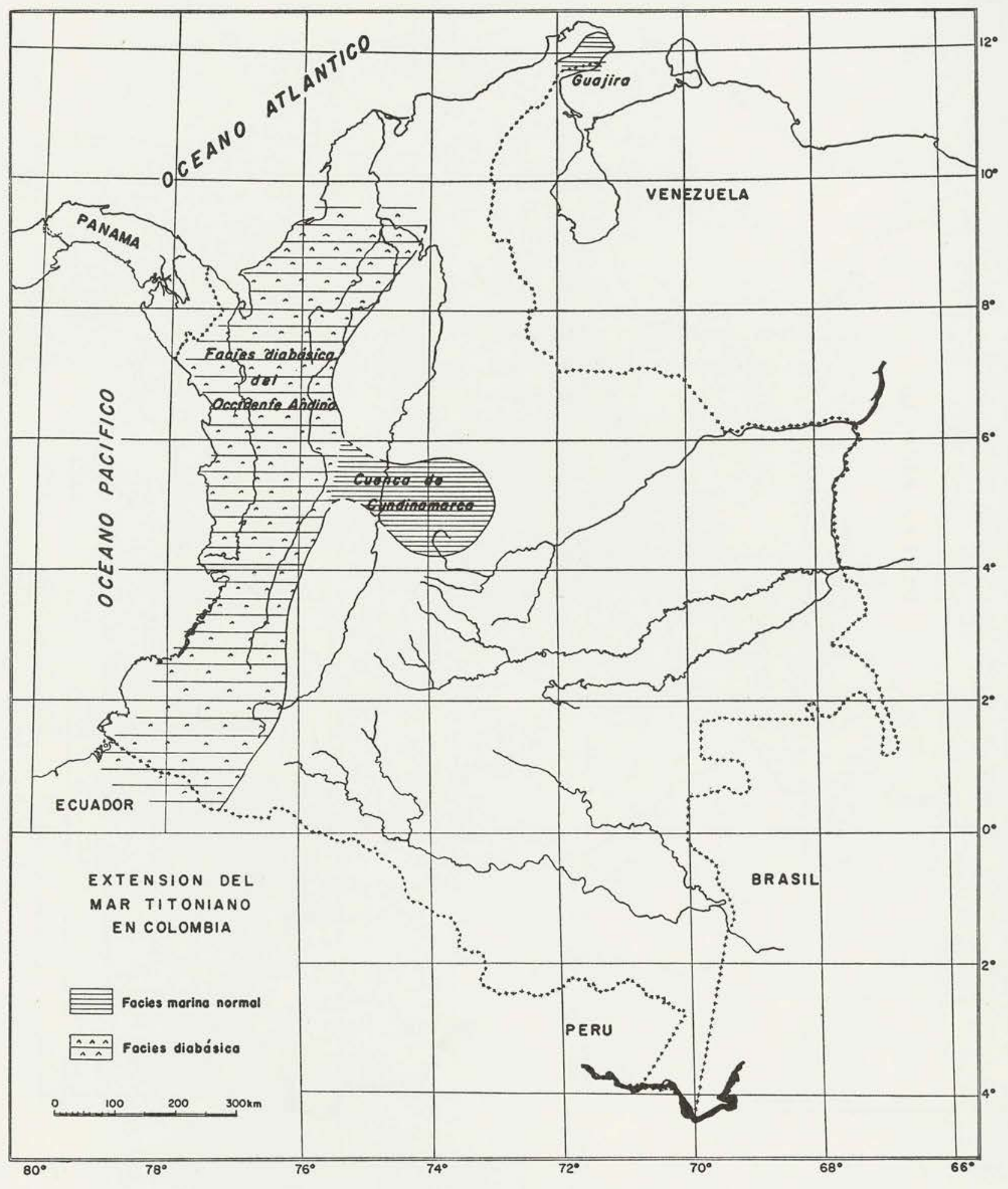

Fig. 19 - Extensión del mar en el titoniano en Colombia. 


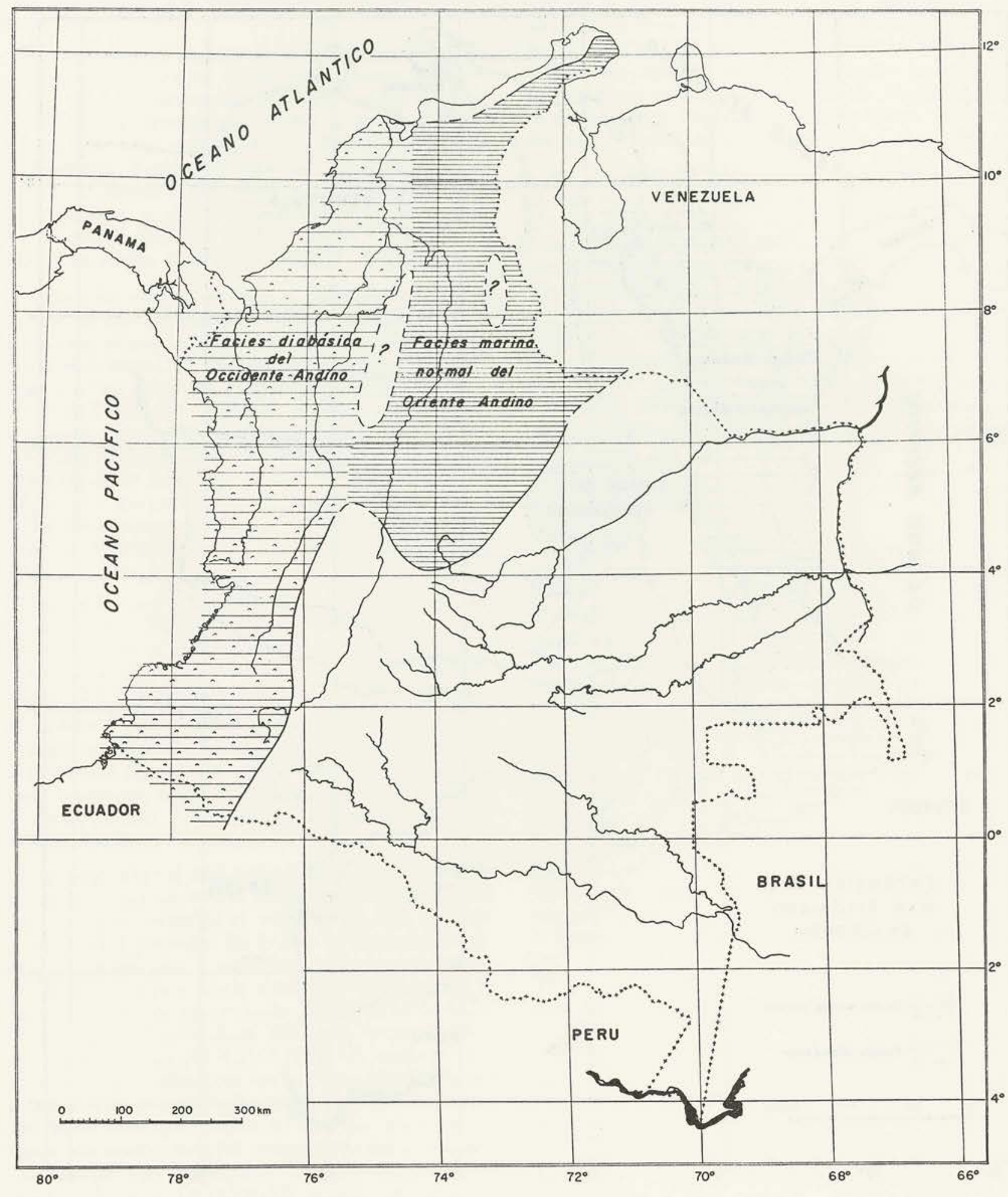

Fig. 20 - Extensión del mar en el hauteriviano en Colombia. 


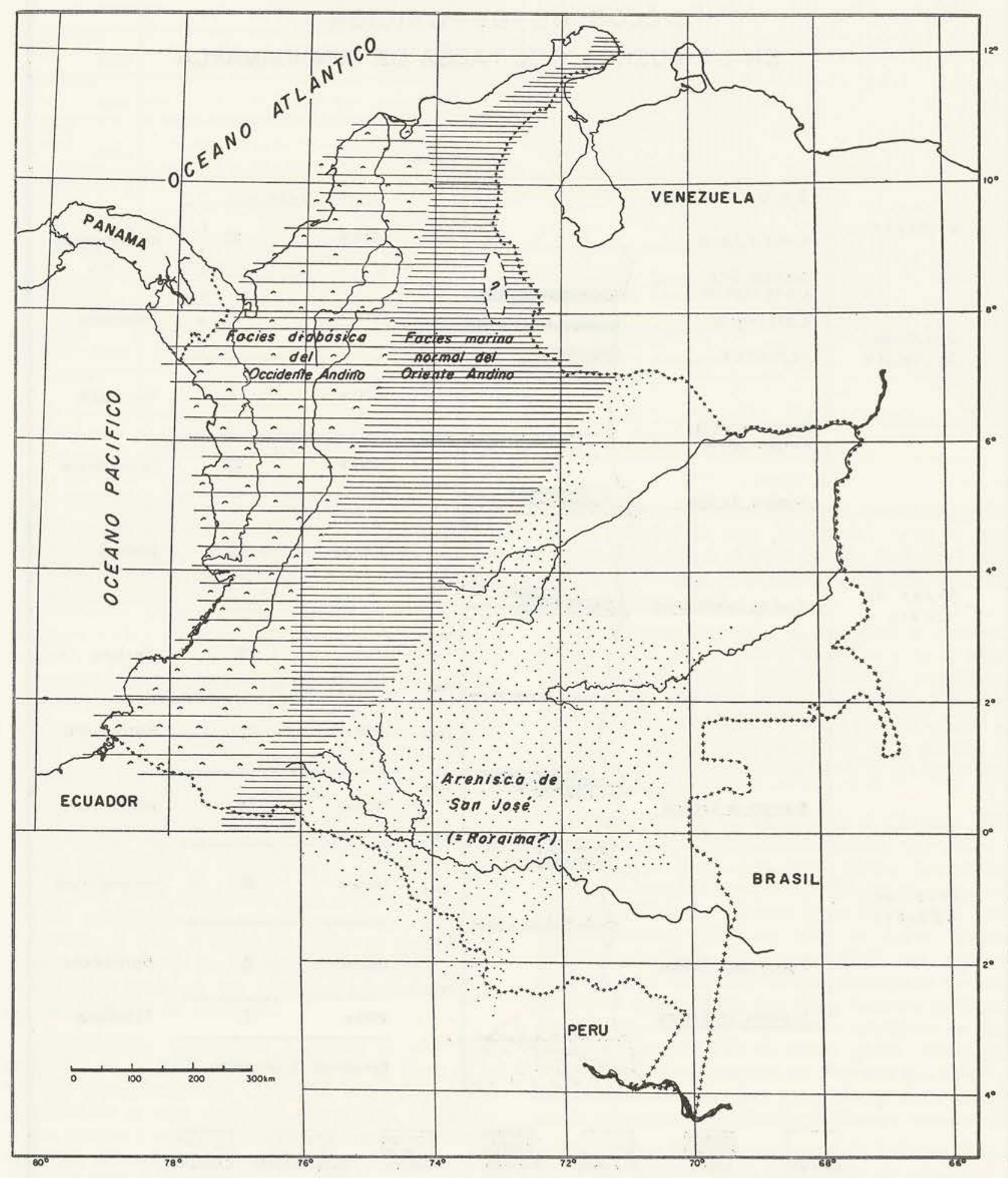

Fig. 21 - Extensión del mar en el Albiano y Cretáceo Superior en Colombia. 


\section{CICLOS DE DEPOSICION}

\section{EN LA CUENCA CRE TACEA DE CUNDINAMARCA}

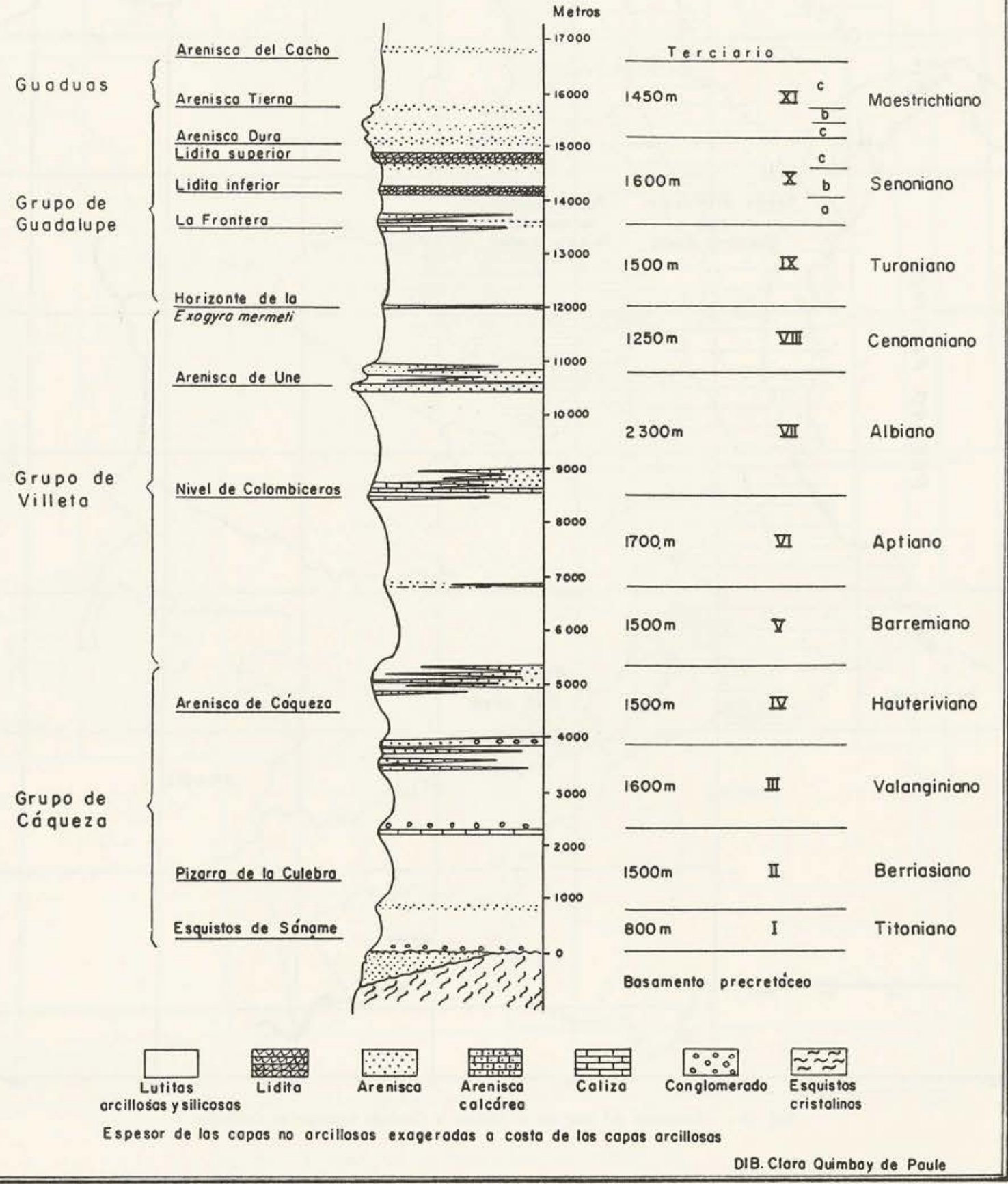

Fig. 22 - Ciclos sedimentarios en el Cretáceo de la Cuenca de Cundinamarca. 


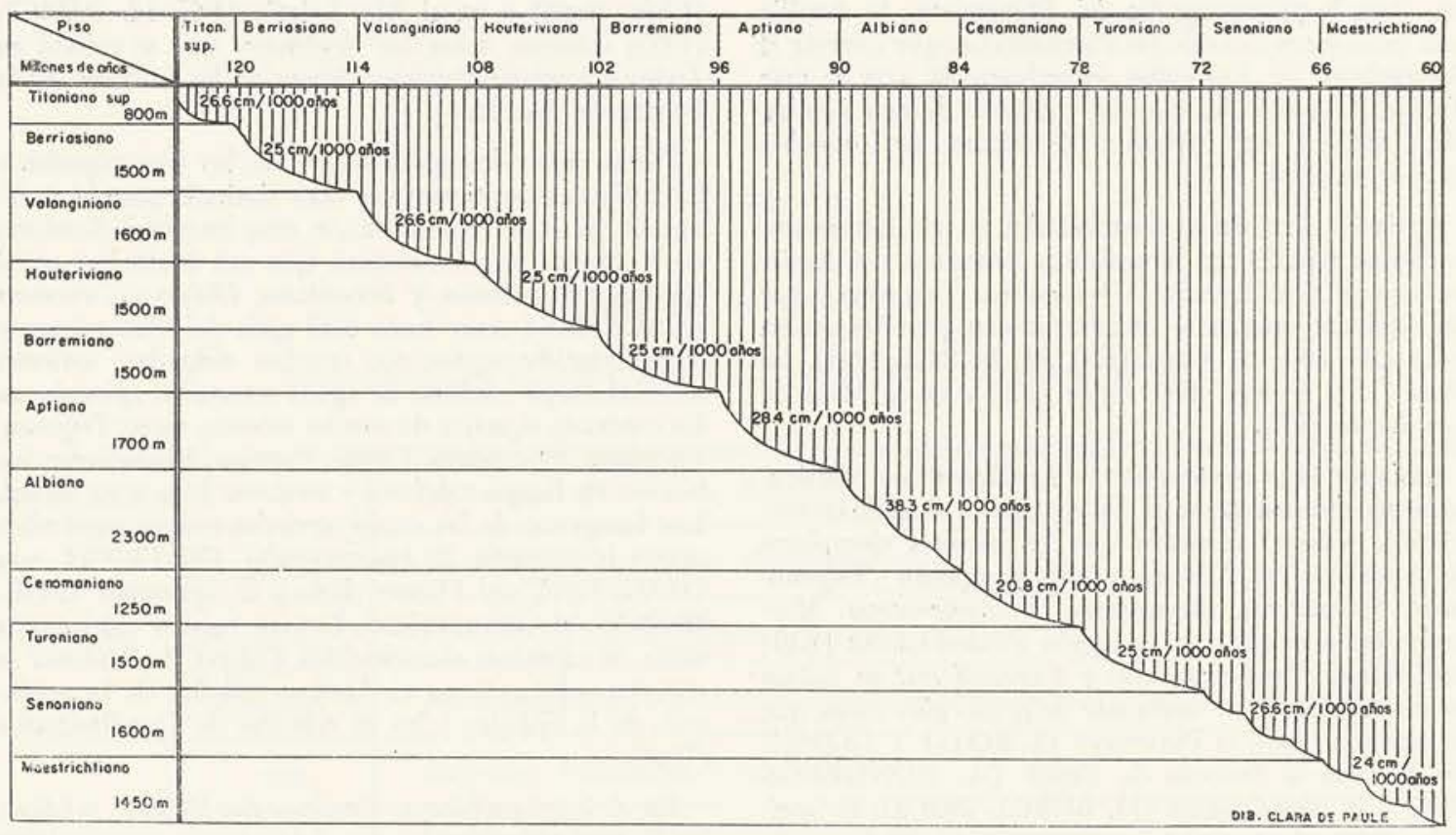

Fig. 23 - Velocidad de hundimiento del fondo de la cuenca de Cundinamarca durante el Cretáceo.

H. BƯRGL concluye que estos pisos y subpisos cretáceos no son arbitrarios como, en cierto grado, las formaciones litológicas, sino unidades estratigráficas y cronológicas naturales, causadas por oscilaciones rítmicas de la costra terrestre (fig. 23).

\section{Fósiles}

Los más característicos y estratigráficamente más importantes son las Amonitas. En las lutitas batiales éstas son muy escasas y están tan mal conservadas que raras veces es posible determinarlas. Pero en capas calcáreas y margosas epineríticas se encuentran con frecuencia y a veces en gran abundancia. Por otro lado, faltan también en los depósitos litorales, en los cuales predominan Gasterópodos y Lamelibranquios. Muy notable es la escasez de Aptychus y Belemnitas en Colombia.

Con muy pocas excepciones, cada género de Amonıtas está restringido a un solo piso o subpiso, tal como lo muestra la tabla I. Como los diferentes pisos suprajurásicos y cretáceos no se distinguen litológicamente, se los puede reconocer con seguridad solamente a base de su contenido de Amonitas.

Kimeridgiano: Conocemos Amonitas de esta edad solamente de la Formación Cocinas de la Fosa de la Guajira (Guajira Trough, O. RENZ 1956). Aunque su conservación es algo deficiente, fue posible identificar varios géneros y especies, los cuales indican una estrecha conexión del mar de la Guajira con el de México ( $H$. BÜRGL 1960 a).

Titoniano: En este piso las Amonitas son bastante escasas y mal conservadas. Con mayor frecuencia se hallan en el Río Batá [F9], unos 4,5 km. aguas abajo del Caserío Quebrada Honda (H. BÜRGL 1960 b). Algunas pocas formas titonianas fueron descritas por J. ROYO Y GOMEZ (1945 a) de la región del Río Guavio y de la carretera Bogotá-Quetame [F9]. Las pocas especies conocidas son idénticas con las de Argentina y México.
Berriasiano: El sitio más rico en Amonitas berriasianas es la mina de yeso "Lusitania", cerca al caserío Quebrada Honda en el Valle del Río Batá (H. BÜRGL 1960 b). Casi todas las especies identificadas se conocen en Argentina y Perú.

Valanginiano: Amonitas de esta edad se encuentran en los bordes del Macizo de Quetame y en el Anticlinorio Villeta-La Palma (Quebradanegra, Nimaima, EI Peñón [E8]). Algunas especies de Colombia fueron ya descritas anteriormente en el Perú, pero la especie más frecuente, Olcostephanus astierianus, es la primera que establece conexión entre Colombia y la provincia mediterránea de Europa.

Hauteriviano: En los alrededores de Cáqueza [F9] y de Villeta [E8] se encuentran buenos ejemplares de Olcostephanus junto con otros fósiles hauterivianos [Toxaster colombianus (LEA), Choffatella sogamosae (KARSTEN)]. En Talauto, aguas abajo de El Peñón (Cundinamarca) [E8], en Villa de Leiva (Boyacá) [F8] y Jesús María (Santander) [F8], este género se halla en gran número pero mal conservado en lutitas pizarrosas negras. Entre San Gil y Zapatoca en Santander [F7] se colectaron muy buenos ejemplares de Acanthodiscus, Favrella y de un nuevo género semejante a Valanginites. Con excepción de Favrella, que es un género andino, las Amonitas hauterivianas están estrechamente relacionadas con formas de Europa meridional.

Barremiano: Las capas calcáreas de Vélez y Villa de Leiva son famosas desde los tiempos de Alejandro de Humboldt por la riqueza y perfecta conservación de las Amonitas. Pero igualmente ricos son los alrededores de Fómeque [F9], San Gil, La Mesa de Los Santos [F7], Simití [F6] y la península de la Guajira [H1-2]. La mayoría de las Amonitas de Colombia descritas por L. VON BUCH (1839) J. LEA (1840), A. D'ORBIGNY (1842), E. FORBES (1845), H. KARSTEN (1856), K. GERHARDT (1897), L. RIEDEL (1938) y J. ROYO Y GOMEZ (1945) provienen del Barremiano y Aptia- 
no. Para la paleogeografía del Barremiano, la familia más interesante es la de las Pulchelliidae, que conecta el Barremiano de Colombia estrechamente con el mar Tethys. A base de las especies y géneros de esta familia, H. BÜRGL (1956) dividió el Barremiano de Colombia en tres subpisos.

Aptiano: Los sitios mencionados en el Barremiano contienen también en abundancia Amonitas del Aptiano inferior (Deshayesites, Cheloniceras, Lytoceras). Las del Aptiano superior se encuentran con gran frecuencia en Apulo (Rafael Reyes [E9], H. BÜRGL 1955), La Mesa [E9], Villeta [E8], Utica [E8] y en la Mesa de Los Santos [F7].

Albiano: Hypacanthoplites y Lyelliceras son particularmente frecuentes en el Occidente de Cundinamarca (Apulo, Villeta) mientras que los mejores ejemplares de Amonitas del Albiano medio y superior (Engonoceras, Knemiceras, Brancoceras, Prohysteroceras, Mortoniceras) provienen de la región Prado-Dolores [E10] en Tolima. Oxytropidoceras y Venezoliceras se hallan en abundancia en un horizonte de lutitas pizarrosas, que se extiende desde el Putumayo (J. ROYO Y GOMEZ 1942) hasta la Serranía de Perijá (A. RONDEROS 1959) y la Alta Guajira (H. BÜRGL 1960 a). El horizonte limítrofe con el Cenomaniano está en la región de Anolaima y San Francisco [E9] caracterizado por Hamites y Mariella (H. BÜRGL 1957).

Cenomaniano: En este piso las Amonitas son muy escasas. Calycoceras se conoce en los departamentos del Tolima (Prado-Dolores) y Boyacá. Concreciones piríticas en los alrededores de San Francisco y Las Mesitas del Colegio [E9] contienen Tropitoides y Tarrantoceras.

Turoniano: Particularmente ricas en Amonitas son las concreciones calcáreas en la parte alta de este piso en Mesitas del Colegio, Anolaima y Bituima [E9] un poco más abajo estratigráficamente se encuentra un horizonte lutítico con numerosos ejemplares aplastados de $\mathrm{Be}$ nueites. Las especies más semejantes a las colombianas son las de Africa septentrional y occidental (REYMENT 1955).

Coniaciano: Las Amonitas de este nivel se encuentran con frecuencia conservadas con su concha original, pero como su interior suele estar lleno de grandes cristales de calcita, es difícil extraer ejemplares completos de las concreciones calcáreas. Sin embargo, se conocen buenos especímenes de los departamentos del Huila, Tolima, Cundinamarca y Santander (E. BASSE 1936, 1942, 1948, 1950).

Santoniano: Peroniceras, Gauthiericeras y tal vez también Prinocycloceras se extienden desde el Coniaciano medio hasta el Santoniano. Con nueva forma se agrega a éstos solamente Texanites.

Campaniano: Ejemplares mal conservados de Stantonoceras, Nostoceras y Solenoceras se colectaron entre Girardot y Nariño [E9] (BÜRGL 1954 b), cerca a La Sierra en la carretera Bogotá-Cambao [E9] y en el Alto del Páramo entre Zipaquirá [F8] y Pacho [E8]. Estas Amonitas como también las del Maestrichtiano indican una conexión marítima entre Colombia y Texas.

Maestrichtiano: Las Amonitas son muy escasas y raras veces identificables. Mejores especímenes de Nostoceras y Coahuilites se hallaron en la Sabana de Bogotá
(Chía, Sopó) y en el Río Lebrija [F6]. H. BÜRGL (1955) informa sobre un Scaphites, que se colectó en Zipaquirá inmediatamente debajo de los carbones de la Formación Guaduas.

Por su lento desarrollo filogénico, los Gasterópodos y Lamelibranquios tienen un valor limitado para la estratigrafía, pero por otra parte son muy buenos indicadores de la facies. Los Inoceramus, que son frecuentes en el Berriasiano, Albiano y Senoniano, Didymotis roemeri (KARSTEN), muy buen fósil guía del Coniaciano, y otros lamelibranquios con conchas delgadas, vivieron sobre el fango arcilloso de aguas tranquilas epineríticas. En contraste aquellos de concha robusta, como Trigonia, Cucullaea, Ptychomya, Corbis, Cyprina, Pholadomya habitaron los fangos calcáreos y arenosos de la zona litoral. Las Exogyras, de las cuales mencionaremos particularmente la pequeña $E$. boussingaultii DIETRICH non D'ORBIGNY del Hauteriviano y E. squamata D'ORBIGNY del Cenomaniano, forman bancos calcáreos, a veces de espesores considerables. Calizas de Rudistas se conocen solamente en el Aptiano inferior de la península de la Guajira y en el Albiano de Cundinamarca (Une).

En el Suprajurásico y Cretáceo del Oriente Andino, los Gasterópodos tienen poca importancia estratigráfica. Con la excepción de Paraglauconia (Barremiano) no hay ninguno que pueda ser considerado como fósil guía. El Gasterópodo más frecuente es indudablemente $T u$ rritella (Haustator) colombiana JAWORSKI (1938), que se extiende desde el Hauteriviano hasta el Coniaciano. En los alrededores de El Calvario [F9], Meta, $7 \mathrm{~km}$. al ENE de Quetame, se encuentran calizas arenosas con bancos de Nerinea, formando probablemente lentejones en la Arenisca de Cáqueza (Hauteriviano). V. PETTERS (1954) informa de una capa con Nerinea en la carretera de $\mathrm{La} \mathrm{Paz}, 2 \mathrm{~km}$. al oeste de Manaure [FG3], que probablemente representa la base del Albiano.

No obstante los trabajos de L. VON BUCH (1839), J. LEA (1840), A. D'ORBIGNY (1842), H. KARSTEN (1856), K. GERHARDT (1897), W. PAULCKE (1903), L. SOMMERMEIER (1913), C. H. FRITZSCHE (1923), R. HEINZ (1928), W. O. DIETRICH (1938), E. JAWORSKI (1938) y ROYO Y GOMEZ (1945 a), existen en el Cretáceo de Colombia muchos Gasterópodos y Lamelibranquios no descritos todavía. Esto es especialmente el caso de los del Campaniano y Maestrichtiano que aparentemente permiten una correlación perfecta con el Taylor Marl y el Navarro Group de Texas.

En el Cretáceo Inferior, los Foraminíferos están restringidos a los sedimentos infraneríticos y litorales en los límites de los pisos. Según V. PETTERS (1954) se conocen los siguientes horizontes:

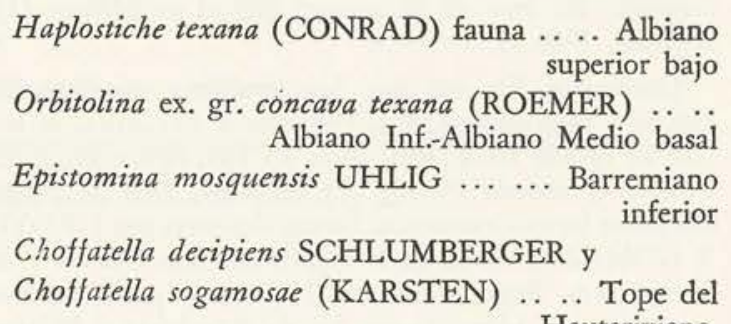
Hauteriviano. 
TABLA I

\section{GENEROS DE AMONITAS}

representados en el Suprajurásico y Cretáceo de la Cordillera Oriental

\begin{tabular}{|c|c|c|}
\hline \multicolumn{2}{|c|}{ Maestrichtiano } & \multirow{2}{*}{$\begin{array}{l}\text { Nostoceras, Coahuilites, Scaphites } \\
\text { Nostoceras, Solenoceras, Stantonoceras }\end{array}$} \\
\hline \multirow{3}{*}{ Senoniano } & Campaniano & \\
\hline & Santoniano & Peroniceras, Gauthiericeras, Texanites \\
\hline & Coniaciano & Prionocycloceras, Peroniceras, Gauthiericeras, Barroisiceras, Niceforoceras \\
\hline \multirow[b]{2}{*}{ Turoniano } & sup. & Scaphites, Mammites, Coilopoceras \\
\hline & inf. & Pseudaspidoceras, Benueites, Vascoceras, Thomasites \\
\hline \multicolumn{2}{|c|}{ Cenomaniano } & Tropitoides, Tarrantoceras, Mantelliceras, Calycoceras \\
\hline \multirow{3}{*}{ Albiano } & sup. & Argonauticeras, Mariella, Dipoloceras, Mortoniceras, Venezoliceras \\
\hline & med. & $\begin{array}{l}\text { Engonoceras, Parengonoceras, Tegoceras, Oxytropidoceras, Eubrancoceras, } \\
\text { Brancoceras, Hysteroceras, Knemiceras }\end{array}$ \\
\hline & inf. & $\begin{array}{l}\text { Hamites, Valdedorsella, Puzosia, Douvilleiceras, Paracanthoplites, } \\
\text { Hypacanthoplites, Lyelliceras }\end{array}$ \\
\hline \multirow{2}{*}{ Aptiano } & sup. & Melchiorites, Parahoplites, Acanthohoplites, Dufrenoyia \\
\hline & inf. & Phylloceras, Lytoceras, Australiceras, Cheloniceras, Deshayesites \\
\hline \multirow{3}{*}{ Barremiano } & sup. & $\begin{array}{l}\text { Crioceratites, Veleziceras, Karsteniceras, Ancyloceras, Heteroceras, Colchidites, } \\
\text { Hamulina }\end{array}$ \\
\hline & med. & Pedioceras, Pseudohaploceras, Pulchellia, Heinzia, Psilotissotia \\
\hline & inf. & Phylloceras, Pedioceras, Pseudohaploceras, Nicklesia \\
\hline \multicolumn{2}{|c|}{ Hauteriviano } & Subastieria, gen. nov. aff. Valanginites, Olcostephanus, Favrella, Acanthodiscus \\
\hline \multicolumn{2}{|l|}{ Valanginiano } & $\begin{array}{l}\text { Olcostephanus, Rogersites, Oosterella, Pseudoosterella, Crioceratites, Leptoceras, } \\
\text { Polyptychites, Simbirskites, Limaites }\end{array}$ \\
\hline \multicolumn{2}{|l|}{ Berriasiano } & $\begin{array}{l}\text { Leptoceras, Kilianiceras, Berriasella, Parodontoceras, Neocomites, Cuyaniceras, } \\
\text { Neocosmoceras }\end{array}$ \\
\hline Titoniano & sup. & $\begin{array}{l}\text { Pseudoinvoluticeras, Substeueroceras, Raimondiceras, Windhauseniceras, } \\
\text { Aulacosphinctes? }\end{array}$ \\
\hline \multicolumn{2}{|c|}{ Kimmeridgiano } & Idoceras, Aspidoceras \\
\hline
\end{tabular}


Del Turoniano superior en adelante, los Foraminíferos se vuelven progresivamente más frecuentes en tanto que las Amonitas escasean. En el Senoniano superior y el Maestrichtiano, la estratigrafía se basa en primer lugar en ellos. En el Campaniano y Maestrichtiano (Taylor y Navarro), V. PETTERS (1955) distingue cuatro provincias de facies de Foraminíferos, que son de norte a sur (fig. 24).

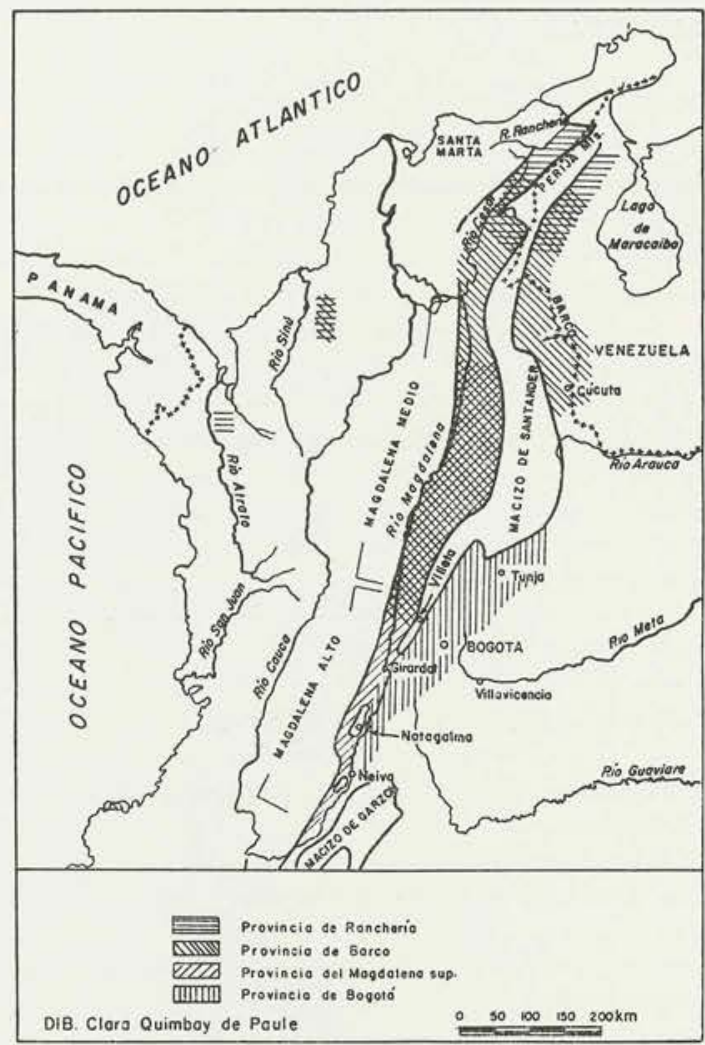

Fig. 24 - Provincias de faunas de Foraminíferos en el Campaniano y Maestrichtiano de Colombia; según V. PETTERS 1955.

1. La provincia de Ranchería: Foraminíferos son frecuentes. Los pelágicos (R. GANDOLFI 1955) son un poco más abundantes que los bentónicos e indican un ambiente infranerítico (40-200 m. de profundidad del mar).

2. La provincia de Barco: La fauna de Foraminíferos, descrita en detalle por CUSHMAN \& HEDBERG (1941), se depositó en un ambiente epinerítico (10-40 m.). Esta provincia sigue el borde oriental del Macizo de Santander y la Serranía de Perijá, el valle medio del río Magdalena y el Valle César.

3. La provincia del alto Magdalena: Comparada con las dos provincias anteriormente mencionadas, la fauna de ésta es muy pobre, particularmente las formas pelágicas son escasas. Por otra parte contiene muchos especímenes grandes de varias especies de Siphogenerinoides y Bulimina (H. BÜRGL \& Y. DUMIT 1954). La facies es epinerítica hasta litoral.

4. La provincia de Bogotá tiene una fauna semejante a la anterior, pero caracterizada por la abundancia de Siphogenerinoides y la escasez de otros géneros. Se sedimentó en una bahía de poca profundidad y casi ce- rrada por todos lados. En el Maestrichtiano superior, la facies marina de las últimas dos provincias se releva por la facies continental de la Formación Guaduas.

De los Equinodermos mencionamos particularmente Toxaster colombianus (LEA), mejor conocido bajo el nombre de Toxaster roulini AGASSIZ, fósil guía de la parte alta del Hauteriviano y no del Aptiano como opinan K. GERHARDT 1897 y L. NOETH 1938. Del mismo nivel proviene Miotoxaster collegnoi SISM. (L. NOETH 1938). En la carretera Villa de Leiva-Chiquinquirá [F8] se encuentran numerosos Equínidos en la base del Albiano, los cuales no han sido estudiados todavía. La fauna más rica en Equínidos (8 especies, 3 nuevas) fue descrita por C. W. COOKE (1955) del Albiano medio del valle de Ranchería, Magdalena [G2]. Algunos especímenes de la familia Phymosomatidae (gen. et spec. indet.) cita K. BEURLEN (1938) en el Cenomaniano superior (junto con Plicatula cf. placunea LAMARCK) del camino Chiquinquirá-Puente Nacional. Probablemente de las capas limítrofes entre el Turoniano y Coniaciano de Albán [E9] proviene el $\mathrm{Mi}$ craster (s. lat.) spec. descrito por K. BEURLEN (1938). Una rareza especial representa el Crinoideo Roiometra columbiana CLARK del Albiano medio de Sasaima [E9] (A. H. CLARK 1945).

De las otras clases de Invertebrados mencionamos el Crustáceo decápodo Hoploparia columbiana BEURLEN de Vélez [F7-8] (K. BEURLEN 1938) y los Cirrípodos de la familia Lepadidae (percebes) Loricula columbiana ROYO del Turoniano de Albán [E9] y Archaeolepas strobila GERHARDT y Loricula alvaradoi ROYO del Albiano medio de Pacho [E8]. Según J. ROYO Y GOMEZ (1941), varios de los fósiles descritos por K. GERHARDT (1897) como Pterópodos (Hyalaea, Vaginella, Creseis) representan en realidad placas de capitulum de Loricula. En Apulo (BÜRGL 1955) y Pacho, se presentan en el Aptiano inferior y en la base del Albiano calizas con Serpula, la cual tal vez es idéntica a la Serpula antiquata SOWERBY, descrita por K. BEURLEN (1938) del camino Chima-Socorro.

Cerca al borde llanero de la Cordillera Oriental, se encuentran en el Cretáceo Inferior (Berriasiano-Albiano), a veces en abundancia, restos de Equisetidae y de Helechos, semejantes a los descritos por R. NEUMANN (1907) del Perú. La forma característica Weichselia peruviana ZEILLER parece tener su máxima dispersión en el Hauteriviano y Barremiano, subiendo tal vez hasta el Aptiano inferior. TH. LIPPS (1938) describió del curso superior del Río Casanare [G7] Weichselia cf. peruviana ZEILLER, Matonidium cf. göpperti SCHENK, Brachyphyllum cf. pompeckji SALFELD y Frenelopsis spec. Impresiones de otras plantas, no estudiadas todavía, se encuentran en el contacto AlbianoCenomaniano cerca a Gachetá y Une, Cundinamarca [F9] (R. DE LA ESPRIELLA \& H. VILLEGAS 1960).

En el Aptiano de Vélez, Sasaima y Apulo se hallan con frecuencia concreciones calcáreas, varias de las cuales son notoriamente semejantes a frutas tropicales. La banana fósil de Sasaima [E9] descrita por G. HUERTAS \& TH. VAN DER HAMMEN (1953) indica que varias de estas "concreciones" podrían representar en efecto frutas fósiles. En gran abundancia se encuentran hojas de Angiospermas en las arcillas que acompañan los carbones de la Formación Guaduas del Maes- 
TABLA II

\section{CORRELACION DE LAS UNIDADES ESTRATIGRAFICAS PRINCIPALES DEL CRETACEO DE LA CORDILLERA ORIENTAL}

\begin{tabular}{|c|c|c|c|c|c|c|c|c|}
\hline \multicolumn{4}{|c|}{ Pisos eURODEOS } & \multirow{2}{*}{\multicolumn{2}{|c|}{$\begin{array}{l}\text { Alrededores de Bogotó } \\
\text { HETTNER } 1892 \text {, HUBACH } 1957 \\
\text { Guoduos inferior } \\
\text { Arenisco Tigerno } \\
\text { Arenisco Eura }\end{array}$}} & \multicolumn{2}{|r|}{$\begin{array}{l}\text { S a n t a n d e r } \\
\text { MORALES ET AL.1958 }\end{array}$} & $\begin{array}{l}\text { Mérida- Perijo- - Guajira } \\
\text { NOTESTEIN Q ALT 1944, ORENZ } 1956\end{array}$ \\
\hline \multirow{3}{*}{$\begin{array}{l}\vdots \\
\vdots \\
\vdots \\
\vdots \\
\vdots \\
\vdots\end{array}$} & \multicolumn{3}{|c|}{ Moestrichtiano } & & & \multirow{2}{*}{\multicolumn{2}{|c|}{ Umir }} & $\begin{array}{l}\text { Cototumbo } \\
\text { Mito Juan }\end{array}$ \\
\hline & \multirow{3}{*}{\multicolumn{2}{|c|}{ Senoniono }} & Componiano & $\stackrel{0}{0}$ & 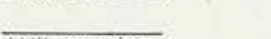 & & & Colón Shale \\
\hline & & & Sontoniono & $\frac{2}{0}$ & Lidito inferior & $\underline{E}$ & Galembo member & \\
\hline \multirow{3}{*}{$\begin{array}{l}\vdots \\
\vdots \\
0 \\
\vdots \\
0\end{array}$} & & & Coniociono & ; & Le Frontero 150 & $\stackrel{0}{c}$ & & La Luna \\
\hline & \multicolumn{3}{|c|}{ Turontono } & 0 & & 0 & Pujamono member & \\
\hline & \multicolumn{3}{|c|}{ Cenomaniono } & \multirow{5}{*}{$\begin{array}{l}\vdots \\
\vdots \\
>\end{array}$} & Exogyro mermett, Colizo de Chipoque & & Solodo member & \\
\hline \multirow{4}{*}{$\begin{array}{l}\vdots \\
\vdots \\
\frac{\vdots}{c}\end{array}$} & \multirow{2}{*}{\multicolumn{3}{|c|}{ Albiano }} & & Arenisce de Une & & Limestone & \\
\hline & & & & & Nixgl de Cotombicares & & Shole & $C \circ 90110$ \\
\hline & \multicolumn{3}{|c|}{ Aptiano } & & & $\check{c}$ & Toblazo Limestone & \\
\hline & \multicolumn{3}{|c|}{ Borremiono } & & & $\begin{array}{ll}0 \\
n \\
0\end{array}$ & La Poja Formation & Yuruma \\
\hline \multirow{4}{*}{$\begin{array}{l}0 \\
u \\
0 \\
\vdots \\
\vdots \\
0\end{array}$} & \multirow{4}{*}{$\begin{array}{l}0 \\
\vdots \\
\vdots \\
\tilde{E} \\
\vdots \\
\vdots \\
z\end{array}$} & \multirow{2}{*}{\multicolumn{2}{|c|}{ Houteriviono }} & & \multirow{3}{*}{ Arenisca de Cóqueza } & & Roso Blanco $\mathrm{Fm}$. & \\
\hline & & & & \multirow{4}{*}{$\begin{array}{l}0 \\
\vdots \\
0 \\
0 \\
0 \\
0\end{array}$} & & & moer Fermetien & Rio Negro \\
\hline & & \multicolumn{2}{|c|}{ Volonginiono } & & & & & \\
\hline & & \multicolumn{2}{|c|}{ Berriosiono } & & Pizarra de la Culebro & & & DIBUso Cloro Quimsay da Poulo \\
\hline$\frac{\epsilon}{0} \stackrel{2}{\vdots}$ & \multicolumn{3}{|c|}{ Titoniano } & & Esauistos de sáname & & & \\
\hline
\end{tabular}

trichtiano superior (E. W. BERRY 1918, H. BÜRGL 1957, pl. XVIII).

Restos de peces se conservaron en las capas margosocalcáreas en el límite Aptiano-Albiano (Sasaima [E9]) y forman un elemento esencial de la fauna del Senoniano y Maestrichtiano. En su gran mayoría son solamente escamas, huesos (vértebras) y aletas aisladas, que forman en el tope del Coniaciano y Campaniano verdaderos "bone-beds" con muchos moldes de Foraminíferos (Siphogenerinoides) transformados en fosfato. Ocasionalmente se presentan en estas capas restos de peces más perfectos, como por ejemplo los que aparecen en $\mathrm{H}$. BÜRGL 1957, pl. XIV, fig. 1 y pl. XVII, fig. 2.

Los restos fósiles más destacados de Colombia son los dos esqueletos casi perfectos de Plesiosaurios, que se hallaron en las calizas del Aptiano inferior en los alrededores de Villa de Leiva [F8] (BÜRGL 1954). R. A. STIRTON, quien dirigió la excavación juntamente con D. HENAO LONDONO, llevó uno de estos esqueletos a la Universidad de Stanford, California, mientras que el otro de $7,30 \mathrm{~m}$. de largo, está expuesto en el Museo Geológico Nacional en Bogotá.

\section{Facies $y$ formaciones}

Las transgresiones sucesivas del mar suprajurásico y cretáceo sobre el Oriente Andino, las oscilaciones cíclicas del fondo geosinclinal y los diferentes grados de hundimiento de las varias partes, causaron una gran variedad de facies en los sedimentos. Esta variedad, a su vez, se refleja en una multitud de nombres estratigráficos de horizontes y formaciones ${ }^{1}$. La nomenclatura estratigráfica surgió esencialmente de tres centros de investigación:

1 Aplicamos aquí el término "formación" para una unidad estratigráfica de uniforme constitución litológica.
1. de los alrededores de la capital de Bogotá (L. VON BUCH 1839, A. HETTNER 1892, E. HUBACH 1945, 1957).

2. de la región petrolífera de Barrancabermeja [F6] (L. G. MORALES \& COLOMBIAN PETROLEUM INDUSTRY 1958).

3. de la región petrolífera al suroeste del Lago de Maracaibo [H4] (NOTESTEIN, HUBMAN \& BOWLER 1944, E. ROD \& W. MAINC 1954).

La tabla II muestra como las principales unidades litostratigráficas se colocan en el esquema cronostratigráfico.

Sin embargo, los nombres litostratigráficos no se tienen que tomar en un sentido demasiado estricto. $\mathrm{La}$ "Arenisca de Cáqueza" y la "Arenisca de Une" (E. HUBACH 1945) constan esencialmente de lutitas, entre las cuales se intercalan en diferente grado areniscas silicosas, limolíticas y calcáreas y en menor grado calizas. Las "Liditas" inferior y superior no constan siempre de una lidita pura, sino varían en su composición desde una lutita silicosa (porcelanita) hasta una arenisca de grano fino, pero estos estratos siempre se pueden reconocer en el terreno por su típica textura. La mayor parte del Grupo de Guadalupe (en el sentido de E. HUBACH) no se diferencia litológicamente del Grupo de Villeta y el límite entre ambos es bastante arbitrario. El "Nivel de la Exogyra Mermeti" (correctamente Exogyra squamata D'ORBIGNY) consta en la región Chipaque-Gachalá de numerosos horizontes calcáreos desde unos centímetros hasta algunos metros de espesor. Al oeste de la sabana, por el contrario consta de areniscas de $0.50 \mathrm{~m}$. a $10 \mathrm{~m}$. de potencia.

Alejándose de la Cuenca de Cundinamarca en dirección norte, las intercalaciones calcáreas y arenosas crecen paulatinamente en espesor, hasta que en la parte septentrional del Oriente Andino (Alta Guajira) reempla- 
zan las lutitas casi por completo. Este cambio de facies se tiene que considerar como una transición de la facies extrema geosinclinal de la Cuenca de Cundinamarca a condiciones epicontinentales.

Las "formaciones", distinguidas por los geólogos en las diferentes regiones del Oriente Andino son por lo tanto facies litológicas de mayor o menor extensión local. Ellas son de valor eminente para la descripción de una pequeña región o para elaborar un mapa en menor escala; pero para tratar la Cordillera Oriental en su totalidad o partes mayores de esta, la clasificación y la nomenclatura cronostratigráfica son más adecuadas.

\section{Plegamientos}

Durante el Suprajurásico y Cretáceo, los movimientos del geosinclinal del Oriente Andino eran esencialmente hundimientos. De todos los estratos respectivos de varios miles de metros de espesor no conocemos ni un solo caso comprobado de una discordancia angular. Sin embargo, no hay duda que en algunos sitios la sucesión estratigráfica está incompleta. En los alrededores de Vélez [F7-8] aparentemente falta el Barremiano superior y el Aptiano inferior está en contacto paraconcordante con el Barremiano medio y al este de Bogotá el Albiano reposa sobre el Aptiano inferior y Barremiano erodados. Probablemente se revelarán más casos de lagunas con el progreso de nuestros conocimientos estratigráficos de estas áreas.

Tales casos de lagunas estratigráficas (diastemas) se acumulan en el Senoniano. En extensas partes de Santander y Santander del Norte falta el Santoniano o está representado por una capa delgada de arenisca glauconítica. En muchos sitios del Huila y Tolima falta el Campaniano o al menos su parte superior, mientras que en otros sitios cercanos está completamente desarrollado. En los alrededores de Girardot [E9] se observan conglomerados con guijas campanianas en la base del Maestrichtiano (H. BÜRL \& Y. DUMIT 1954). También en los alrededores de Chía [E9] falta el Campaniano superior, mientras que en las laderas de la sabana está bien desarrollado. El mapa de isopacas del Senoniano de Cundinamarca (fig. 25) muestra con claridad el diferente grado de hundimiento o el solevantamiento relativo de ciertas zonas: un eje a lo largo de la línea Tocaima-Villeta-Topaipí, y otro a lo largo de la línea Monserrate-La Calera-Guasca se hundieron menos o se solevantaron en comparación con sus alrededores.

Estas observaciones indican que en el Senoniano el geosinclinal del Oriente Andino empezó a formar pliegues de pequeña amplitud. La relación de las potencias del Senoniano total por un lado, los conglomerados en la base del Maestrichtiano por el otro, indican que estos plegamientos tuvieron lugar durante el Senoniano pero alcanzaron un máximo al final de esta época. A grandes rasgos podemos correlacionar estas fases tectónicas con las subhercínicas en Europa. El mar de Maestrichtiano inferior transgredió sobre las irregularidades pequeñas del fondo y formó otra vez extensas regiones de facies uniforme. Sin embargo, la barrera a lo largo del Anticlinorio de Apulo-Villeta-Vélez-Bucaramanga persistió durante el Maestrichtiano y separó la provincia de la facies del Guadalupe de la provincia de la facies Umir.
Es prematuro aún evaluar la extensión regional de los plegamientos subhercínicos en los Andes colombianos. Sin embargo, la coincidencia en el Oriente Andino de las zonas de movimiento positivo y negativo en el Senoniano con los anticlinorios y sinclinorios terciarios hace pensar que todas las grandes depresiones estructurales de Colombia, los sinclinorios de Bolívar, Cauca, Magdalena etc., empezaron a diferenciarse como unidades tectónicas ya en el Senoniano. Una cierta idea de la extensión de los fenómenos tectónicos subhercínicos nos la dan las liditas de la Cordillera Oriental. Ellos se formaron aparentemente por la diagénesis de tobas vol cánicas, producidas por erupciones en el Occidente Andino (V. PETTERS 1955). Intercalaciones lidíticas se encuentran en la Cordillera Oriental desde el Coniaciano inferior hasta el Maestrichtiano medio, pero están mejor desarrolladas en la base del Santoniano y del Campaniano.

\section{TERCIARIO}

\section{Areas de sedimentación}

Anteriormente se explicó cómo, durante el Paleozoico, la región andina de Colombia formó parte de un gran geosinclinal, cuyo centro estaba localizado probablemente en el Perú. Al principio del Mesozoico, este geosinclinal se dividió en dos: el eugeosinclinal del Occidente Andino, que se continuaba al Ecuador y Perú y el miogeosinclinal (en el sentido de H. STILLE 1940) del Oriente Andino con la rama de la Serranía de Mérida y sus continuaciones en el territorio venezolano. Con razón H. GERTH (1939) designa el Occidente Andino con el término de Colombiandes, mientras que el Oriente Andino de Colombia y las Cordilleras venezolanas con el de Caribeandes.

El contenido sedimentario de estos geosinclinales fue suavemente plegado durante el Senoniano (fases subhercínicas, plegamiento peruviano STEINMANN). Como resultado de dicho plegamiento se presentan al iniciarse el Cenozoico cinco sinclinorios principales o zonas de hundimiento, en los cuales se depositaron sedimentos terciarios y cuaternarios de espesor apreciable. Entre ellas se solevantaron sucesivamente los anticlinorios, que quedaron expuestos a la erosión durante todo el Cenozoico y su detrito fue transportado por ríos a los sinclinorios donde se acumuló.

Las zonas de solevantamiento o anticlinorios de oeste a este son:

1. La Serranía de Baudó y su extensión meridional en las islas de Gorgona y Gorgonilla [A11], en la literatura geológica con frecuencia citada como Cordillera Costanera.

2. La Cordillera Occidental, cuyas estribaciones septentrionales (Serranías de San Jerónimo, San Jacinto, etc.) se extienden hasta Barranquilla [E2-3].

3. La Cordillera Central, que continúa tectónicamente en la Sierra Nevada de Santa Marta y los macizos antiguos de la Península de la Guajira.

4. El anticlinorio occidental de la Cordillera Oriental (Apulo-Villeta), que se bifurca en los anticlinorios de la Cordillera de los Cobardes y de Arcabuco.

5. El anticlinorio oriental de la Cordillera Oriental, que comprende los macizos antiguos de Garzón y Quetame y la Sierra de Murillo. 


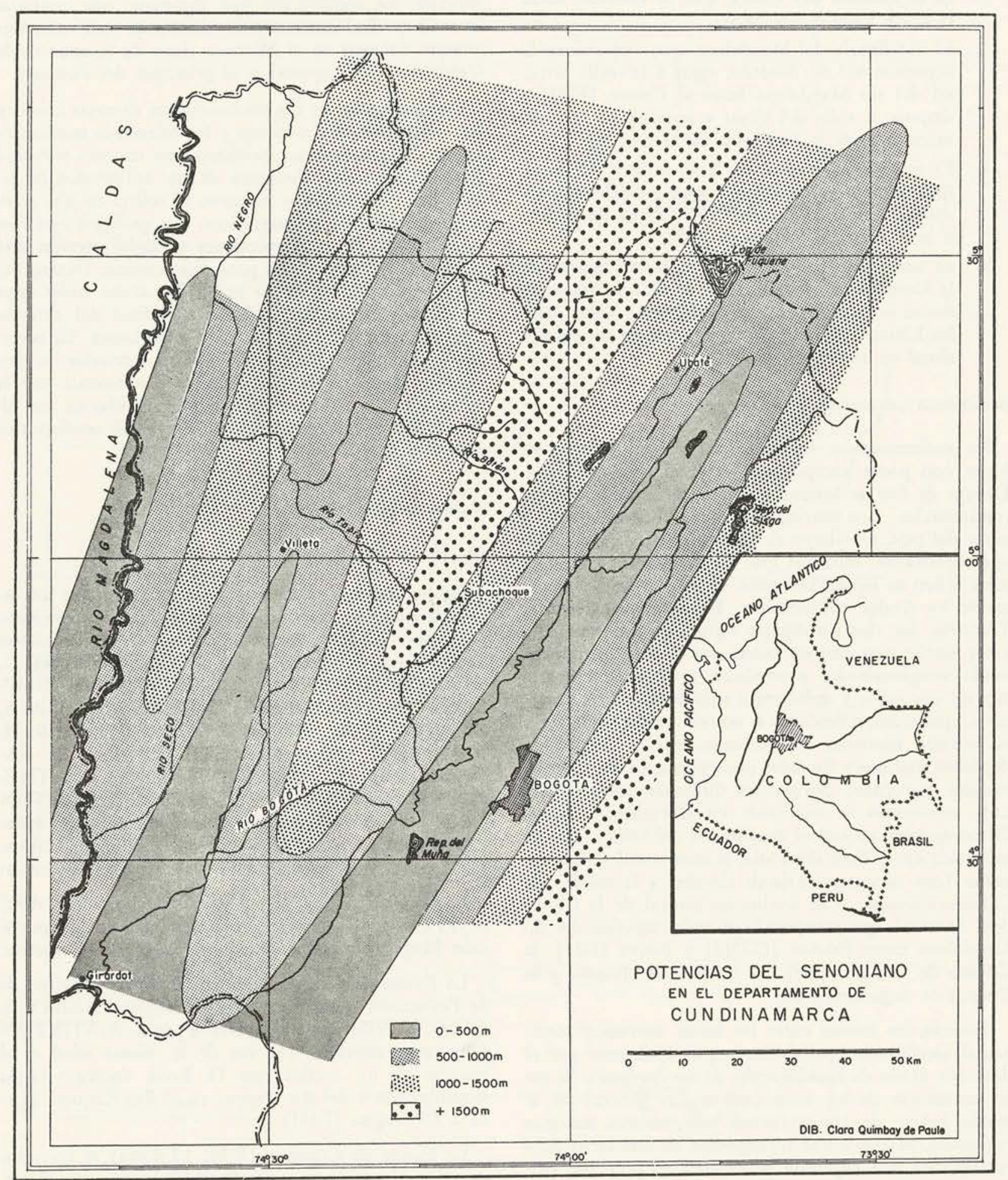

Fig. 25 - Isocapas del Senoniano en Cundinamarca. Las diferentes potencias son causadas por los plegamientos subhercínicos. 
Las cinco zonas de hundimiento de oeste a este son (fig. 26) :

1. El Sinclinorio del Pacífico (sinclinorio Bolívar de A. A. OLSSON 1956), que se bifurca hacia el norte en la rama de Turia y en la de Cartagena.

2. El Sinclinorio del Cauca, que se extiende hacia el norte hasta Santa Marta.

3. El Sinclinorio del Magdalena, que empieza en la depresión del río Saldaña, sigue a la orilla oriental del río Magdalena hasta el Centro [F6-7] y después al valle del César y termina en la parte meridional de la Península de la Guajira.

4. El sinclinorio central de la Cordillera Oriental, que empieza ya en la parte superior del río Magdalena, siguiendo después a la Sabana de Bogotá y la Cuenca de Sogamoso [G8].

5. El sinclinorio pre-andino en el borde llanero de la Cordillera Oriental, desde el cual las transgresiones se extendieron temporalmente sobre todo los Llanos Orientales, que representan un geosinclinal en statu nascendi.

\section{Sedimentación marina y continental}

La sedimentación terciaria en los sinclinorios tuvo lugar, con pocas excepciones, cerca al nivel del mar. Debajo de éste se formaron estratos marinos, encima continentales. Los marinos predominan en el oeste y norte del país, a lo largo de las costas pacífica y caribe respectivamente, mientras que los sedimentos continentales tienen su mayor extensión en la parte sur y oriental de los Andes colombianos. Desde el principio del Terciario, los ríos principales siguieron aparentemente a los sinclinorios con un curso sur a norte, sedimentando conglomerados y areniscas gruesas en la parte alta de sus valles y sedimentos más finos en las partes bajas, que transgreden más o menos paulatinamente a los estratos marinos. Sin embargo, esta repartición de depósitos marinos y fluviales finos y gruesos de ninguna manera es regular, porque en dirección longitudinal, cada sinclinorio se subdivide en diferentes cuencas. Como ejemplo se cita el Sinclinorio del Cauca, que se subdivide en la Fosa del Patía, la cuenca del Cauca superior (con subcuencas), la de Combia y la marina de Calamar-Ciénaga; o el sinclinorio central de la Cordillera Oriental, que comprende el valle superior del río Magdalena entre Pitalito [C-D12] y Neiva [D11], la Cuenca de Melgar [E9], la Sabana de Bogotá y la Cuenca de Sogamoso [G8].

Además, los límites entre las facies marina y continental cambiaron repetidamente, principalmente por el diferente grado de hundimiento de las cuencas y de solevantamiento de los anticlinorios. En general no se puede hablar de transgresiones y regresiones marinas regionales, porque a una transgresión en una cierta área corresponde una regresión simultánea en otra. Sin embargo, se observan transgresiones de mayor extensión en el Eoceno medio y superior del Valle Medio Magdalena y otra en la base del Oligoceno superior ${ }^{1}$. Esta

1 Aplicamos aquí el término "Oligoceno superior" en el sentido de la clasificación tradicional en Colombia. Estrictamente hablando, esta transgresión corresponde a la base de las zonas de Catapsydrax stainforthi (BOLLI 1957), Robulus wallacei (H. H. RENZ 1948) y Siphogenerina basispinata (PETTERS \& SARMIENTO 1956). El "Oligoceno superior" de Colombia en este sentido es probablemente última se manifiesta particularmente en la Península de la Guajira (BÜRGL 1960 a), en la base de las calizas de Cicuco y Magangué [E4], en el Valle del Cauca (Calizas de Vijes [C10]) y en las intercalaciones marinas de las formaciones León, La Cira y Usme superior (BÜRGL 1955). Esta gran transgresión del Oligoceno superior fue seguida por una regresión que continúa hasta hoy día, interrumpida solamente por menores avances del mar en el Mioceno (base de la zona de la Uvigerina subperegrina) y al principio del Plioceno.

La subdivisión de los sinclinorios en diversas cuencas, las oscilaciones de las costas y los diferentes movimientos en los anticlinorios causaron una enorme variedad en la composición litológica de los sedimentos terciarios. Esta variedad, por su parte, se refleja en una multitud de términos estratigráficos. Los geólogos que han estudiado las diversas sucesiones terciarias crearon una clasificación especial casi para cada cuenca. Dentro del límite de este artículo no se pueden tratar todas estas unidades y la tabla estratigráfica al final del artículo (fig. 40) cita solamente las más importantes. La correlación cronológica de las formaciones terciarias ha presentado considerables dificultades y solamente por la aplicación de métodos micropaleontológicos en los últimos años se ha logrado alcanzar avances satisfactorios en este respecto.

\section{Fósiles y estratigrafía}

\section{a) Facies terrestre}

De los restos orgánicos que se conservaron en los depósitos continentales de Colombia queremos mencionar en primer lugar los de los Vertebrados. Estos fueron descritos por L. CUERVO MARQUEZ (1938), H. G. STEHLIN (1939), C. C. MOOK (1941), G. G. SIMPSON (1940, 1943), J. ROYO Y GOMEZ (1942), R. A. STIRTON (1946, 1951), D. E. SAVAGE (1951), R. H. REINHART (1951), R. A. STIRTON \& D. E. SAVAGE (1951), M. C. MCKENNA (1956) y E. THENIUS \& H. BÜRGL (1957). En 1953, R. A. STIRTON compiló todos estos datos y elaboró un esquema estratigráfico de las varias faunas de vertebrados de Colombia, las más importantes de las cuales son las siguientes:

La Fauna de Tama (en el Río Oponcito, $5 \mathrm{~km}$. al SE de El Centro, Santander [F6-7]) se halló en la Formación Mugrosa y es probablemente del Eoceno superior.

La Fauna de Chaparral [D10] (Tolima) proviene de la Formación Tuné (= La Cira según PILSBRY \& OLSSON 1935) y está considerada por R. A. STIRTON Oligocena inferior. Tal vez de la misma edad es el maxilar de un roedor que O. Renz encontró en la desembocadura del Río Peneya en el Río Caquetá (cerca a La Tagua [E14]).

La Fauna de Coyaima [D10] (Tolima) se encontró en varios sitios al este y sur de esta población, en la Formación Honda y su edad es probablemente Oligoceno superior.

La Fauna de La Venta (Villavieja [D10], Huila), también de la Formación Honda y de edad miocena superior es la más rica en Colombia.

contemporáneo al Aquitaniano en Europa (o Aquitaniano superior según STAINFORTH 1960). 


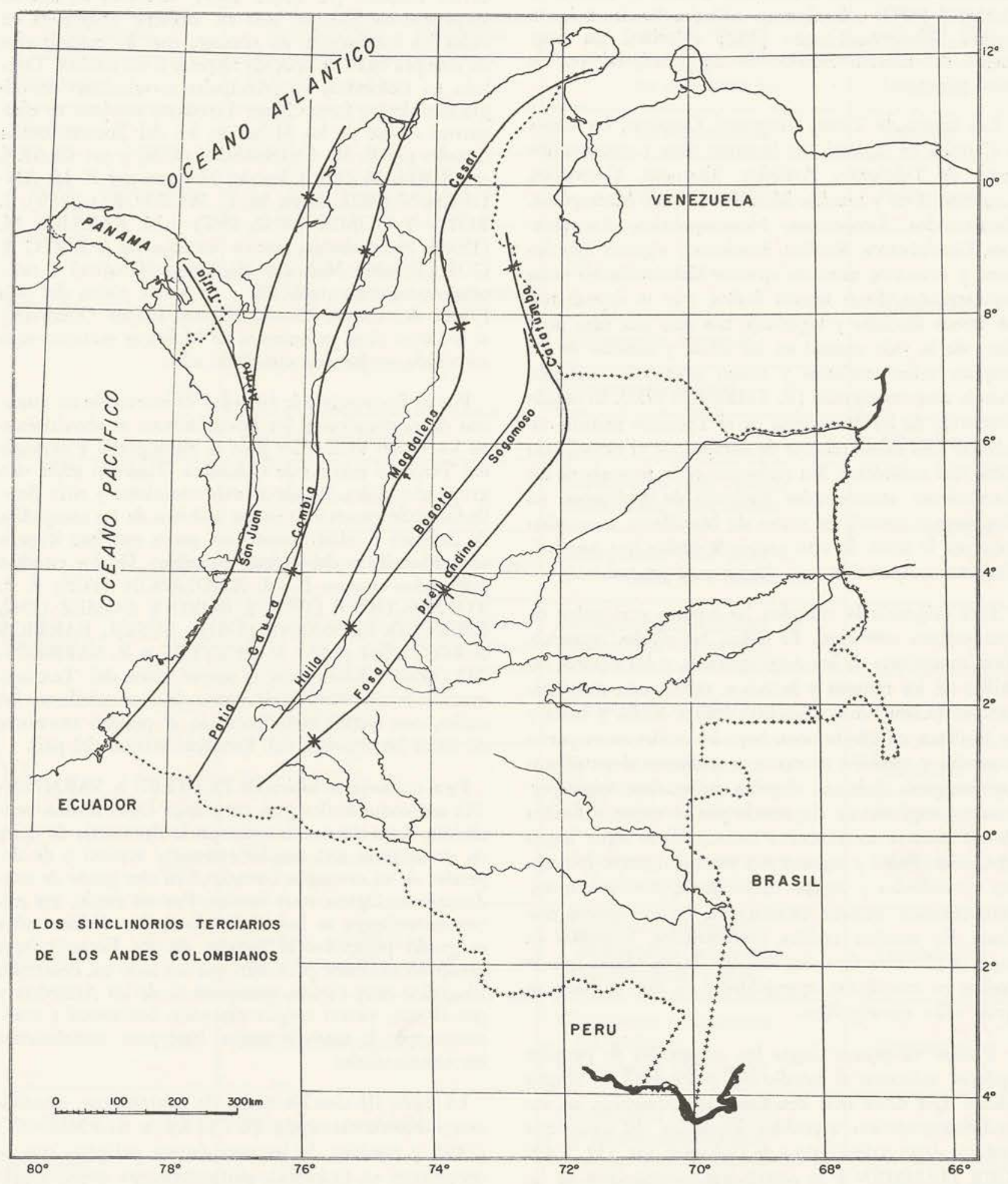

Fig. 26 - Los principales sinclinorios terciarios de los Andes colombianos. 
La Fauna de Carmen de Apicalá [E9] es casi contemporánea a la de La Venta y se halló también en la Formación Honda.

En las areniscas de la Sierra Penata, $4 \mathrm{~km}$. al $\mathrm{N}$ de Sincelejo [D4], se hallaron dos dientes de un roedor del Mioceno superior o Plioceno inferior y ROYO Y GOMEZ (1942) colectó cerca a Cocha Verde en la carretera Túquerres-Tangua [B12] (Nariño) un fragmento del maxilar inferior de un pécari, tal vez de edad pliocena.

Las faunas de Tama, Chaparral, Coyaima, La Venta y Carmen de Apicalá son bastante ricas y comprenden restos de Teleósteos, Anfibios, Tortugas, Cocodrilos, Lagartos, Aves y muchos Mamíferos, como Marsupiales, Desdentados, Litopternos, Notoungulados, Astrapoterios, Condylartros, Sirenios, Roedores y algunos Quirópteros y Primates, mientras que los Carnívoros no están representados. Estas faunas fósiles, que se depositaron en arenas fluviales y lagunales, nos dan una idea muy clara de la vida animal en las selvas y sabanas de los amplios valles terciarios y tienen gran valor también para la cronostratigrafía (E. THENIUS 1959). El rápido desarrollo de los Mamíferos en el Terciario permite establecer una escala relativa de tiempo que el estratígrafo tiene que considerar. Sin embargo, de la mayoría de las formaciones continentales terciarias de Colombia no disponemos todavía de restos de Mamíferos y necesitamos por lo tanto de otro grupo de fósiles que nos facilita una comparación cronológica más general.

Esta exigencia la cumplen las esporas y el polen de una manera casi ideal. El polen, las células reproductoras masculinas de los Angiospermas, y las esporas, semillas de los musgos y helechos, tienen una envoltura externa (Exine) muy resistente contra ácidos y bases y se fosilizan en condiciones, bajo las cuales otras partes vegetales y también animales se hubiesen desintegrado por completo. Además, el polen de muchas Angiospermas es ampliamente dispersado por el viento y facilita de tal manera correlaciones estratigráficas sobre largas distancias. Polen y esporas son particularmente frecuentes en carbones y arcillas carbonáceas, pero se encuentran también, aunque escasamente, en sedimentos marinos. En muchas arcillas continentales, formadas en lagos y planicies fluviales, son los únicos fósiles que se hallan en cantidades apreciables y en esto se basa su gran valor estratigráfico.

Fueron en primer lugar las compañías de petróleo quienes aplicaron el estudio del polen fósil en amplia escala. Los datos más detallados se encuentran en sus archivos y no son accesibles al público. El único que publicó datos palinológicos de Colombia fue TH. VAN DER HAMMEN y la correlación estratigráfica de las formaciones continentales terciarias en la tabla de la figura 40 se basa esencialmente en sus resultados no publicados aún (1960).

Otros restos vegetales, como hojas y frutas, del Terciario fueron descritos por E. W. BERRY (1918, 1924 a, b, c, 1925, 1937) y moluscos de agua dulce por H. A. PILSBRY \& A. A. OLSSON (1935). b) Facies marina

Desde DESHAYES (1824-37), CH. LYELL (1832) y MAYER-EYMAR (1857), los Moluscos marinos constituyen la base para la subdivisión del Terciario en $\mathrm{Pa}$ leoceno, Eoceno, Oligoceno, Mioceno, Plioceno y los varios subpisos (A. PAPP 1959), términos en uso no solamente en Europa sino en manera progresiva en todos los continentes, no obstante que los estratígrafos no siempre están de acuerdo respecto a sus límites. También en Colombia, las principales correlaciones estratigráficas de las formaciones Terciarias marinas se efectuaron a base de los Moluscos; los del Eoceno fueron tratados por F. M. ANDERSON (1928) y por CLARK \& DURHAM (1946), los del Mioceno por F. M. ANDERSON (1927, 1929), N. E. WEISBORD (1929), J. ROYO Y GOMEZ $(1942,1947)$ y M. BARRIOS M. (1960). Sin embargo, varios estudios de J. ROYO Y GOMEZ sobre Moluscos oligocenos (Guajira) y miocenos no se han publicado y en varias partes del país (Valle del Cauca, Chocó, Nariño, Llanos Orientales) se hallaron ricos yacimientos de Moluscos marinos cuyo contenido no ha sido estudiado aún.

Por su frecuencia y la facilidad de extracción de muestras de perforaciones, los Foraminíferos se convirtieron en los fósiles más útiles para la estratigrafía y ecología del Terciario marino de Colombia. También sobre este grupo de fósiles, los datos más completos y más detallados están encerrados en los archivos de las compañías de petróleo y relativamente son pocos que han llegado al conocimiento del mundo científico. De los estudios publicados citamos F. M. ANDERSON (1928), I. P. TOLMACHOFF (1934), J. ROYO Y GOMEZ (1942, 1950), C. D. REDMOND (1953) y BÜRGL, BARRIOS \& RÖSTRÖM (1955). V. PETTERS \& R. SARMIENTO (1956) subdividieron la mayor parte del Terciario marino en un número de zonas de Foramíniferos, las cuales, con ciertas modificaciones, se pueden reconocer en todas las regiones del Terciario marino del país.

Esta subdivisión básica de PETTERS \& SARMIENTO usa como fósiles guía en primer lugar formas bentónicas. Estas tienen sin embargo, la desventaja de tener en su mayoría una amplia extensión vertical y de depender en su extensión horizontal en alto grado de condiciones ecológicas muy locales. Por tal razón, los micropaleontólogos se han dedicado en los últimos años en grado progresivo al estudio de los Foraminíferos planctónicos. Estos presentan por un lado un desarrollo filogénico muy rápido, semejante al de las Amonitas y por el otro, tienen amplia extensión horizontal y constituyen por lo tanto la mejor base para correlaciones intercontinentales.

La tabla III cita las zonas de microfaunas esencialmente bentónicas según PETTERS \& SARMIENTO (1956) y también de las microfaunas pelágicas que se encuentran en Colombia, particularmente considerando los resultados fundamentales de H. BOLLI (1957) en Trinidad.

A la izquierda indicamos los nombres de pisos y subpisos usados en la estratigrafía tradicional en Colombia, y a la derecha los pisos europeos según la correlación de R. M. STAINFORTH (1960) a base de los Foraminíferos planctónicos. 
TABLA III

ZONAS DE FORAMINIFEROS DEL TERCIARIO DE COLOMBIA

\begin{tabular}{|c|c|c|c|c|}
\hline \multicolumn{2}{|c|}{$\begin{array}{l}\text { Clasificación tradicional } \\
\text { en Colombia }\end{array}$} & $\begin{array}{c}\text { Zonas de la facies bentónica esencialmente } \\
\text { según PETTERS \& SARMIENTO }\end{array}$ & $\begin{array}{c}\text { Zonas de la facies pelágica esencialmente } \\
\text { según H. BOLLI }\end{array}$ & $\begin{array}{l}\text { Pisos curopeos } \\
\text { en parte según } \\
\text { STAINFORTH (1960) }\end{array}$ \\
\hline \multicolumn{2}{|l|}{ Pleistoceno } & Archaias angulatus & no representada & Pleistoceno \\
\hline \multicolumn{2}{|l|}{ Plioceno } & & no representada & Plioceno \\
\hline \multirow{5}{*}{ Mioceno } & sup. & $\begin{array}{l}\text { casi sin Foraminíferos } \\
\text { con muchos Moluscos }\end{array}$ & no representada & Sarmatiano \\
\hline & med. & $\begin{array}{l}\text { Streblus beccarii } \\
\text { (Nonion scaphum y } \\
\text { Robulus cushmani procedendus) }\end{array}$ & Globigerina haitiensis & \multirow[t]{3}{*}{ Tortoniano } \\
\hline & \multirow{3}{*}{ inf. } & \multirow{2}{*}{ Uvigerina subperegrina } & Globorotalia menardii & \\
\hline & & & Globorotalia mayeri & \\
\hline & & Bulimina carmenensis & & Helveciano \\
\hline \multirow{5}{*}{ Oligoceno } & \multirow{3}{*}{ sup. } & Sigmoilina tenuis & $\begin{array}{l}\text { Globorotalia fohsi robusta } \\
\text { Globorotalia fohsi lobata }\end{array}$ & \multirow{2}{*}{ Burdigaliano } \\
\hline & & Siphogenerina Planulina karsteni & $\begin{array}{l}\text { Globorotalia fohsi fohsi } \\
\text { Globorotalia fohsi barisanensis }\end{array}$ & \\
\hline & & $\begin{aligned} \text { S. basispinata } & \text { Guttulina caudriae } \\
& \text { y Robulus wallacei }\end{aligned}$ & $\begin{array}{l}\text { Globigerinatella insueta } \\
\text { Catapsydrax stainforthi }\end{array}$ & sup. \\
\hline & med. & $\begin{array}{l}\text { Uvigerina mexicana y } \\
\text { U. topilensis }\end{array}$ & Catapsydrax dissimilis & inf. \\
\hline & inf. & Cibicides cushmani & $\begin{array}{l}\text { Globigerina ciperoensis } \\
\text { Globorotalia opima opima } \\
\text { Globigerina ampliapertura }\end{array}$ & $\begin{array}{l}\text { Oligoceno } \\
\text { (Lattorfiano y } \\
\text { Rupeliano) }\end{array}$ \\
\hline \multirow{3}{*}{ Eoceno } & sup. & $\begin{array}{l}\text { Bulimina truncana y } \\
\text { B. jacksonensis }\end{array}$ & $\begin{array}{l}\text { Hantkenina alabamensis y } \\
\text { Clavigerinella jarvisi }\end{array}$ & $\begin{array}{l}\text { Wemmeliano y } \\
\text { Lediano }\end{array}$ \\
\hline & med. & $\begin{array}{l}\text { Cibicides grimsdalei y } \\
\text { Spiroplectammina zigzag }\end{array}$ & $\begin{array}{l}\text { Hastigerina bolivariana } \\
\text { Hantkenina aragonensis } \\
\text { Clavigerinella akersi }\end{array}$ & Lutetiano? \\
\hline & inf. & Bathysiphon sakuensis & $\begin{array}{l}\text { Globigerina soldadoensis, } \\
\text { Gl. collactea } \\
\text { Globorotalia wilcoxensis }\end{array}$ & Ypresiano? \\
\hline \multirow[b]{2}{*}{ Paleoceno } & sup. & fauna no característica & $\begin{array}{l}\text { Globorotalia velascoensis } \\
\text { y Globorotalia whitei }\end{array}$ & Paleoceno \\
\hline & inf. & Rzehakina epigona & $\begin{array}{l}\text { Globigerina triloculinoides } \\
\text { y Globorotalia quadrata }\end{array}$ & \\
\hline \multicolumn{2}{|l|}{ Maestrichtiano } & $\begin{array}{l}\text { Ammobaculites columbianus } \\
\text { Siphogenerinoides bramlettei }\end{array}$ & & \\
\hline
\end{tabular}




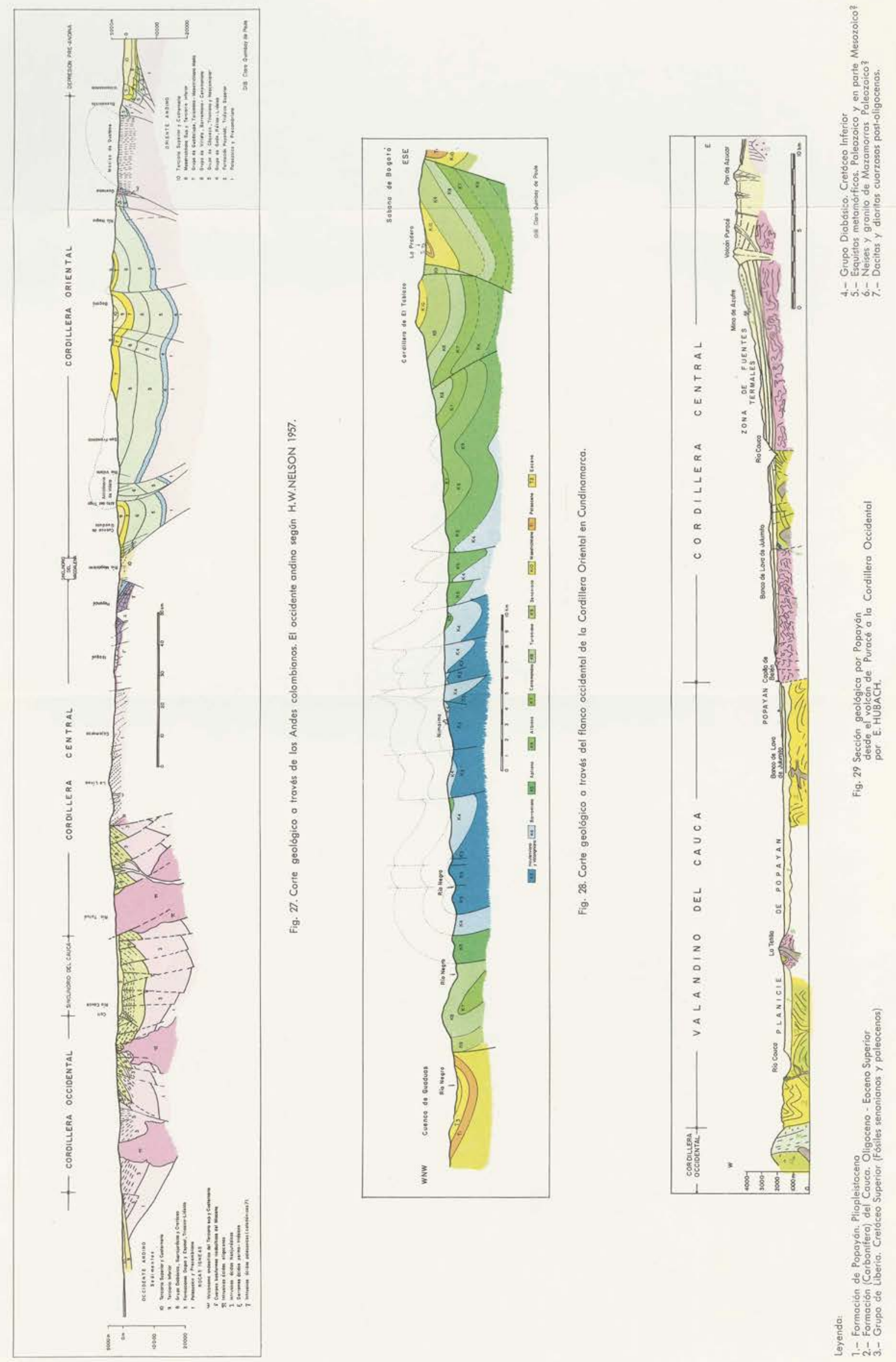




\section{Movimientos tectónicos}

Durante todo el Terciario, los sinclinorios se hundieron y los anticlinorios se solevantaron progresivamente. Sin embargo, estos movimientos no sucedieron continuamente, sino que fases de relativa tranquilidad alternaron con fases de mayor inquietud. Las primeras fases tectónicas de mayor intensidad se constatan según $L$. G. MORALES \& ALT. (1958) y TH. VAN DER HAMMEN (1960) en la base del Eoceno inferior, por ejemplo en la base de la Formación La Paz en la parte media del Valle del río Magdalena. Otra muy intensa se nota en la base de la Formación Mugrosa, la cual descansa discordantemente sobre diferentes niveles terciarios y cretáceos hasta sobre el Girón. MORALES \& ALT. (1958) y TH. VAN DER HAMMEN (1960) consideran esta como Oligoceno inferior y medio. Sin embargo, la fauna de Tama indica que por lo menos su parte baja corresponde al Eoceno superior (R. A. STIRTON 1953). Estos movimientos se correlacionan aproximadamente con las fases pirenáicas en Europa. G. STEINMANN (1929) designa todos los movimientos del Eoceno y Oligoceno como "Plegamiento incaico". Al final del Oligoceno medio (en el sentido de la clasificación en uso en Colombia) tuvieron lugar movimientos bastante fuertes. En muchas partes del Terciario marino, la zona de Catapsydrax dissimilis y también a veces las zonas inferiores fueron erodadas y el Oligoceno superior (zonas de Siphogenerina transversa, $S$. basispinata y Robulus wallacei) descansan discordantemente sobre el Eoceno. El sinclinorio del Cauca se hundió tan profundamente que el mar avanzó hasta los alrededores de Cali (Formación Vijes). Las cuencas de Bogotá y Sogamoso fueron solevantadas con los anticlinorios adyacentes y carecen de sedimentación hasta el Plioceno. Otras regiones, en contraste, como la cuenca de Mompós-Cicuco y la Alta Guajira, que eran tierra firme durante la mayor parte del Paleogeno, se hundieron bajo el mar.

Los movimientos alcanzaron aparentemente su máxima intensidad durante el Mioceno y las fases tectónicas siguieron rápidamente una después de otra. Durante esta época, por lo menos cuatro fases pueden ser distinguidas (VAN DER HAMMEN 1960).

Los eventos geológicos durante el Plioceno no son bien conocidos por las dificultades estratigráficas que este piso todavía presenta. Pero es seguro, que el Plioceno de la costa (Formación La Popa) está ligeramente inclinada y discordante sobre el Mioceno. Al principio del Cuaternario las Cordilleras andinas alcanzaron aproximadamente su altura actual y relativamente fueron muy pocos los cambios que sufrieron durante el último millón de años de la historia terrestre.

La extensión de los movimientos verticales nos enseñan las potencias de los sedimentos que se acumularon en los sinclinorios. En el Chocó (Sinclinorio de Bolívar, W. E. NYGREN 1950) el Terciario tiene casi $12.000 \mathrm{~m}$. de potencia, el Mioceno solamente consta de $4600 \mathrm{~m}$. En el valle del río Magdalena, el Terciario alcanza $7500 \mathrm{~m}$. y solamente el Mioceno $4000 \mathrm{~m}$. Allí se conocen fallas hasta de $5000 \mathrm{~m}$. de resalto. Por otra parte, las masas erodadas durante el Terciario, por ejemplo en el anticlinorio de Villeta [E8-9], se calculan en más de $7000 \mathrm{~m}$. de espesor. No resulta exagerado decir que la diferencia entre los sitios más solevantados durante el Terciario y los más hundidos en los Andes colombianos es más de $15.000 \mathrm{~m}$.

\section{Magmatismo}

Estos movimientos tectónicos terciarios fueron acompañados por extensas intrusiones y extrusiones magmáticas. Las más antiguas en el Terciario son las básicas y ultrabásicas que se observan particularmente en la Serranía de Baudó y la Cordillera Occidental, y se extienden tal vez hasta la Cordillera Oriental. Los diques y vetas constan predominantemente de basalto y dolerita, mientras que los mayores cuerpos intrusivos están constituídos de gabro, peridotita y piroxenita. En la Serranía de Baudó (Cabo Corrientes) tales rocas penetran las lutitas silicosas del Paleoceno y Eoceno inferior y bloques de calizas de Algas del Eoceno medio flotan en las masas de dolerita, basalto y gabro. Las mismas rocas, ocasionalmente con olivina, constituyen la mayor parte de las islas Gorgona y Gorgonilla [A11] (A. GANSSER 1950). En la Cordillera Occidental se formaron derrames y "enjambres de diques" (A. A. OLSSON 1956) de dolerita que siguen las laderas orientales de los valles de los ríos San Juan [C8-9] y Atrato [C8-5] y se extienden hasta la Serranía de San Jerónimo [D5]. Estas intrusiones y extrusiones tuvieron lugar después del Eoceno medio y se continuaron hasta el final del Eoceno. Son por lo tanto contemporáneos con los movimientos pirenaicos.

Tal vez pertenecen al mismo ciclo magmático y tectónico las intrusiones ultrabásicas (pegmatita y gabro cuarcítico) que A. GANSSER encontró en el Albiano de los alrededores de Muzo en la Cordillera Oriental (D. TRUMPY 1943, A. A. OLSSON 1956). Se supone generalmente que la mineralización esmeraldífera está en estrecha conexión con cuerpos básicos en la profundidad. En esta conexión es muy llamativo el hecho, de que la región esmeraldífera (Muzo, Gachalá, Chivor) coincide con la Cuenca de Cundinamarca, la región de máximo hundimiento durante el Cretáceo.

El segundo ciclo magmático terciario se manifiesta en las intrusiones de tonalitas de las Cordilleras Central y Occidental y tal vez también en la Serranía de Baudó (A. A. OLSSON 1956). Estas forman extensos batolitos al norte de la Fosa del Patía, en los Farallones de Cali, al este de los ríos San Juan y Atrato, y cerca de Pijao [D9], Pradera (Río Fraile) y Tacueyó (entre el Río Palo y la quebrada Frísoles) en la Cordillera Central (H. W. NELSON 1957). Estos cuerpos intruyeron el Grupo de Cajamarca, las formaciones Dagua, Espinal, el Grupo Diabásico-Porfirítico y atraviesan también los diques básicos del Eoceno superior. A. GANSSER (1950) y A. A. OLSSON (1956) atribuyen a estas intrusiones por lo tanto una edad oligocena, mientras que $\mathrm{H}$. W. NELSON (1957) a base de observaciones de J. Keizer las considera como pre-paleocenas, una opinión que sin duda necesita una revisión. En el contacto de las tonalitas con las diabases del Cretáceo y los diques básicos y ultrabásicos del Eoceno superior se formaron las vetas de platino y oro, que son el origen de los yacimientos secundarios de Andagoya [C-8] (Chocó) y Barbacoas [A12] (Nariño).

Al tercer ciclo magmático terciario pertenecen las andesitas, dacitas, riolitas y tobas que están ampliamente dispersas en las cordilleras Central y Occidental desde 
Pasto [B12] en el sur hasta la Alta Guajira en el norte. Atraviesan en forma de diques todas las formaciones antiguas hasta el Oligoceno superior $(\mathrm{H}$. W. NELSON 1957). Este ciclo comienza aparentemente en el límite Oligoceno-Mioceno, alcanza su máxima intensidad en el Mioceno medio y superior y se continúa en el PlioPleistoceno (formación Popayán) y con intensidad reducida hasta hoy día en los volcanes de Cumbal [B13], Azufral de Túquerres [B12] y Chiles [AB13] de la Cordillera Occidental y Sotará [C11], Puracé [C11], Pan de Azúcar [C11], Huila [CD10], Tolima [D9] y Ruiz [D9] de la Cordillera Central. Las tobas de los volcanes se extienden hasta la costa caribe, donde su aparición se puede reconocer claramente en la zona de la Globorotalia fohsi lobata.

Esporádicamente hay diques andesíticos y dacíticos también en la Cordillera Oriental: en Iza, cerca a Sogamoso [G8], en las inundaciones de Labranza Grande y en el Macizo de Quetame. Las fuentes calientes de Paipa [F8] tienen probablemente su origen en un cuerpo andesítico-dacítico a poca profundidad.

Si consideramos en su conjunto todos los eventos tectónicos que tuvieron lugar en el Terciario de Colombia, es decir, las discordancias, transgresiones marinas y las fases magmáticas, llegamos al siguiente esquema histórico:

TABLA IV

\section{TABLA DE LOS MOVIMIENTOS TECTONICOS DE LOS ANDES COLOMBIANOS EN EL SUPRACRETACEO Y CENOZOICO}

\begin{tabular}{|c|c|c|c|}
\hline $\begin{array}{c}\text { Pisos según la clasificación } \\
\text { conservativa }\end{array}$ & Fases tectónicas & Transgresiones y regresiones & $\begin{array}{l}\text { Pisos europeos } \\
\text { Oligo-Mioceno según } \\
\text { STAINFORTH } 1960 \\
\end{array}$ \\
\hline \multirow[t]{2}{*}{ Cuaternario } & & \multirow[t]{2}{*}{ Regresión progresiva } & \\
\hline & $\begin{array}{l}\text { Solevantamiento general, leve } \\
\text { volcanismo }\end{array}$ & & \\
\hline \multirow[t]{2}{*}{ Plioceno } & & \multirow[t]{2}{*}{ Transgresiones locales } & Plioceno \\
\hline & ligeras dislocaciones, volcanismo & & \\
\hline \multirow[t]{2}{*}{$\begin{array}{l}\text { Mioceno sup. } \\
\text { Mioceno med. } \\
\text { Mioceno inf. alto }\end{array}$} & & \multirow[t]{2}{*}{$\begin{array}{l}\text { Leve transgres. seguida por } \\
\text { regresión }\end{array}$} & $\begin{array}{l}\text { Sarmatiano } \\
\text { Tortoniano }\end{array}$ \\
\hline & $\begin{array}{l}\text { volcanismo andesítico-dacítico - } \\
\text { movimientos de menor inten- } \\
\text { sidad }\end{array}$ & & \\
\hline \multirow[t]{2}{*}{$\begin{array}{l}\text { Mioceno inf. bajo } \\
\text { Oligoceno sup. }\end{array}$} & & \multirow[t]{2}{*}{ Transgres. seguida por regresión } & $\begin{array}{l}\text { Helveciano } \\
\text { Burdigaliano } \\
\text { Aquitaniano sup. } \\
\end{array}$ \\
\hline & $\begin{array}{l}\text { intrusión de tonalitas }- \text { movi- } \\
\text { mientos de mayor intensidad }\end{array}$ & & \\
\hline \multirow[t]{2}{*}{$\begin{array}{l}\text { Oligoceno med. } \\
\text { Oligoceno inf. } \\
\text { Eoceno superior } \\
\text { Eoceno med. en parte }\end{array}$} & & Transgresión & $\begin{array}{l}\text { Aquitaniano infer. } \\
\text { Oligoceno } \\
\text { Eoceno superior } \\
\text { Eoceno med. en parte }\end{array}$ \\
\hline & $\begin{array}{l}\text { intrusiones y extrusiones básicas y } \\
\text { ultrabásicas }- \text { movimientos de } \\
\text { mayor intensidad }\end{array}$ & & \\
\hline \multirow[t]{2}{*}{$\begin{array}{l}\text { Eoceno med. en parte } \\
\text { Eoceno inf. }\end{array}$} & & Transgres. seguida por regresión & $\begin{array}{l}\text { Eoceno med. en parte } \\
\text { Eoceno inferior }\end{array}$ \\
\hline & plegamientos & & \\
\hline Paleoceno & & Transgresión & Paleoceno \\
\hline \multirow[t]{2}{*}{ Maestrichtiano } & & Transgres. seguida por regresión & Maestrichtiano \\
\hline & suaves plegamientos & & \\
\hline \multirow[t]{2}{*}{ Campaniano } & - & \multirow[t]{2}{*}{ Transgres. seguida por regresión } & Campaniano \\
\hline & suaves plegamientos & & \\
\hline Santoniano & & Transgres. seguida por regresión & Santoniano \\
\hline Coniaciano & $\overline{\bar{\nu}}$ & Transgres. seguida por regresión & Coniaciano \\
\hline
\end{tabular}


En lo general se puede decir, que cada fase tectónica está seguida por una transgresión en los sinclinorios, mientras que el solevantamiento de los anticlinorios reanima la erosión. Durante el período subsiguiente de relativa quietud, las cuencas se rellenan con sedimentos, el mar retrocede progresivamente y la intensidad de la erosión se disminuye. Sin embargo, las regresiones marinas están interrumpidas con frecuencia por avances de menor tamaño, como lo muestran BÜRGL, BARRIOS \& RÖSTROM (1955) para el Mioceno inferior (Aquitaniano, Burdigaliano y Helveciano) del Arroyo Saco [B3] (Atlántico).

El volcanismo andesítico-dacítico no está restringido a las fases tectónicas sino sigue durante todo el Neogeno y Cuaternario. Sin embargo, muestra mayor intensidad en las fases tectónicas.

\section{Tipos de estructuras}

Las estructuras de los Andes colombianos son en primer lugar el resultado de los movimientos tectónicos del Mesozoico y Cenozoico descritos en los párrafos anteriores. Las etapas principales de estos movimientos son:

1. El hundimiento cíclico de los geosinclinales durante el Mesozoico, particularmente durante el Cretáceo.

2. El solevantamiento de los anticlinorios y hundimiento de los sinclinorios durante el Terciario.

3. El solevantamiento general de la región andina al principio del Cuaternario.

Respecto a estas etapas tectónicas, los Andes colombianos coinciden aproximadamente con las cordilleras "alpinotípicas" (H. STILLE 1940) terciarias. Sin embargo, respecto a sus estructuras no queremos designarlos como Cordilleras de tipo alpino. La estructura de los Alpes está caracterizada por pliegues amplios y mantos de sobrescurrimiento de extensa dislocación. En los Andes colombianos, tales formas tectónicas faltan por completo. Su estructura está caracterizada en primer lugar por bloques y fallas. Los pliegues suaves que aparecen en los cortes geológicos son generalizaciones que resultan al desatender las fallas y las abruptas torsiones locales. En Santander y Norte de Santander se puede observar, que las distintas facies del Cretáceo inferior están delimitadas por líneas bastante rectas, hecho que indica que ya el hundimiento del geosinclinal cretáceo tuvo lugar en forma de bloques y no de ondulaciones suaves. También los sinclinorios terciarios seguramente estaban en gran parte limitados lateralmente por fallas. Hoy día es raro encontrar un área de 100 $\mathrm{km} .^{2}$ que no esté atravesada por una falla de mayor dislocación. Es cierto que hay pliegues también, pero ellos no desempeñan un papel tan importante y son de un tipo distinto de los de las cordilleras "alpinotípicas".

Como lo muestra la figura 27, son particularmente las series sedimentarias y los cuerpos cristalinos del Occidente andino, los que están cortados por numerosas fallas en bloques largos y estrechos en forma de láminas, los cuales se trasladan uno encima del otro a manera de tejados (estructuras imbricadas). No se conoce ningún sitio donde se pueda observar una sucesión completa del grupo porfirítico-diabásico, de las formaciones Espinal y Dagua o del Grupo de Cajamarca.

La Cordillera Central se solevantó al principio del Mesozoico y fue cubierta, por lo menos parcialmente, por sedimentos liásicos y cretáceos, que fueron erodados en su mayor parte durante los solevantamientos terciarios. Las estructuras que expone hoy día son el resultado de todos los movimientos e intrusiones ígneas desde, por lo menos, la fase caledónica. Los conocimientos actuales no permiten analizar históricamente estas complicadas estructuras.

Las estructuras de la Cordillera Oriental son mucho más suaves. A grandes rasgos se reconocen pliegues amplios, a veces con un flanco invertido, como es el caso en el Anticlinorio de Villeta, en los bordes de la Sabana de Bogotá y en el borde llanero del Macizo de Quetame (fig. 27). En Cundinamarca, la Cordillera Oriental se yergue en forma de un hongo sobre las regiones adyacentes, como entre las puñazas de un torno. Sin embargo, donde existen afloramientos en una densidad suficiente para facilitar estudios detallados, las estructuras resultan mucho más complicadas por fallas de lo que aparece a primera vista (fig. 28). En su mayoría son fallas inversas, es decir causadas por compresión y no por tensión. Particularmente los anticlinales son los que están tan fracturados, mientras que los sinclinales son más regulares y menos afectados por fallas (fig. 30).

Los sinclinorios interandinos terciarios tienen unas veces la forma de sinclinales suaves (fig. 31 , parte izquierda), y otras la de fosas (grábenes) muy fracturadas (fig. 31, parte derecha). En ellos las areniscas y conglomerados del Terciario inferior ocupan con frecuencia posiciones pendientes hasta verticales o inversas y forman lomas largas y angostas. El Terciario superior, en contraste, es con frecuencia horizontal o casi horizontal y forma paisajes de mesetas (fig. 29).

Las regiones del Terciario marino, que fueron inundadas por el mar relativamente tarde, presentan estructuras suaves con domos sedimentarios, como es por

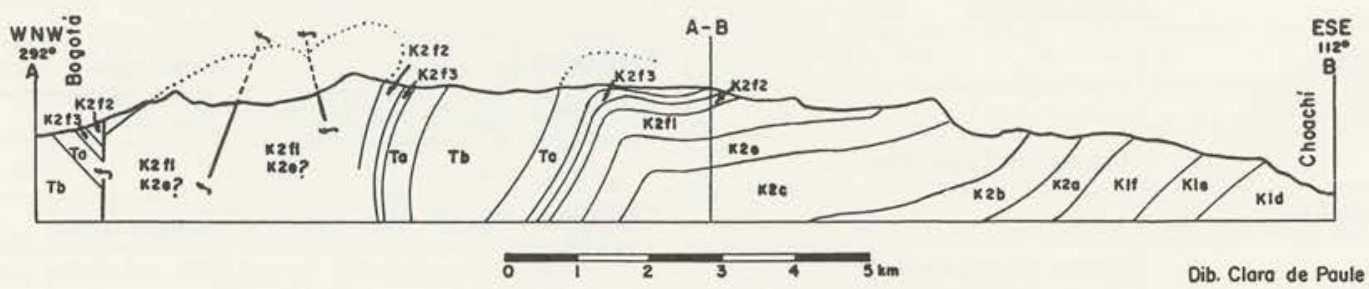

Fig. 30 - Corte geológico Bogotá-Choachí según R. DE LA ESPRIELLA \& VILLEGAS 1960. ('Tb, Eoceno inferior; Ta, Paleoceno; K2f3, Maestrichtiano superior; K2f2, Maestrichtiano medio; K2f1, Mestrichtiano inferior; K2e, Campaniano; K2c, Coniaciano; K2b, Turoniano; K2a, Cenomaniano; K1f, Albiano; Kle, Aptiano; K1d, Barremiano). 


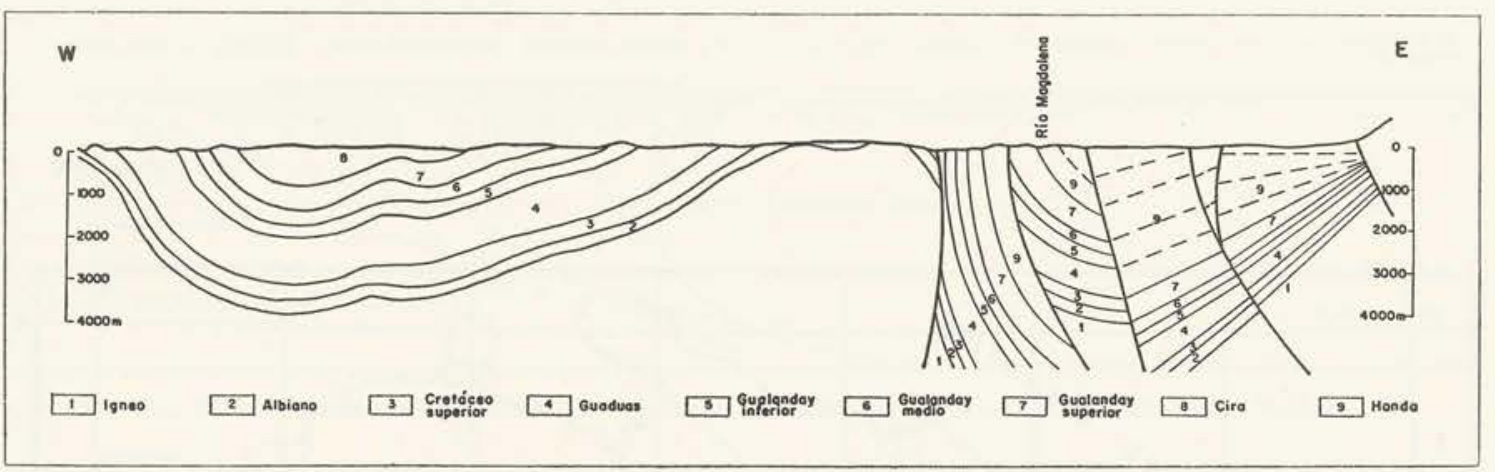

Fig. 31 - Corte geológico a través del valle superior del río Magdalena según I. TORRES 1958, ligeramente modificado.

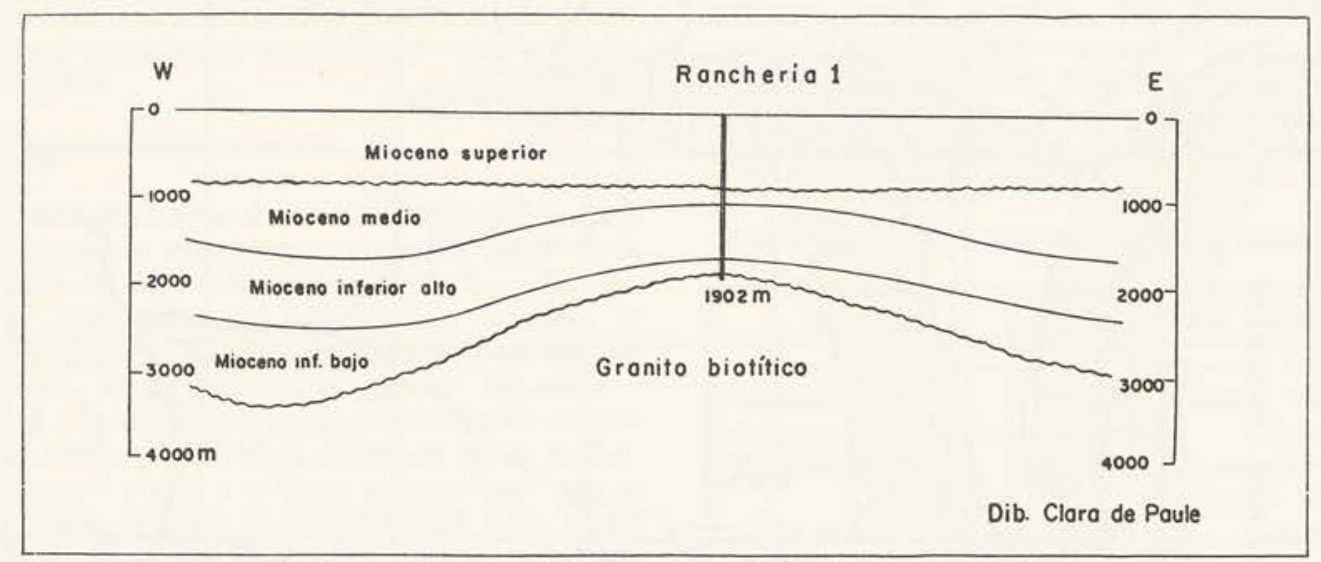

Fig. 32 - Corte a través de la estructura de Ranchería en la Guajira.

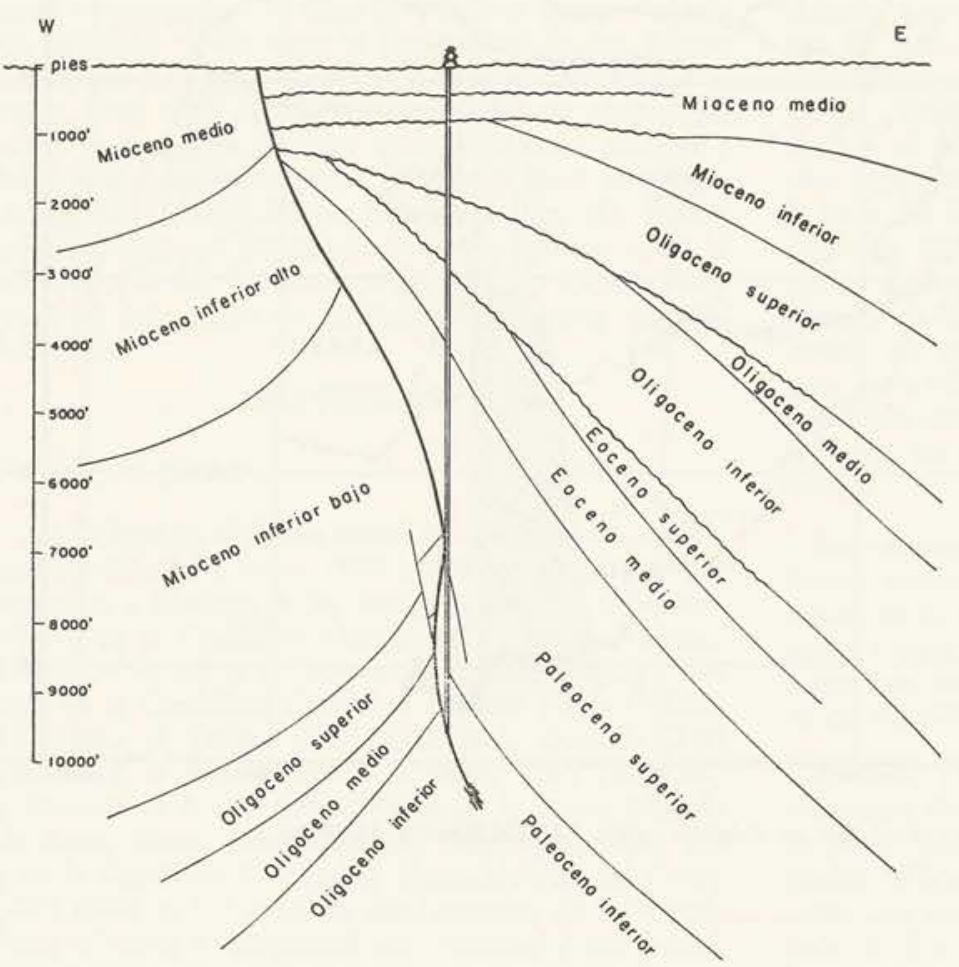

Fig. 33

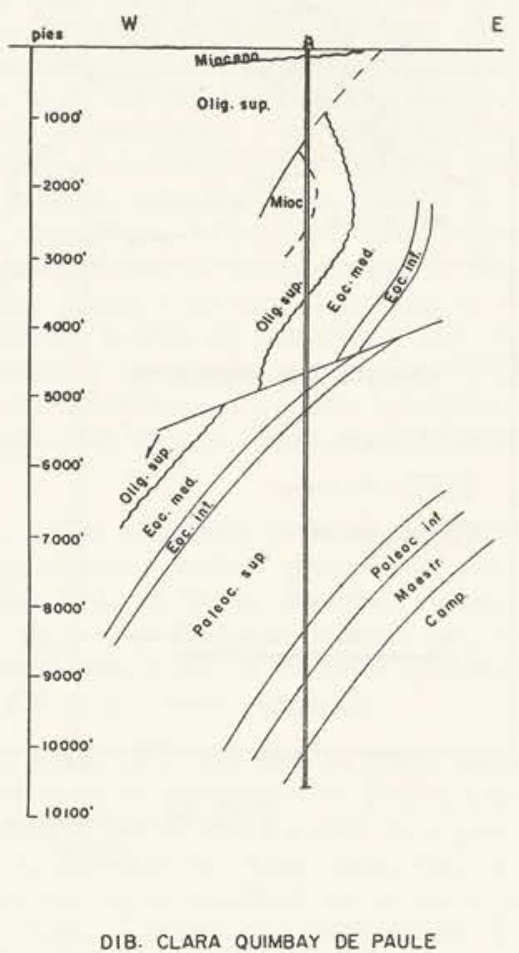

Fig. 34

Estructuras del Terciario marino en la zona costanera al sur de Cartagena 


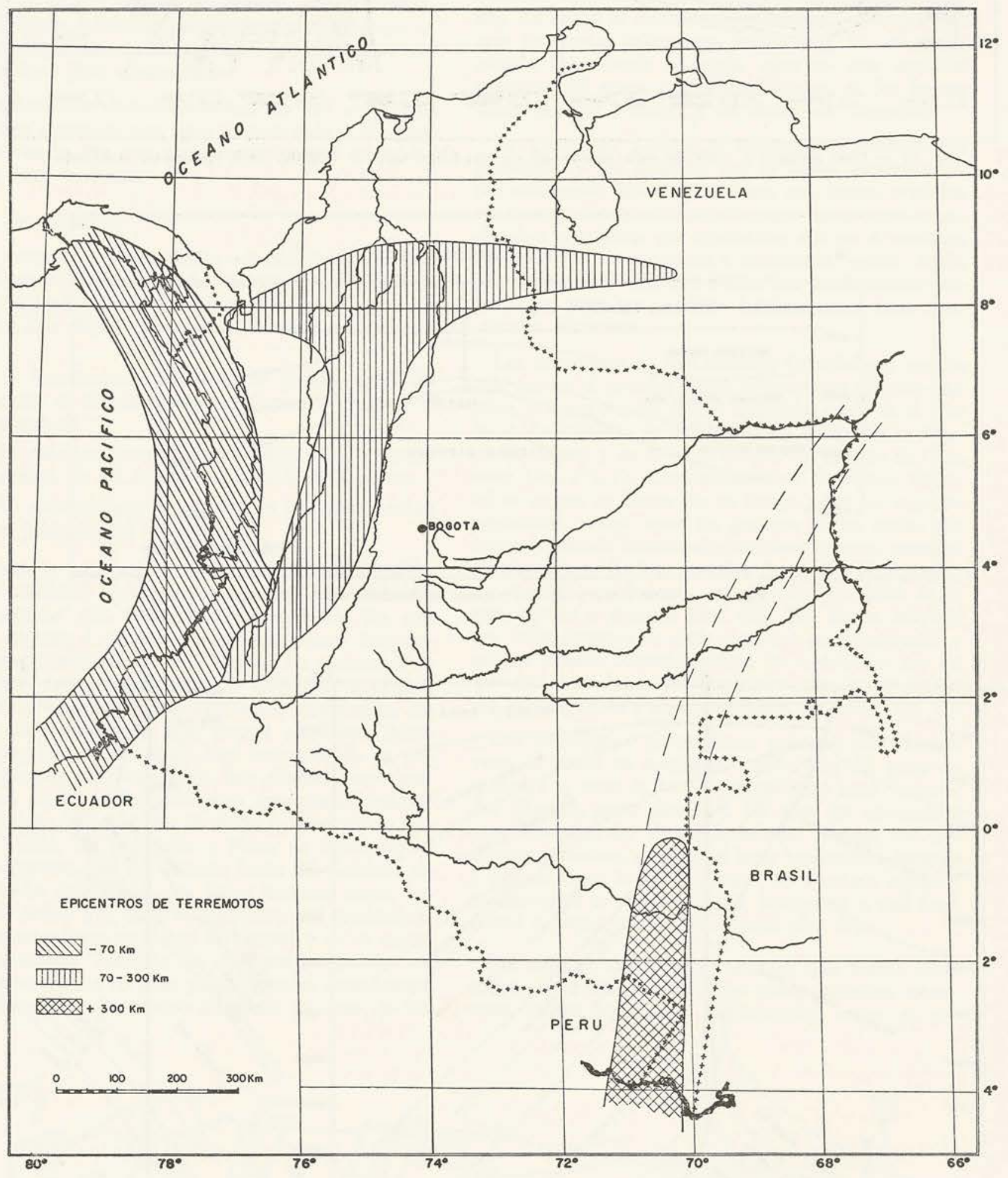

Fig. 35 - Epicentros de terremotos en Colombia según GUTENBERG \& RICHTER. 


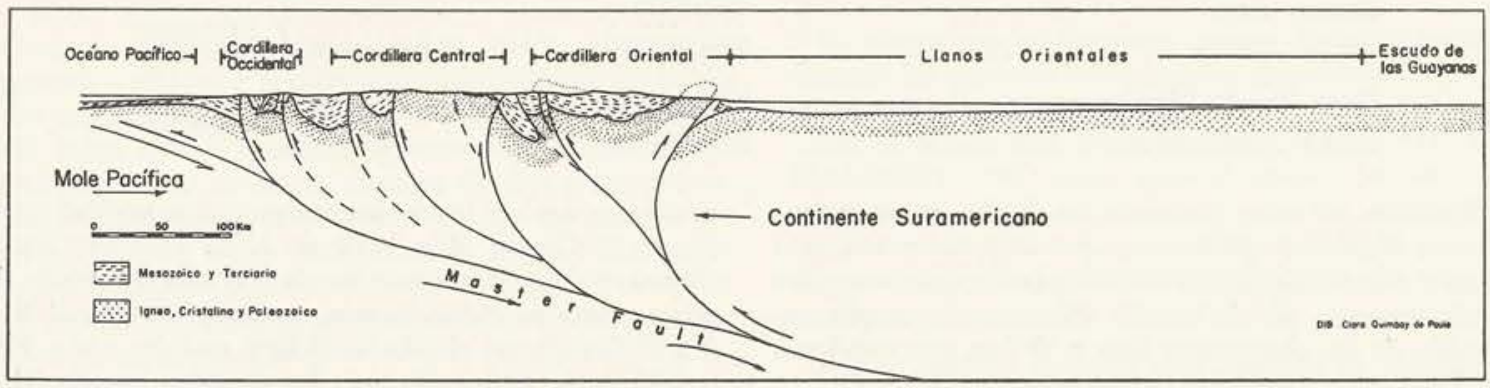

Fig. 36 - Esquema del movimiento del continente suramericano sobre la mole estable del Océano Pacífico.

ejemplo el caso en la región de Cicuco [DE4] y en la estructura de Ranchería en la Guajira [G2] (fig. 32). Pero en las regiones donde también el Paleogeno está desarrollado, se encuentran fallas pendientes de sobrescurrimiento, discordancias apreciables y capas invertidas (figs. 33 y 34 ).

\section{Terremotos}

Una cierta clave para el entendimiento de los movimientos tectónicos, mesozoicos y terciarios nos la da la distribución de los terremotos en Colombia (fig 35). Según su profundidad, los epicentros se localizan en tres zonas distintas: a) los terremotos de poca profundidad (hasta $70 \mathrm{~km}$.) tienen su máxima frecuencia e intensidad a lo largo de la costa pacífica; b) los de profundidad media (70-300 km.) tienen un eje en la Cordillera Central y otro a lo largo de una línea que se extiende desde el Golfo de Urabá [BC5] hasta el sur del Lago de Maracaibo [H4]; este último corresponde a importantes dislocaciones terciarias; c) la zona de terremotos profundos (de más de $300 \mathrm{~km}$. de profundidad) corresponde a la línea de charnela (hinge line, L. G. WEEKS 1959) entre el geosinclinal de los Llanos Orientales y el Escudo de Las Guayanas. Si conectamos todos estos sitios de epicentros, resulta un plano que corta la superficie terrestre cerca a la costa pacífica y buza con aproximadamente 20 grados hacia el sureste debajo del Escudo de las Guayanas (fig. 36). Parece que el continente suramericano deriva hacia y sobre la mole estable del fundamento del Océano Pacífico a lo largo de este plano de máxima perturbación (master fracture).

\section{CUATERNARIO}

\section{Fenómenos glaciales}

En Colombia, el límite actual de la nieve está situado aproximadamente entre 4650 y $4900 \mathrm{~m}$. de altura. Varios altos y macizos de los Andes se yerguen sobre esta altura: en la Cordillera Occidental el Nevado Cumbal [B13] (4750 m.) y el Nevado de Chiles [AB13] (4748 m.), en la Cordillera Central el Nevado Huila [CD10] (4750 m.), el Tolima [D9] (5215 m.), Quindío [D9] (5110 m.), el Nevado de Santa Isabel [D9] (5100 m.) y Nevado el Ruiz [D9] (5400 m.), la Sierra Nevada de Santa Marta (Pico Cristóbal Colón [F3] $5800 \mathrm{~m}$.) y en la Cordillera Oriental la Sierra Nevada del Cocuy [G7] (5493 m.). Varios de estos nevados de las Cordilleras Central y Occidental son volcanes y sus formas superficiales están influenciadas por su actividad eruptiva. Pero las de los nevados no volcánicos dependen principalmente de la actividad del hielo.
Las formas superficiales causadas por los glaciares, tales como morrenas, valles en forma de U, planos cepillados, ollas y lagos glaciales, circos y cols fueron estudiadas en detalle en la Sierra Nevada de Santa Marta por A. GANSSER (1955) y a base de fotografías aéreas por H. C. RAASVELDT (1957). Estos autores distinguen allí cuatro estados glaciares, cuya extensión (fig. 37) y altura se especifican en la siguiente tabla:

\section{Glaciaciones de la Sierra Nevada de Santa Marta}

\begin{tabular}{|c|c|c|}
\hline Estado glaciar & Extensión & $\begin{array}{c}\text { Límite inferior de los } \\
\text { glaciares }\end{array}$ \\
\hline $\begin{array}{l}\text { Reciente } \\
\text { Subreciente (Bolívar) } \\
\text { Mamancanaca } \\
\text { Aduriameina }\end{array}$ & $\begin{array}{l}39 \mathrm{~km}^{2} \text {. } \\
105 \mathrm{~km}^{2} \text {. } \\
856 \mathrm{~km}^{2} \text {. } \\
\text { ? }\end{array}$ & $\begin{array}{c}4800-5000 \mathrm{~m} . \\
4500 \mathrm{~m} . \\
\text { Raasveldt } 3450, \\
\text { Gansser } 3300 \mathrm{~m} . \\
2800 \mathrm{~m} .\end{array}$ \\
\hline
\end{tabular}

Ambos autores están de acuerdo en la suposición de que la máxima extensión de huellas glaciales (estado Aduriameina) corresponde a la última glaciación pleistocena (Würm II en Europa, Wisconsin en Norteamérica) y el estado Mamancanaca a un estado de retroceso postpleistoceno. RAASVELDT compara el estado Bolívar con la máxima extensión de los glaciares de los Alpes en 1850, en todo caso lo considera como perteneciente al tiempo histórico. El hecho de que la Sierra Nevada de Santa Marta y las otras montañas en Colombia no presentan huellas de glaciaciones más antiguas (pre-würmianas) hace suponer a A. GANSSER, que las cordilleras colombianas no fueron levantadas en la región de nieve sino hasta la última glaciación pleistocena.

Sin embargo, si esta suposición fuera correcta, deberíamos encontrar terrazas marinas pleistocenas, por lo menos en la costa de Santa Marta, elevadas a alturas de algunos cientos de metros. Como lo mostrará más adelante, este no es el caso, y por tal razón la explicación de A. GANSSER no nos parece aceptable.

Además, TH. VAN DER HAMMEN (1960) calculó los límites de nieve en los alrededores de Bogotá a base de polen fósil para el glacial Riss I a $2800 \mathrm{~m}$. y para el glacial Würm a 3050-3215 m. Estos datos casi coinciden con las alturas de las morrenas en la Sierra Nevada de Santa Marta. Tomando los resultados de TH. VAN DER HAMMEN como base, las glaciaciones de la Sierra Nevada de Santa Marta se correlacionan en la siguiente manera: 
Estado actual .. .............

Estado Bolívar ...............

Gran Estado Mamancanaca ... . . . . . .

Estado Aduriameina .............

También en otras partes de los Andes, las morrenas y otras huellas de glaciaciones pre-würmianas son muy escasas (G. STEINMANN 1906), hecho que se explica probablemente por la erosión intensa y la amplia extensión de las glaciaciones Riss y Würm que cubrieron las huellas de las glaciaciones anteriores.

En los mismos niveles como en la Sierra Nevada de Santa Marta, A. GANSSER (1955) encontró morrenas en los nevados de Chita y del Ruiz. En lo general se puede decir que todos los páramos extensos de las cordilleras colombianas (superiores a $3000 \mathrm{~m}$.) presentan rastros de glaciaciones más o menos bien conservados.

\section{El Lago de Bogotá}

TH. VAN DER HAMMEN (1960) estudió detenidamente el polen de muestras de una perforación efectuada en el terreno de la Universidad Nacional en Bogotá, que atravesó capas pleistocenas hasta una profundidad de $300 \mathrm{~m}$. Los sedimentos son arcillas micáceas (limo) y arenas con intercalaciones de turba, depositados en un lago que se transformó temporalmente en pantano. A base de polen fósil construyó curvas de temperatura y comparando estas con las de EMILIANI y otros, logró correlacionar los sedimentos pleistocenos del Lago de Bogotá con los varios estados glaciales e interglaciales reconocidos en Europa y Norteamérica. Sus

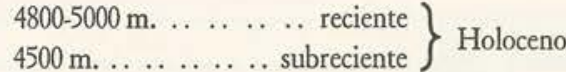

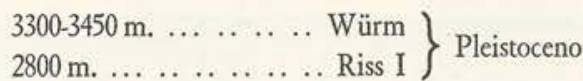

resultados son en breve: las temperaturas medias anuales en el Glacial Riss eran de $11^{\circ} \mathrm{C}$ y en el Glacial Würm $8^{\circ}$ más bajas que las de hoy día. El límite de nieve, como ya mencionamos, estaba en el Glacial Riss I a $2800 \mathrm{~m}$. y en el Glacial Würm oscilaba entre 3050 y $3215 \mathrm{~m}$. de altura. Durante los períodos interglaciales, el lago de la sabana estaba rodeado por bosques de Quercus, Alnus y Podocarpus, mientras que en los períodos glaciales el límite del bosque estaba 200 a $900 \mathrm{~m}$. bajo del nivel de la Sabana $(2600 \mathrm{~m}$.) y la flora que rodeaba el lago se componía de hierbas, gramíneas y arbustos bajos, tales como los que se encuentran hoy en los páramos altos. El desecamiento de la sabana fue un evento de tiempos relativamente modernos (históricos o prehistóricos) y es bien posible que este suceso haya pasado a la tradición indígena y exista todavía en forma de la leyenda de Bochica.

\section{Abanicos y terrazas de ríos}

Los períodos glaciales no eran solamente épocas frías sino también húmedas. En las regiones situadas debajo de $3000 \mathrm{~m}$. se manifestaron esencialmente como períodos pluviales.

Hoy día observamos que cada aguacero provoca deslizamientos y aumenta la fuerza transportadora de los arroyos y ríos en tan alto grado que dichos caudales

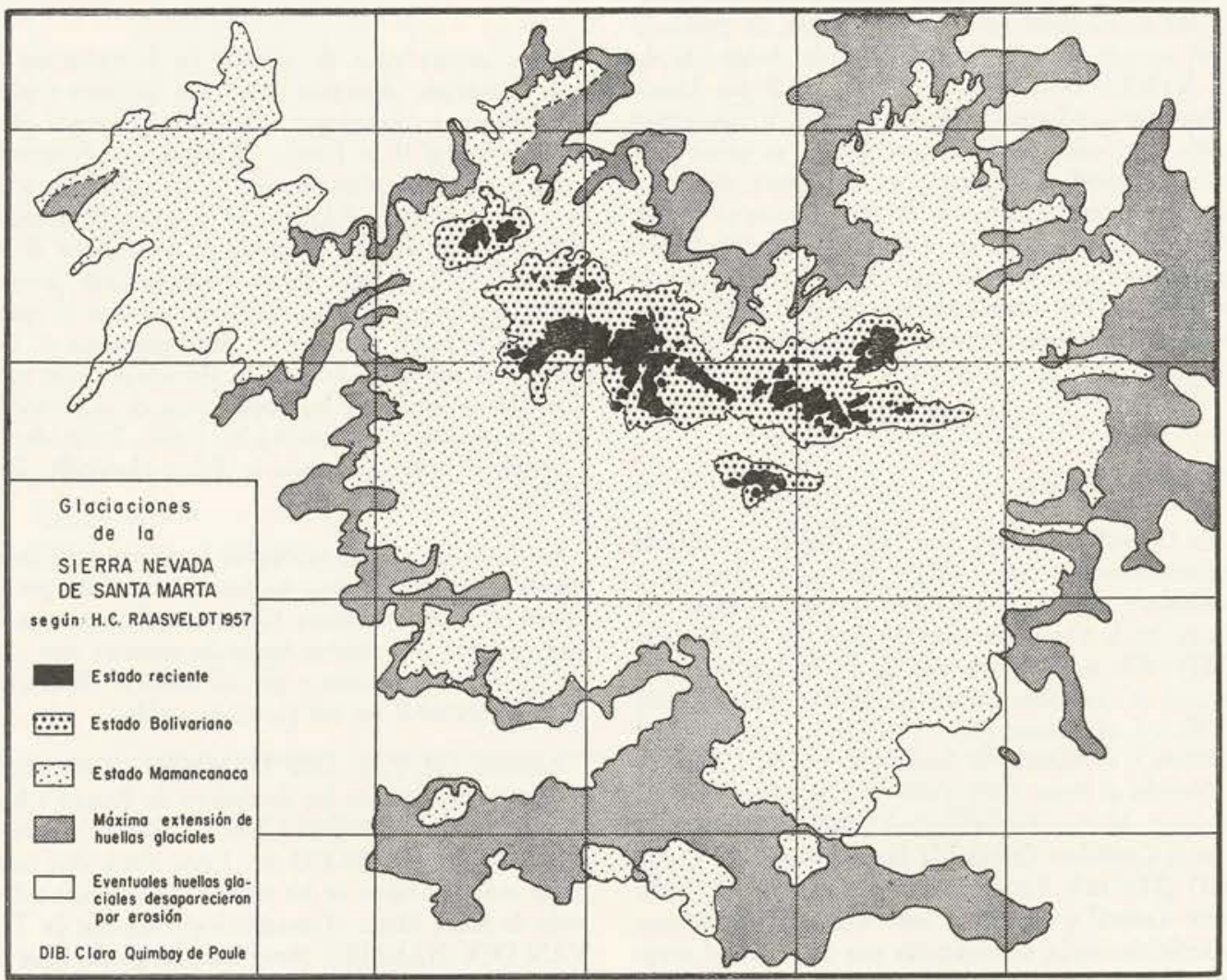

Fig. 37 - Glaciaciones de la Sierra Nevada de Santa Marta, según H. C. RAASVELDT 1957, modificado. 
arrastran bloques enormes aguas abajo, rompiendo puentes y diques y causando inundaciones en las planicies bajas. Los cascajos, la arena y el lodo se depositan allí hasta que el próximo aguacero siga el proceso de transporte. Los inviernos, tiempos de alta precipitación, son los períodos de más intensa erosión en las regiones altas y de más fuerte sedimentación en los valles al pie de las montañas. Durante el verano, los arroyos cortan un poco los sedimentos acumulados durante el invierno, pero la sedimentación cesa casi por completo.

El mismo contraste que observamos hoy día entre invierno y verano existió en el Pleistoceno entre los períodos pluviales e interpluviales. Durante los glaciales-pluviales aumentaron los glaciares, impulsando las morrenas frontales y laterales hacia adelante. Los arroyos recogieron en parte este material y el detrito de las laderas resquebrajado por el hielo y lo transportaron aguas abajo acumulándolo al pie de las montañas en forma de abanicos y en los valles más amplios en forma de terrazas. Durante los interpluviales hundieron su curso y cortaron a través de estos obstáculos, transportaron en un trecho reducido escaso material de los depósitos pluviales de un sitio a otro, aumentando apenas el volumen total de los sedimentos (fig. 38).

Siempre se observa que los abanicos más extensos son el resultado del Pleistoceno inferior y tal vez ya del Plioceno, del período de apreciable solevantamiento de las cordilleras. Como ejemplo mencionamos el de $\mathrm{Fu}-$ sagasugá, que tiene una longitud de $20 \mathrm{~km}$., una inclinación de $900 \mathrm{~m}$. y se convierte hacia abajo en la terraza más alta (Formación Mesa?) del Río Fusagasugá [E9]. Entre abanicos y terrazas no hay límite preciso. Las terrazas más antiguas están por lo general inclinadas aguas abajo y constan de cascajos grandes, mientras que las más modernas comprenden material fino y tienen una superficie casi horizontal (A. JOURNAUX \& E. NICHOLLS V. 1959, foto 9).

En todas las partes de los Andes colombianos, las terrazas pleistocenas de ríos están entre los fenómenos morfológicos más frecuentes. Sin embargo, su estudio está poco avanzado aún y descripciones detalladas como la de las terrazas del río Magdalena en los alrededores de Neiva [D11], por J. ROYO Y GOMEZ (1942) y la de la terraza de Bucaramanga [F6] por J. DE PORTA (1959) son todavía escasas. En los alrededores de Garzón, Huila [D11], TH. VAN DER HAMMEN (1957) distinguió siente terrazas del río Magdalena posteriores a la Formación Mesa y las correlacionó con los períodos glaciales europeos en la siguiente manera:

\begin{tabular}{|c|c|c|}
\hline Terraza & $\begin{array}{c}\text { Altura sobre } \\
\text { el cauce actual }\end{array}$ & Edad \\
\hline Formación Mesa & $200 \mathrm{~m}$. & Plioceno o Günz \\
\hline $\begin{array}{l}\text { Terraza de Garzón, D1 } \\
\text { Terrazi D2 }\end{array}$ & $\begin{array}{l}145 \mathrm{~m} . \\
115 \mathrm{~m} .\end{array}$ & \} Mindel \\
\hline $\begin{array}{l}\text { Terraza de Altamira, E1 } \\
\text { Terraza E2 }\end{array}$ & $\begin{array}{l}70 \mathrm{~m} . \\
45 \mathrm{~m} .\end{array}$ & \} Riss \\
\hline $\begin{array}{l}\text { Terraza F } 1 \\
\text { Terraza F } 2\end{array}$ & $\begin{array}{l}24 \mathrm{~m} . \\
10 \mathrm{~m} .\end{array}$ & \} Würm \\
\hline Terraza G & $1.5 \mathrm{~m}$. & \\
\hline
\end{tabular}

Es seguro que se formaron ciertos depósitos también durante los períodos interglaciales (interpluviales). Este es el caso, por ejemplo, de la caliza de agua dulce que cubre la terraza baja de Aipe [D10]. TH. VAN DER HAMMEN (1957) tiene razón al suponer que esta capa se formó en un clima caliente y seco. Sin embargo, su conclusión de que todos los sedimentos de las terrazas de ríos son productos de los períodos interpluviales parece una generalización no justificada.

Varios autores suponen que durante el Pleistoceno tuvieron lugar considerables solevantamientos de los Andes colombianos (A. GANSSER 1955) u otros movimientos tectónicos (A. JOURNAUX \& E. NICHOLLS V. 1959). Los datos que tenemos actualmente a nuestra disposición sobre las terrazas de los ríos no confirman esta suposición. La verdad es que la terraza o mejor dicho el abanico de Fusagasugá, por ejemplo, está atravesado por numerosas fallas que contribuyen a su considerable inclinación. Sin embargo, estas fallas presentan resaltos de no más de algunos pocos metros y en su totalidad corresponden tal vez a un desplazamiento de $50 \mathrm{~m}$. Además es posible, que este abanico sea en parte de edad pliocena. De las terrazas seguramente pleistocenas no conocemos ni un caso de dislocaciones o deformaciones apreciables. Todas las observaciones indican que hubo relativamente muy pocos movimientos tectónicos en los Andes colombianos desde el Pleistoceno inferior o más preciso desde el principio del Mindel.

\section{Terrazas marinas}

Las terrazas marinas indican la misma tranquilidad del Pleistoceno. Mientras que los estratos pliocenos de la zona costanera, por ejemplo las calizas de la Formación Popa, están casi siempre inclinadas y fracturadas, las terrazas pleistocenas son siempre horizontales y poco elevadas.

En los alrededores de Cartagena [D3], J. ROYO Y GOMEZ (1950) observó dos niveles bien claros de diferentes edades; uno a unos 20 a $26 \mathrm{~m}$. del Pleistoceno inferior, otro del Pleistoceno superior a $3 \mathrm{~m}$. sobre el nivel del mar. La terraza alta "está integrada por calizas terrosas blanquecinas con algas calcáreas (Lithothamnion) y púas y otros restos de equínidos, con todo el aspecto, en conjunto, de las brechas externas de los arrecifes madrepóricos". La terraza baja representa una playa levantada y está formada por arenas calcáreas y arcillosas con gran cantidad de fósiles, particularmente Lamelibranquios, Gasterópodos y Foraminíferos.

En la Península de la Guajira, H. BÜRGL (1960) observó tres terrazas marinas de sedimentación: una que está $10 \mathrm{~m}$. sobre el nivel del mar y consta de arcilla y gravilla fina sin fósiles, la cual considera de edad pliocena; otra, $5 \mathrm{~m}$. sobre el nivel del mar, constituída de caliza arenosa blanda y rica en Moluscos; la tercera, situada $2 \mathrm{~m}$. sobre el mar, es una playa levantada con arenas y arcillas semejantes a las de las playas recientes, también con muchos Lamelibranquios de especies recientes. BÜRGL supone que la edad de esta terraza más baja sea subreciente (Holoceno).

\section{Restos orgánicos}

La lista más extensa de fósiles marinos pleistocenos la cita J. ROYO Y GOMEZ (1950) de los alrededores de 


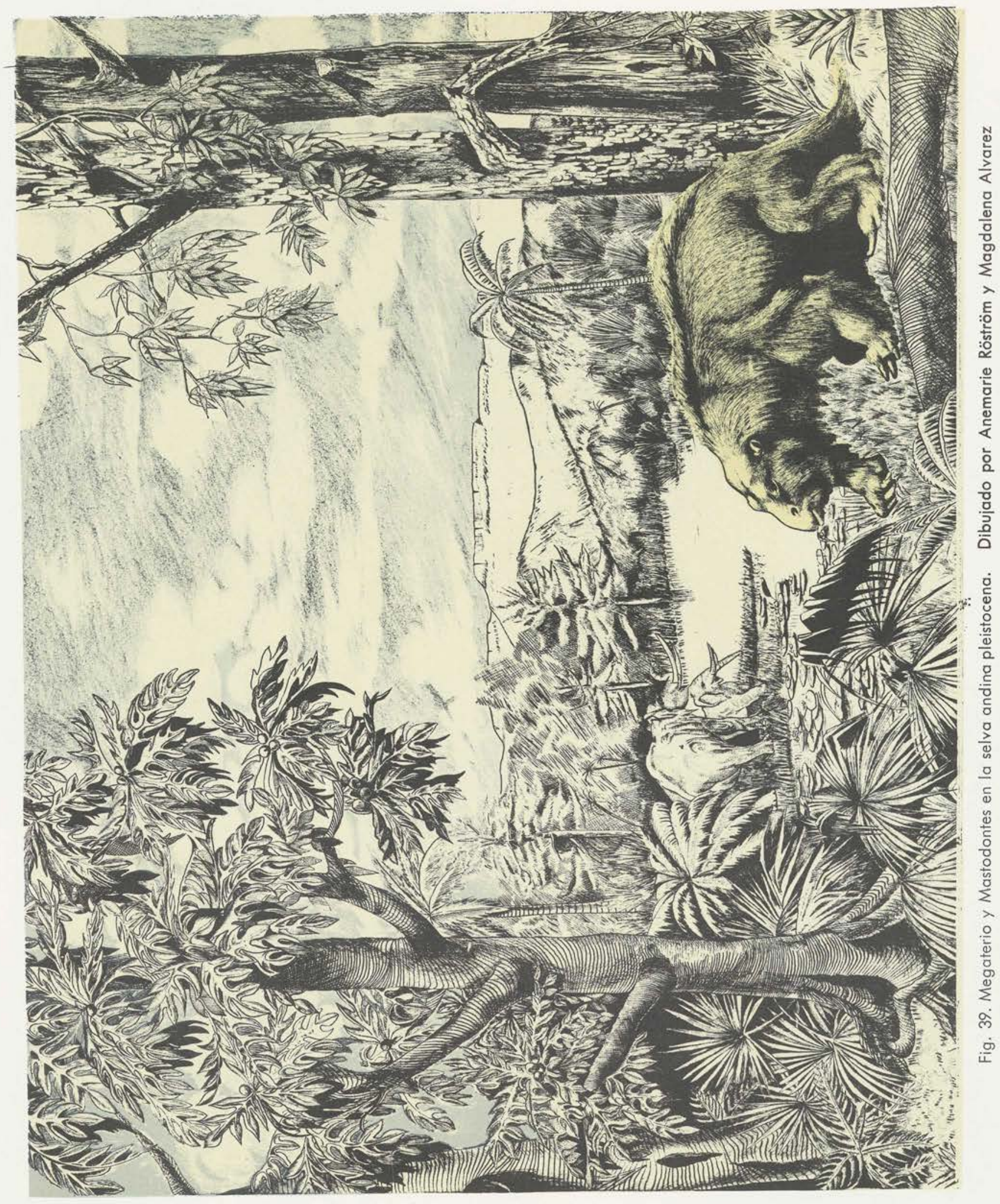




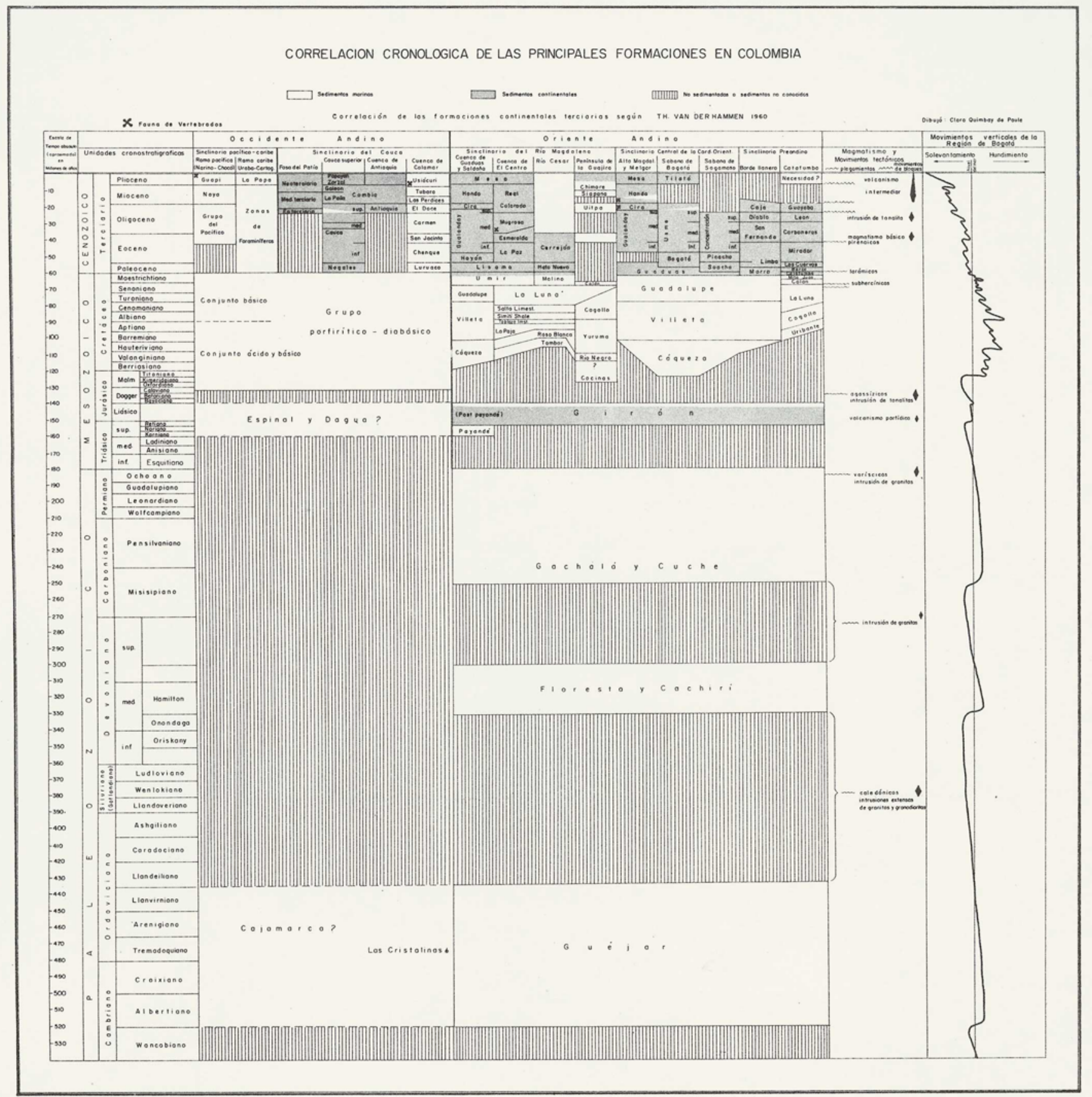

En esta tabla las dimensiones verticales de las formaciones corresponden al tiempo absoluto de la duración de su deposición y, por lo tonto, no reflejan los espesores de las formaciones. Se ve, por ejemplo, que la deposición de la Formación Güejar duró 85 millones de años, la de la Formación Girón 14 millones de años y la de la Formación Honda 12. Los espesores de las Formaciones no están indicados en la tabla, porque varían de un sitio a otro.

De esta disposición de la tabla se puede reconocer que los eventos geológicos, como transgresiones y regresiones del mar, movimientos verticales de la costra terrestre, intrusiones y extrusiones magmáticas se intensificaron progresivamente en el curso de la historia geológica de Colombia. El Paleozoico y el Mesozoico fueron Eras relativamente tranquilas en comparación con los eventos revolucionarios del Cenozoico.

Este fenómeno se observa no solamente en Colombia sino también en muchas otras partes de la tierra y demuestra, que nuestro planeta no se acerca a un estado de vejez sino al contrario, está pasando o pasó hace pocos millones de años por uno de los periodos más inquiełos de su evolución histórica. 


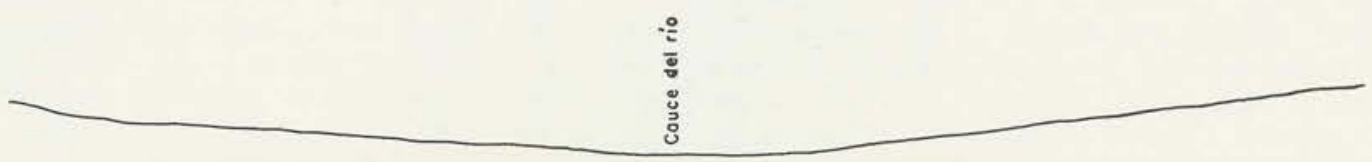

Estado 1: Valle de un río ontes del periodo glocial

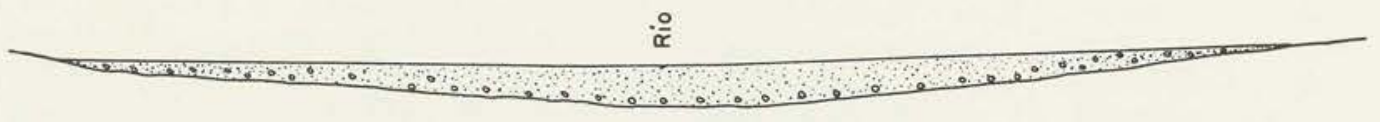

Estado 2: Relleno del valle y formación de la primera terraza durante el primer periodo glacial

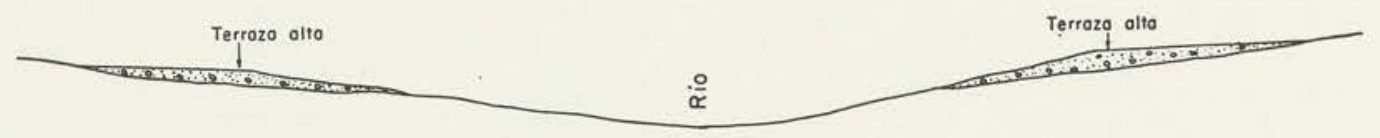

Estado 3: Erosión durante el primer período interglacial

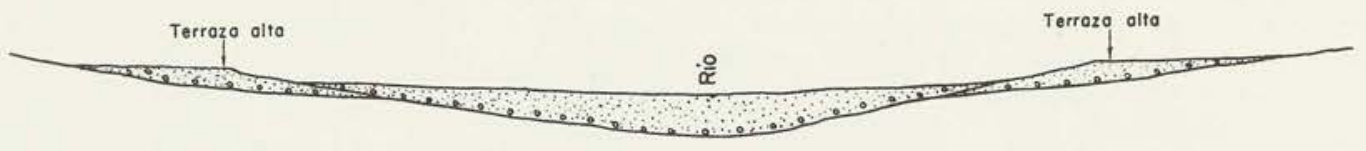

Estado 4: Formación de la segunda terraza durante el segundo periodo glacial

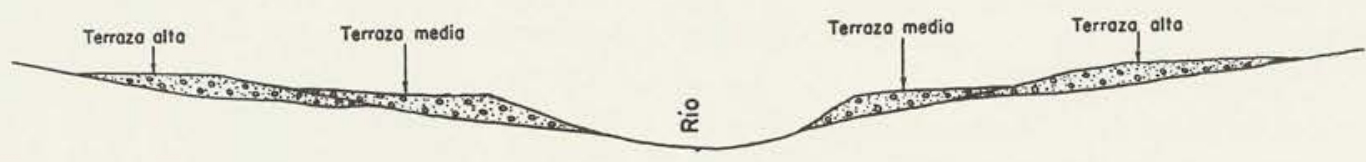

Estado 5: Erosión durante el segundo período interglacial

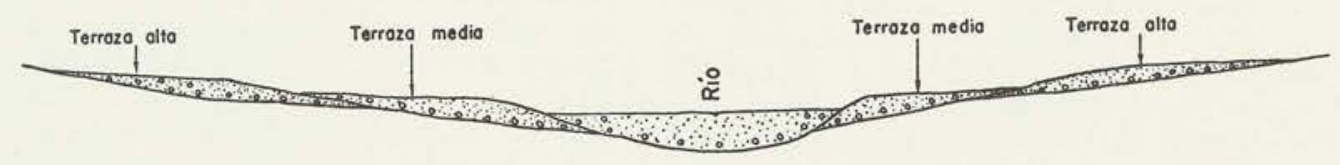

Estado 6: Formación de la tercera terraza durante el tercer período glacial

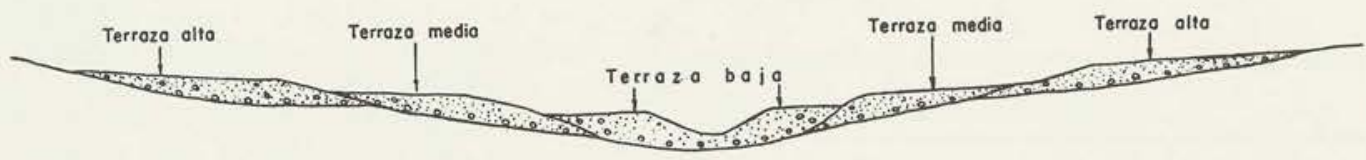

Estado 7: Erosión durante el tercer periodo interglacial

Fig. 38 - La formación de terrazas de ríos por la alternancia de períodos glaciales (pluviales) e interglaciales (interpluviales). 


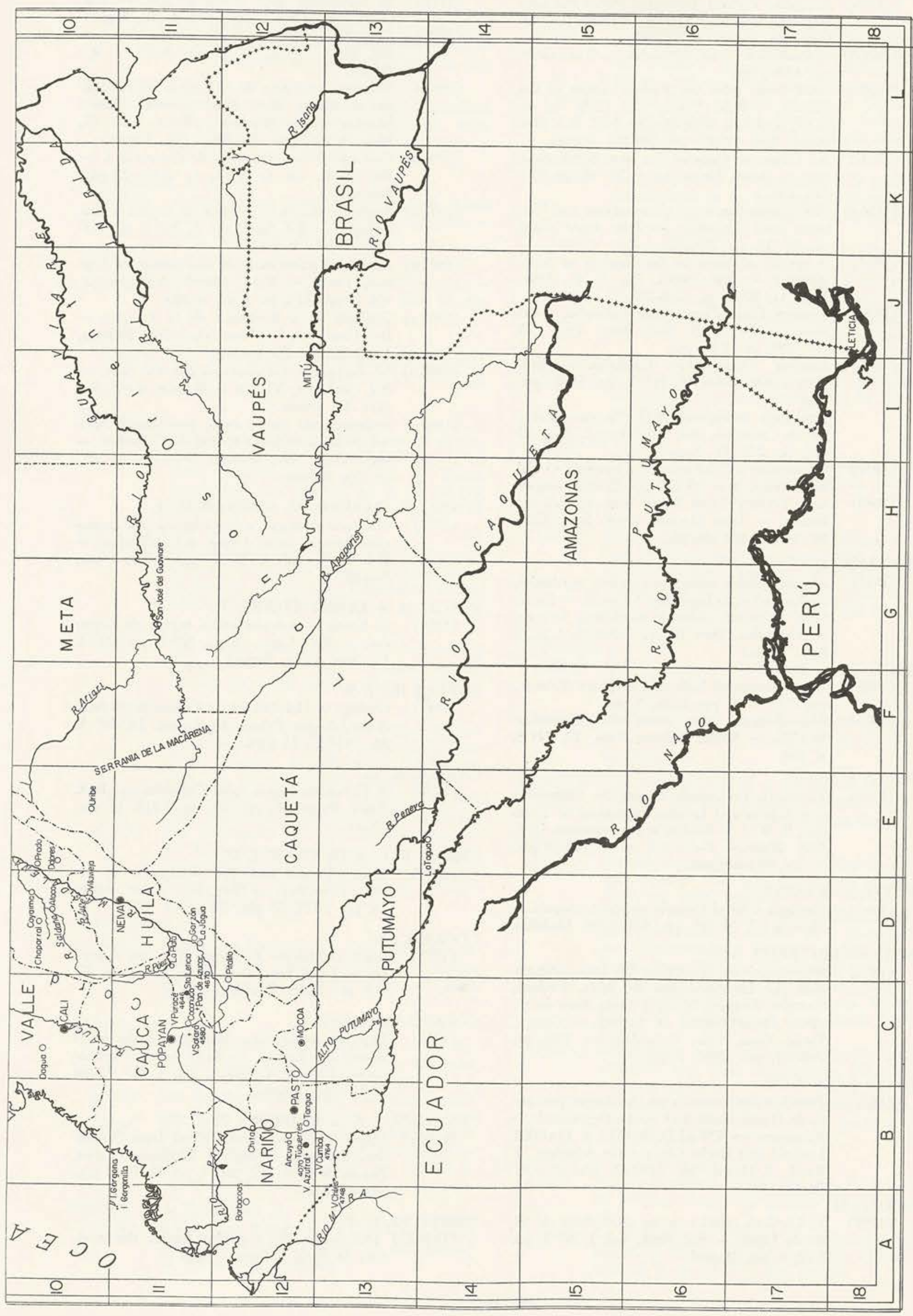


Cartagena. Son restos de Foraminíferos, Esponjas, Equínidos, Lamelibranquios, Escafópodos, Gasterópodos, Gusanos, Ostrácodos, Crustáceos y Teleósteos. Entre los Foraminíferos predominan en número Archaias angulatus (FICHTEL \& MOLL), Cymbaloporetta squamosa (D'ORBIGNY) y numerosas especies de Quinqueloculina, habitantes de las praderas submarinas. Varias de las especies de Moluscos citadas de Cartagena colectó H. BƯRGL (1960) también en la Guajira. Los Moluscos pleistocenos y recientes se diferencian, si es el caso, solamente por características subespecíficas.

Como ya se mencionó anteriormente, las informaciones más completas sobre la flora pleistocena se deben a los estudios palinológicos de TH. VAN DER HAMMEN (1960). También las especies de plantas (o las formas del polen) se diferencian poco de las actuales. Solamente las regiones de floras variaron según los cambios del clima.

Simultáneamente con el solevantamiento de la región andina durante o al final del Plioceno se levantó también América Central, formando un puente terrestre entre Norte y Suramérica, que estaban separados por el mar, con pocas interrupciones, desde el Terciario inferior. El nuevo puente facilitó el intercambio de faunas terrestres entre los dos continentes: a Suramérica inmigraron los Mastodontes, Equidos, muchos Carnívoros y Roedores, mientras que representantes de varias familias típicas de Suramérica emigraron hacia el norte (E. THENIUS \& H. BÜRGL 1957). De los últimos mencionamos particularmente el Didelphis (Opossum) y los Megaterios. En Colombia, son relativamente frecuentes los hallazgos de restos de animales pleistocenos, pero estos pertenecen exclusivamente a animales grandes como Megaterios, Mastodontes y Equidae (R. A. STIRTON 1953). Los huesos más pequeños de carnívoros, roedores y ungulados no llaman aparentemente la atención de la gente y no llegan a manos de los científicos. El Megaterio, un pariente del perezoso actual, era un verdadero gigante que alcanzó unos $6 \mathrm{~m}$. de largo y vivió en las selvas andinas (fig. 39). Sus restos se encuentran en todas las alturas desde el río Magdalena (Villavieja, Aipe) hasta la Sabana de Bogotá (Mosquera). Otro gigante del Pleistoceno suramericano fue el Mastodonte (Haplomastodon waringi HOLLAND), que se alimentó de las hojas de árboles selváticos y no de gramíneas como los elefantes, sus parientes actuales.

Uno de los últimos seres vivientes aparecidos en Suramérica fue el Homo sapiens. La mayoría de los antropólogos supone, que atravesó el Estrecho de Bering durante el Würm-Interstadial (Brady), es decir hace unos 35.000 años y se extendió progresivamente hacia Norte y Suramérica. Sus descendientes son los indígenas americanos. Además es una suposición bastante generalizada que antes de la inmigración del Homo sapiens desde el Asia Oriental, ningún ser humano o prehumano pobló la tierra americana. Sin embargo, en la base de la terraza de Garzón, $145 \mathrm{~m}$. encima del cauce actual del río Magdalena, se hallaron hace pocos años herramientas de ópalo, las cuales, sin duda, fueron talladas y usadas por un ser apreciablemente inteligente (H. BUURGL 1957). Junto con estas hachas de mano y piedras de moler primitivas se hallaron también huesos de Megaterio y una muela de Mastodonte. TH. VAN DER HAMMEN (1957) y H. BÜRGL (1957) consideran la edad de la terraza de Garzón como Mindel
(Kansas), es decir que terminó de formarse hace unos 180.000 años. Al estado actual de nuestros conocimientos de los fenómenos pleistocenos parece que el Homo sapiens sí tuvo un precursor en Suramérica, que vivió contemporáneamente con los Mastodontes y Megaterios.

\section{BIBLIOGRAFIA CITADA}

Una lista bibliográfica más completa sobre la geología de Colombia se encuentra en

RAMIREZ J. E.

Bibliografía de la Biblioteca del Instituto Geofísico de Los Andes Colombianos sobre Geología y Geofísica de Colombia. Seg. ed. corr. y aument. Inst. Geof. de Los Andes Colomb., Boletín N 6, 221 pp., Bogotá.

VENEGAS LEYVA, A.

Bibliografía de los informes del Instituto Geológico Nacional. Comp. Estud. Geol. Ofic. Colombia, t. IX, 591 pp., Bogotá.

\section{ANDERSON, F. M.}

(1927) The Marine Miocene Deposits of North Colombia. - Calif. Acad. Sci. Proc. 16, № 3 , pp. 87-95, pls., San Francisco.

(1928) Notes on the Lower Tertiary Deposits of Colombia and their Molluscan and Foraminiferal Fauna. - Calif. Acad. Sci. Proc. 17, No 1 , pp. 1-29, 1 pl., 11 figs., San Francisco.

(1929) Marine Miocene and related deposits of North Colombia. - Calif. Acad. Sci. Proc. 18, № 4, pp. 73-213, pls. 8-23, San Francisco.

BARRIOS M., M.

(1960) Algunos Moluscos del Terciario medio de Colombia. - Boletín Geol., Vol. VI, 12 pls., en prensa.

BASSE, E.

(1936 a) Quelques remarques sur le caractère mediterranéen des faunes aptiennes de la province sud-andine. - C. R. somm. S. G. France, p. 125, París.

(1936 b) Sur la faune malacologique de Crétacé moyen de la Cordillere andine. - C. R. somm. S. G. France, pp. 87-88, París.

(1942) Révison des genres néocrétacés sud-américains: Lenticeras GERHARDT etc. - Bull. S. G. France, 5, pp. 351-363, 1 pl., París.

(1948) Quelques Ammonites nouvelles du Crétacé de Colombie (Am. Sud.). - Bull. S. G. France, 5, XVIII, pp. 691-698, 1 pl., París.

(1950) Quelques Mollusques du Crétacé de Colombie. - Bull. S. G. France, 5, XX, pp. 245 255, 1 pl., París.

BENAVIDES-CACERES, V. E.

(1956) Cretaceous System in Northern Perú. - Bull. Amer. Mus. Nat. Hist., vol. 108, art. 4, pp. $355-493,58$ figs., 66 pls., New York.

BERGT, W.

(1899) Geologische Studien in der Republik Colombia, II, Petrographie. 2, Die älteren Massengesteine. - En W. REISS \& A. STUBEL, Reisen in Südamerika, Asher \& Co. Berlín.

(1907) Zur Geologie der colombianischen Mittelkordillere. - Centr. Bl. f. Mineralogie etc., Jahrg. 1907, No 23, pp. 720-722, Stuttgart.

BERRY, E. W

(1918) Age of certain Plant-bearing beds and associated Marine Formations in South America. Bull. Geol. Soc. Amer. 30, pp. 637-648. 


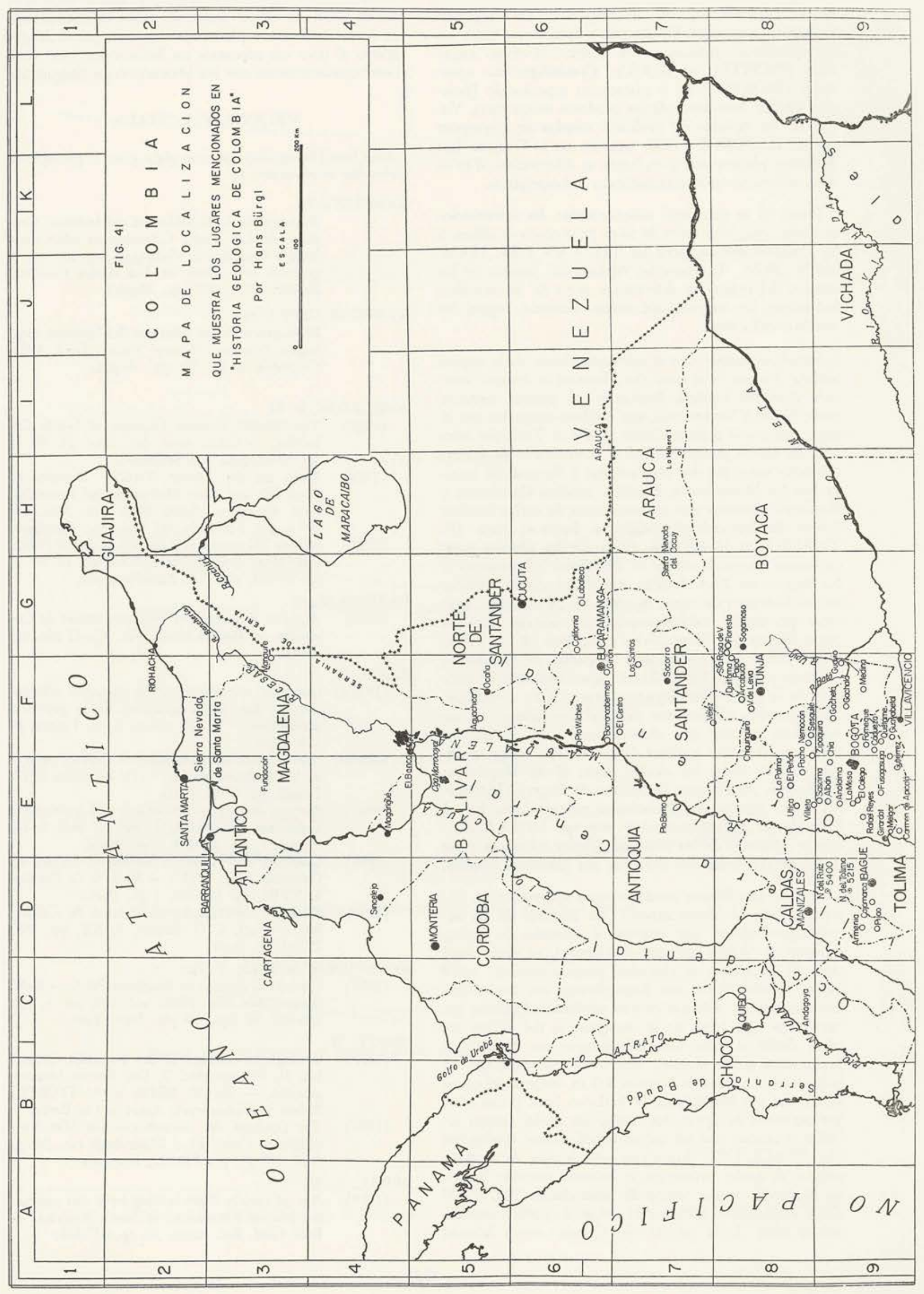


(1924 a) American Tertiary Terrestrial Plants and their interdigitation with Marine Deposits. - Bull. Geol. Soc. Amer. 35, p. 782.

(1924 b) A fossil Celtis from Colombia. - Torreya 24, pp. 44-46, fig.

(1924 c) Fossil fruits from the Eastern Andes of Colombia. - Bull. Torrey Bot. Club 51, pp. 61-67, traducido al español en 1937, Bol. Min. Petrol. Nos. 97-102, pp. 243-252, Bogotá.

(1924 d) An Oligocene Cashew Nut from South America. - Amer. Journ. Sci. 8, No 44, pp. 123126 , figs.

(1924 e) New Tertic Species of Anacardium and Vantanea from Colombia. - Pan Amer. Geol. 42 , No 11 , pp. $259-262$.

(1925) A species of Musa in the Tertiary of South America. - Nat. Acad. Sci. U. S. Amer. Proc. 11, № 6, pp. 298-299.

(1929) Tertiary Fossil Plants from Colombia, South America. - U. S. Nat. Mus. Proc. 75, No 2795 , pp. 1-12, pls.

(1936) Miocene Plants from Colombia. - Bull. Torrey Bot. Club. 63, № 2, pp. 53-66, pls., figs.

Traducido en español 1937; Plantas miocénicas de Colombia, Bol. Min. Petrol., Nos. 97. 102, pp. 221-241, Bogotá.

(1937) Un banano del Terciario de Colombia. - Bol. Min. Petrol. Nos. 97-102, pp. 253-263, Bogotá.

(1945) Late Tertiary Fossil Plants from Eastern Colombia. - John Hopkins Univ. Stud. Geol. No 14 , pp. 171-186, pls.

BEURLEN, $\mathrm{K}$.

(1938) Algunos fósiles cretácicos (vermes, equínidos, crustáceos) de la Cordillera Oriental. - Estud. Geol. Paleontol. sobre la Cordillera Oriental de Colombia, parte III, pp. 128-136, 1 pl., 9 figs., Bogotá.

BOCK, W.

(1953 a) American triassic Estherids. - Journ. Paleont., vol. 27 , No 1 , pp. $62-76,3$ pls.

(1953 b) Howellisaura, new name for Howellites BOCK. - Journ. Paleont., vol. 27, № 5, p. 759 .

BOLLI, H.

(1957) Planctonic Foraminifera from the Oligo-Miocene Cipero and Lengua formations of Trinidad. B. W. I. - Studies in Foraminifera, U. S. Nat. Museum Bull. 215, pp. 97-123, 8 pls., 5 figs., Washington.

BOTERO ARANGO, G.

(1940) Geología sobre el Ordoviciano de Antioquia. Minería 17, N⿳999, pp. 8249-8256, Medellín.

BOTERO RESTREPO, G.

(1950) Reconocimiento geológico del área comprendida por los municipios de Belén, Cerinza, Corrales, Floresta, Nobsa y Santa Rosa de Viterbo, Departamento de Boyacá. - Compil. Estud. Geol. Ofic. Colombia, vol. VIII, pp. 245-311, pls. 48-90, Bogotá.

BUCH, LEOP. VON

(1839) Pétrifications recueillis en Amérique par Mr. A. de Humboldt et par Charles Degenhardt. Reimpreso en EWALD, ROTH \& DAMES, Leopold von Buchs Gesammelte Schriften, 4. Band, 2. Hälfte, pp. 519-542, pls. 30 y 31 , Berlín 1885.

BƯRGL, H.

(1954) El Cretáceo inferior en los alrededores de Villa de Leiva. - Bol. Geol., vol. 2, No 1, pp. 5-22, 4 pls., Bogotá.
(1955 a) El Guadalupe entre Tabio y Chía. - Bol Geol., vol. 3, № 2, pp. 23-55, 4 pls., Bogotá.

(1955 b) Globorotalia fohsi en la Formación Usme. Bol. Geol. vol. 3, № 2, pp. 56-65, 1 fig., Bogotá.

(1956 a) Situación geológica de las minas de esmeraldas de Muzo. Rev. Acad. Colomb. Cienc. Exactas, Físico-Químicas y Natur., vol. IX, Nos. 36 y 37, pp. 381-388, 2 pls., Bogotá.

(1956 b) Catálogo de las Amonitas de Colombia I. Bol. Geol., vol. 4, № 1, p. $1-119,28$ pls., Bogotá.

(1957 a) Biostratigrafía de la Sabana de Bogotá y alrededores. - Bol. Geol. vol. 5, № 2, pp. 113 185, 20 pls., Bogotá.

(1957 b) Artefactos paleolíticos de una tumba en Garzón, Huila. - Rev. Colomb. Antropología, vol. 6, pp. 7-24, pls. I-XI, Bogotá.

(1960 a) Geología de la Península de la Guajira. Bol. Geol., vol. VI, Nos. 1-3, 5 figs., 20 fotos, 1 pl., Bogotá. En prensa.

(1960 b) El Jurásico e Infracretáceo del Río Batá. Bol. Geol., vol. VI, No 1, 20 fotos, 6 pls., Bogotá. En prensa.

(1960 c) Sedimentación cíclica en el geosinclinal cretáceo de la Cordillera Oriental de Colombia. Serv. Geol. Nal., Informe $N^{\circ} 1347,60$ pp., 10 figs. Inédito.

BÜRGL, H., BARRIOS, M. \& RÖSTRÖM, A

(1955) Micropaleontología y Estratigrafía de la sección Arroyo Saco, Depto. del Atlántico. Bol. Geol., vol. 3, No 1, pp. 1-114, 9 pls., Bogotá.

BÜRGL, H. \& DUMIT TOBON, Y.

(1954) El Cretáceo Superior en la región de Girardot. - Bol. Geol., vol. 2, No 1, pp. 23-48, 12 fotos, 8 pls., Bogotá.

BUTLER JR., J. W.

(1942) Geology of Honda District, Colombia. - Bull Amer. Assoc. Petrol. Geol., vol. 26, № 5, pp. 793-837, 14 figs.

CASTER, K. E

(1939) A Devonian Fauna form Colombia. - Bull. Amer. Paleontol., vol. 24, pp. 1-218, 14 pls. Ithaca.

CLARK, B. L. \& DURHAM, J. W.

(1946) Eocene Faunas from the Department of Bolívar, Colombia. - Geol. Soc. Amer., Mem. 16 , pp. $1-126,28$ pls., Baltimore, MD.

COOKE, C. W.

(1955) Some cretaceous Echinoids from the Americas. - Geol. Surv. Prof. Paper 264-E, pp. 87112 , pls. 18-28, Washington.

CUERVO MARQUEZ, L.

(1938) Especies extinguidas, hallazgos fósiles en la sabana de Bogotá. - Rev. Acad. Colomb. Cienc. Exact. Fís. Natur., vol. 2, № 5, pp. 38-42, figs., Bogotá.

CUSHMAN, J. A. \& HEDBERG, H. D.

(1941) Upper Cretaceous Foraminifera from Santander, Colombia, Contrib. Cushman Labor. Foram. Res., vol. 17, part 4, pp. 79-100, 3 pls., Sharon, Mass.

DESHAYES, G. P.

(1824-37) Description des coquilles fossiles des environs de Paris. 2 tomos, Paris. 
DICKEY, P. A.

(1941) Pre-cretaceous sediments in the Cordillera Oriental of Colombia. - Bull. Americ. Assoc. Petr. Geol., vol. 25, № 9, pp. 1789-1795, figs.

DIETRICH, W. O.

(1938) Lamelibranquios cretácicos de la Cordillera Oriental. - Estud. Geol. y Paleontol. sobre la Cordillera Oriental de Colombia, parte 3, pp. $81-127,8$ pls., Bogotá.

ESPRIELLA, R. DE LA

(1960) Investigaciones sobre carbones en el límite Albiano-Cenomaniano al sureste de Bogotá. Serv. Geol. Nal., informe inédito.

ESPRIELLA, R. DE LA \& H. VILLEGAS, $H$.

(1960) Geología de la carretera Bogotá-Choachí. Serv. Geol. Nal. Informe No 1356, 27 pp., 1 pl., 2 figs., 8 fotos, inédito.

EUGSTER, $\mathrm{H}$.

(1922) Zur Geologie der columbianischen Ostkordilleren. - Ecl. Geol. Helv. vol. 17, No 2, pp. 251-266, 1 pl., 4 figs.

FORBES, E

(1845) Report on the Fossils from Santa Fé de Bogotá, presented to the Geological Society by Evan Hopkins, Esqu. F. G.S. - Quart. Journ. Geol. Soc. London, vol. 1, pp. 174-179, 8 figs., London.

FRITZSCHE, C. H.

(1923) Neue Kreidefaunen aus Südamerika (Ammoniten aus Turon und Senon von Kolumbien). N. Jahrb. f. Mineral. etc., Beilageband 50, pp. 1-56, 313-334, 9 figs., Stuttgart.

GANDOLFI, R.

(1955) The Genus Glototruncana in Northeastern Colombia. - Bull. Amer. Paleontol., vol. 36, No 155 , pp. $1-118,10$ pls., Ithaca, N. Y.

GANSSER, A.

(1950) Geological and Petrographical Notes on Gorgona Island in relation to North-Western South America. - Bull. Suisse de Min. et Pétr., vol. 30, pp. 219-237, 6 figs., 5 pls.

(1954) The Guiana Shield (S. America). - Ecl. Geol. Helv., vol. 47, pp. 77-112, 12 figs., 4 pls.

(1955) Ein Beitrag zur Geologie und Petrographie der Sierra Nevada de Santa Marta (Kolumbien, Südamerika). - Schweiz. Mineral. und Petrog. Mitt., Bd. 35, Heft 2, pp. 209-279, 1 pl., 36 figs., Zürich.

GERHARDT, $\mathrm{K}$.

(1897) Beitrag zur Kenntnis der Kreideformation in Colombien. N. Jahrb. f. Mineral. etc., Beilageband 11, pp. 118-208, 5 pls., 14 figs., Stuttgart.

GERTH, H.

(1939) Die Kordilleren von Südamerika. - En Regionale Geologie der Erde, Bd. 3, Abschnitt IVb, pp. 1-63, 1 pl., 12 figs., Leipzig.

(1955) Bau der südamerikanischen Kordillere. - 264 pp., 6 pls., 20 diagr., 12 figs., Leipzig.

(1957) Die Bedeutung der alten Kerne für die geologische Struktur der jungen Kordillere. Geol. Rundsch., 45, Heft 3, pp. 707-721, 1 fig., Stuttgart.

GERTH, H. \& KRÄUSEL, R.

(1931) Beiträge zur Kenntnis des Carbons in Südamerika. - N. Jahrb. f. Miner. etc. Beilageband 65, pp. 521-543, Stuttgart.
GROSSE, E.

(1926) Geologische Untersuchung des kohlenführenden Tertiärs Antioquias; Estudio geológico del Terciario carbonífero de Antioquia. 361 pp., 105 figs., 4 mapas, D. Reimer Berlín.

(1935) Acerca de la geología del sur de Colombia II. - Compil. Estud. Geol. Ofic. Colombia, vol. 3, pp. 139-231, figs. 49-85, 3 pls., Bogotá.

HAMMEN, TH. VAN DER

(1957) Las terrazas del río Magdalena y la posición estratigráfica de los hallazgos de Garzón. Rev. Colomb. Antropología, vol. 6, pp. 261. 270, 2 figs., Bogotá.

(1959) Historia de clima y vegetación del Pleistoceno superior y del Holoceno de la Sabana de Bogotá. - Serv. Geol. Nal. Informe $N^{\circ} 1322$.

(1960) Estratigrafía del Terciario y del Maestrichtiano y Tectogénesis de los Andes colombianos. Bol. Geol., vol. 7, Nos. 1 y 2, 7 pls., en prensa.

HARRINGTON, J. \& KAY, M.

(1951) Cambrian and Ordovician faunas of eastern Colombia. - Journ. Paleont., vol. 25, № 3, pp. $655-668,2$ pls.

HARRISON, J. V.

(1930) The Magdalena Valley, Colombia, South America. - C. R. 15th Int. Geol. Congr. Pretoria, 2, pp. 399-409.

HEINZ, R.

(1928) Uber die Oberkreide-Inoceramen Südamerikas und ihre Beziehungen zu denen Europas und anderer Gebiete. Beiträge zur Kenntnis der oberkretazischen Inoceramen V. Mitt. Min. Geol. Staatsinstitut Hamburg, Heft 10, pp. $41-100,1$ pl., fig.

HETTNER, A.

(1892) Die Kordillere von Bogotá. - Petermanns Mitt., Bd. 22, Ergänzungsheft 104, 131 pp., figs., Gotha.

(1907) Zur Geologie der columbianischen Zentralkordillere. - Centr. Bl. f. Min. etc., pp. 545-547, Stuttgart.

HOFFSTETTER, FUENZALIDA \& CECIONI

(1957) Chile. - Lexique Stratigraph. Intern., vol. V, fasc. 7, 444 pp., Congr. Géol. Intern. París.

HUBACH, E.

(1931) Exploración en la región de Apulo-San Antonio-Viotá - Bol. Min. Petrol., vol. 4, Nos. 25-27, pp. 41-60, Bogotá.

(1933) Columna estratigráfica en la Cordillera Oriental, Fajas interior u oriental de la Cordillera en Cundinamarca y Boyacá. - Bol. Min. Petrol. Nos. 49-54, p. 123 , Bogotá.

(1945) La formación "Cáqueza", región de Cáqueza, Oriente de Cundinamarca. - Comp. Estud. Geol. Ofic. Colombia, vol. 6, pp. 23-26, 1 pl., Bogotá.

(1957 a) Contribución a las unidades estratigráficas de Colombia. Inst. Geol. Nal., Informe N 1212, 166 pp., inédito.

(1958) Estratigrafía de la Sabana de Bogotá y alrededores. - Bol. Geol., vol. 5, № 2, pp. 93-112, 3 pls., Bogotá.

HUBACH, E. \& ALVARADO, B.

(1934) Estudio geológico de la ruta Popayán-Bogotá. - Serv. Geol. Nal., Informe No 213, inédito.

(1945) La altiplanicie de Paletará, Departamento del Cauca. - Comp. Estud. Geol. Ofic. Colombia, vol. 6 , pp. $39-59,3$ pls., Bogotá. 
HUERTAS, G. G. \& VAN DER HAMMEN, TH.

(1953) Un posible banano (Musa) fósil del Cretáceo de Colombia. - Rev. Acad. Colomb. Ciencias Exact., Fís.-Químicas y Nat., vol. IX, Nos. 33 y 34, pp. 115-118, 1 pl., Bogotá.

JAWORSKI, E.

(1922) Die marine Trias in Südamerika. - N. Jahrb. f. Min. etc., Beilageband 47, pp. 93-200, 2 pls., Stuttgart.

(1938) Gasterópodos del Cretácico inferior de Colombia. - Estud. Geol. y Paleont. sobre la Cord. Oriental de Colombia, parte 3, pp. 109-121, 1 pl., Bogotá.

JOURNAUX, A. \& NICHOLLS, V. E.

(1959) Aspectos morfológicos de la Cordillera Oriental Colombiana. - Rev. Acad. Colomb. Cienc. Exact., Fís. y Natur., vol. X, No 41, pp. 315 326, 11 figs., 11 fotos, Bogotá.

JULIVERT, M.

(1959) Geología de la vertiente W del macizo de Santander en el sector de Bucaramanga. - Bol. de Geol., No 3, pp. 15-34, 12 figs., Bucaramanga.

KARSTEN, $\mathrm{H}$.

(1856) Géologie de l'ancienne Colombie bolivarienne, Venezuela, Nouvelle-Grénade et Ecuador. 60 pp., 6 pls., 11 sec. geol., Berlín, Friedländer.

KEHRER, G.

(1933) El Carboniano del borde llanero de la Cordillera Oriental. - Publ. Colegio Alemán, № 4, 21 pp., 2 pls., Bogotá.

(1935) Estudios geológicos en un viaje por Nariño y el Alto Putumayo. - Bol. Min. Petrol. 13, Nos. 73-78, Bogotá.

(1939) Zur Geologie der südlichen Zentral und Ostkordillere der Republik Kolumbien. - N. Jahrb. Min. etc., Beilageband 80, pp. 1-30, Stuttgart.

LANGENHEIM, J. H.

(1959) Preliminary notes on plant fossils from late paleozoic and early mesozoic rocks in the Cordillera Oriental of Colombia. - Bol. de Geol., № 3, pp. 51-54, Bucaramanga.

LANGENHEIM JR., R. L.

(1959) Preliminary report on the stratigraphy of the Girón formation in Santander and Boyacá. Bol. de Geol., No 3, pp. 35-50, 4 figs., Bucaramanga.

LEA, I.

(1840) Notice of the Oolitic Formation in America, with descriptions of some of its Organic Remains. - Trans. Amer. Phil. Soc. 2d Series, vol. 7, pp. 1-10, 3 pls.

LIPPS, TH.

(1938) Acerca de la flora subcretácica de Colombia. Estud. Geol. y Paleont. sobre la Cordill. Orient. Colombia, parte 3, pp. 137-144, 2 pls., Bogotá.

LLERAS CODAZZI, $\mathrm{R}$.

(1926) Notas geográficas y geológicas. - Bibl. Museo Nal., pp. 1-127, pls., Bogotá.

(1928) Las rocas de Colombia. - Bibl. Mus. Nal., pp. 1-102, Bogotá.

LYELL, CH.

(1832) Principles of Geology, Vol. II, Anexo.

MASSACHUSETTS INSTITUT OF TECHNOLOGY, DEPARTMENT OF GEOLOGY AND GEOPHYSICS
(1958) Samples from the Western Part of the Guayana Shield in Colombia. - Sixth Annual Progr. Rep., U.S.A. Atomic Energy Commission, p. 123-126.

MAYER-EYMAR, $\mathrm{K}$.

(1857) Essai d'un tableau synchronistique des terrains Tertiaires de l'Europe. - Impr. O. Füssli \& Co.

MCNAIR, A. H.

(1940) Devonian Bryozoa from Colombia. - Bull. Amer. Paleont., vol. 25, № 93, 34 pp., 6 pls., Ithaca, N. Y.

MILLER, A. K. \& WILLIAMS, V. ST.

(1945) Permian cephalopods from northern Colombia. - Journ. Paleont., Vol. 19, № 4, pp. 347-349, 1 fig., 1 pl.

MOOK, C. C.

(1941) A new fossil crocodilian from Colombia. U. S. Nat. Mus. Proc., vol. 91, pp. 55-58, 6 pls.

MOORE, R. C.

(1958) Introduction to Historical Geology. - 2 nd ed., 656 pp., figs., pls., McGraw-Hill Book Comp., New York, Toronto, London.

MORALES, L. G. \& COLOMBIAN PETROLEUM

INDUSTRY

(1958) General Geology and Oil Occurences of Middle Magdalena Valley, Colombia. - En L. G. WEEKS, Habitat of Oil, pp. 641-695, 29 figs., Amer. Assoc. Petr. Geol., Tulsa.

NELSON, H. W.

(1957) Contribution to the geology of the Central and Western Cordillera of Columbia in the sector between Ibagué and Cali. - Leidse Geol. Meded., deel 22, pp. 1-76, 28 figs., 6 pls., Leiden.

NEUMANN, R.

(1907) Beiträge zur Kenntnis der Kreideformation in Mittel-Perú. - N. Jahrb. f. Min. etc., Beilageband 24, pp. 69-132, 5 pls., 2 figs., Stuttgart.

NEWELL, N. D., CHRONIC, J. \& ROBERTS, T. G.

(1953) Upper Paleozoic of Peru. - Geol. Soc. Amer. Mem. 53, 276 pp., 43 pls., New York.

NOETH, L.

(1938) Dos especies de equínidos del neocomiano de Colombia. - Estud. Geol. y Paleont. sobre la Cord. Orient. de Colombia, parte 3, pp. 122136, 1 pl., Bogotá.

NOTESTEIN, F. B., HUBMAN, C. W. \& BOWLER, J. W.

(1944) Geology of the Barco Concession, Republic of Colombia, South America. - Geol. Soc. Amer. Bull., vol. 55, pp. 1165-1216, 10 figs., 6 pls.

NYGREN, W. E.

(1950) Bolivar Geosyncline of Northwestern South America. - Amer. Ass. Petr. Geol. Bull., vol. 34 , № 10 , pp. 1998-2006, 3 figs.

OLSSON, A. A.

(1956) Colombia. - En W. F. JENKS, Handbook of South American Geology. Geol. Soc. America, Mem. 65, pp. 293-326, 2 figs., New York.

OLSSON, A. A. \& CASTER, K. E.

(1937) Devonian Fossils from Colombia, South America. - Proc. Geol. Soc. America, 1936, p. 369.

OPPENHEIM, V.

(1940 a) Glaciaciones cuaternarias en la Cordillera 
Oriental de la República de Colombia. Rev. Acad. Colomb. Cienc. Exact. Fís. Natur., vol. 4, № 13, pp. 70-82, 1 pl., figs., Bogotá.

(1940 b) Jurassic-Cretaceous (Giron) Beds in Colombia and Venezuela. - Amer. Ass. Petrol. Geol. Bull., vol. 24, № 9, pp. 1612-1619, fotos.

(1941) Geología del sur de la Cordillera Orienta entre los Llanos y el Magdalena. - Bol. Min. Petrol. (1939-1940), Nos. 121-144, pp. 81-95; 3 pls., Bogotá.

ORBIGNY, A. D'.

(1842) Coquilles et échinodermes fossiles de Colombie, recueillis par M. Boussingault. - 64 pp., 6 pls., Bertrand París, Levrault Strassbourg.

OSPINA, $\mathrm{T}$.

(1911) Reseña sobre la geología de Colombia y especialmente del antiguo departamento de Antioquia. - 102 pp., Medellín.

PABA SILVA, F. \& VAN DER HAMMEN, TH.

(1960) Sobre la geología de la parte S de la Macarena, Intendencia del Meta. - Serv. Geol. Nal., informe $\mathrm{N}^{\circ} 1321,16$ pp., 3 pls., 13 fots., inédito.

PAPP, A.

(1959) Tertiär, 1. Teil. Grundzüge regionaler Stratigraphie. - En F. LOTZE, Handbuch der Stratigraphischen Geologie; 411 pp., 89 figs., 63 tab., Stuttgart.

PAULCKE, W

(1903) Über die Kreideformation in Südamerika und ihre Beziehungen zur anderen Gebieten. N. Jahrb. f. Min. etc., Beilageband 17, pp. 252-312, 3 pls., 4 figs., Stuttgart.

PETTERS, V.

(1954) Typical Foraminiferal Horizons in the Lower Cretaceous of Colombia, S. A. - Contr. Cushman Found. Foram. Res., vol. 5, part 3, pp. 128-137, 7 figs., 1 pl.

(1955) Development of Upper Cretaceous foraminiferal faunas in Colombia. - Journ. Paleont., vol. 29 , pp. $212-225,7$ figs.

PETTERS, V. \& SARMIENTO, R.

(1956) Oligocene and Lower Miocene biostratigraphy of the Carmen-Zambrano area, Colombia. Micropaleontology, vol. 2, № 1 , pp. 7-35, 1 pl., 2 figs., 7 tabls.

PILSBRY, H. A. \& OLSSON, A. A.

(1935) Tertiary Fresh-Water Mollusks of the Magdalena Embayment, Colombia. - Acad. Nat. Sci. Proc., vol. 77, pp. 7-21. Traducido en español en 1941, Rev. Acad. Colomb. Cienc. Exact. Fís. Natur., vol. 4, Nos. 15 y 16, pp. 410-417, Bogotá.

PORTA, J. DE

(1959) La terraza de Bucaramanga. - Bol. de Geol., No 3, pp. 5-13, 1 pl., Bucaramanga.

RAASVELDT, H. C.

(1957) Las glaciaciones de la Sierra Nevada de Santa Marta. - Rev. Acad. Colomb. Cienc. Exact. Fís.-Quím. y Natur., vol. 9, № 38, pp. 469. 482, 20 figs., 1 pl., Bogotá.

RAMIREZ, J. E.

(1953) Excursión a la Cueva de los Guácharos, Corregimiento de Palestina, Municipio de Pitalito, Depto. del Huila. - Rev. Javeriana, vol. 40, ํo 199, pp. 197-208, fotos, figs., Bogotá.
REDMOND, C. D.

(1953) Miocene Foraminifera from the Tubara beds of Northern Colombia. - Journ. Paleont., vol. 27 , No 5 , pp. 708-733, pls. 74-77, 1 fig.

REINHART, R. H.

(1951) A new Genus of Sea Cow from the Miocene of Colombia. - Bull. Dep. Geol. Sci., vol. 28, No 9, pp. 203-214, figs.

RENZ, O.

(1956) Cretaceous in Western Venezuela and the Guajira (Colombia). - 20th session Int. Geol. Congr. Mexico City, 13 pp., 6 pls., Manuscrito.

REYMENT, R. A.

(1955) The Cretaceous Ammonoidea of Southern Nigeria and the Southern Cameroons. - Geol. Surv. Nigeria, Bull. 25, 112 pp., 24 pls.

(1958) Über einige Ammoniten aus dem Coniac Kolumbiens und Venezuelas, Südamerika. Stockholm Contrib. Geology, vol. II: 1, pp. 1-24, 4 pls., 10 figs., Stockholm.

REYMOND, E.

(1942) Informe sobre los yacimientos de azufre del Macizo del Ruiz, en los departamentos de Caldas y Tolima. - Comp. Estud. Geol. Ofic. Colombia, vol. 5, pp. 397-416, 4 figs., 3 pls., Bogotá.

(1938) Amonitas del cretácico inferior de la Cordillera Oriental. - Estud. Geol. y Paleont. sobre la Cord. Orient. de Colombia, parte 2, pp. 7-78, 12 pls., Bogotá.

ROD, E. \& MAINC, W.

(1954) Revision of Lower Cretaceous stratigraphy in Venezuela. - Amer. Assoc. Petrol. Geol. Bull., vol. 38, No 7, pp. 193-283, 30 figs., Tulsa.

ROYO Y GOMEZ, J.

(1941) Crustáceos y Seudopterópodos del Cretáceo de Colombia. - Bol. Min. Petrol. 1939-1940, Nos. 121-144, pp. 209-214, 8 figs., Bogotá.

(1942 a) Contribución al conocimiento de la geología del Valle superior del Magdalena (Departamento del Huila). - Compil. Estud. Geol. Ofic. Colombia, vol. 5, pp. 261-326, figs., pls. y fotos, Bogotá.

(1942 b) Fósiles devónicos de Floresta (Departamento de Boyacá). Compil. Estud. Geol. Ofic. Colombia, vol. 5, pp. 389-395, Bogotá.

(1942 c) Fósiles del Terciario Marino del Norte de Colombia. - Compil. Estud. Geol. Ofic. Colombia, vol. 5, pp. 461-488, Bogotá.

(1942 d) Datos para la geología económica de Nariño y Alto Putumayo. - Compil. Estud. Geol. Ofic. Colombia, vol. 5, pp. 53-180, 53 figs., pls., Bogotá

(1945 a) Fósiles carboníferos e infracretáceos del Oriente de Cundinamarca. - Compil. Estud. Geol. Ofic. Colombia, vol. 6, pp. 193-245, 7 pls., Bogotá.

(1945 b) Fósiles del Barremiense colombiano. - Compil. Estud. Geol. Ofic. Colombia, vol. 6, pp. 455484, 3 figs., 6 pls., Bogotá.

(1950) Geología de la Isla de Tierra Bomba, Cartagena. - Compil. Estud. Geol. Ofic. Colombia, vol. 8 , pp. 33-66, 2 pls., Bogotá.

RUTTEN, L.

(1940) Remarks on the geology of Colombia and Venezuela. - Koninkl. Nederl. Akad. van Wetensch., Proceedings, vol. 43, Nos. 3 y 4, pp. $340-349,472-483,485-493$. 
SAUER, W.

(1957) El mapa geológico del Ecuador. - 70 pp., 1 mapa, Ed. Univers., Quito.

SAVAGE, D. E.

(1951 a) Report on Fossil Vertebrates from the Upper Magdalena Valley, Colombia. - Science, vol. 114 , No 2955, pp. 186-187.

(1951 b) A Miocene Phyllostomatid Bat from Colombia. - Bull. Dep. Geol. Sci., vol. 28, No 12 , pp. 357-366.

SCHAUFELBERGER, P.

(1944) Apuntes geológicos y pedológicos de la zona cafetera de Colombia. - vol. 1, 94 pp., figs., fotos, mapas; Imprenta Oficial, Manizales.

SCHEIBE, E. A.

(1938) Estudios geológicos sobre la Cordillera Oriental. - Estud. Geol. y Paleont. Cordill. Orient. Colombia, parte 1 , pp. $1-58,6$ pls., Bogotá.

SCHEIBE, $R$.

(1925) Das Salzvorkommen von Nemocon. - N. Jahrb. f. Min. etc., Beilageband 53, pp. 315320 , Stuttgart.

(1926) Informe sobre los resultados del trabajo de la Comisión Científica Nacional en Antioquia. Docum. Comis. Cient. Nal., No 3, 1919, 71 pp. Bogotá. Reimpreso en Comp. Est. Geol. Ofic. Colombia, vol. 1, pp. 97-167, Bogotá 1933.

SCHLAGINTWEIT, O.

(1911) Die Fauna des Vracon und Cenoman in Peru. - N. Jahrb. f. Min. etc., Beilageband 33, pp. $43-135,5$ figs., 3 pls., Stuttgart.

SCHMIDT, W. E.

(1938) Fósiles paleozoicos de la Cordillera Oriental. Estud. Geol. y Paleont. Cordill. Orient. Colombia, parte 2, pp. 1-6, 2 pls., Bogotá.

SCHUCHERT, $\mathrm{CH}$.

(1935) Historical Geology of the Antillean-Caribbean Region. - 811 pp., 106 figs., 16 pls., John Willey \& Son, New York y London.

SHOCKLEY, O.

(1960) Colombia. En E. W. CLARK, Petroleum Developments in South America and Caribbean Area in 1959. - Bull. Amer. Assoc. Petrol. Geol., vol. 44, № 7, pp. 1022-1028, 2 pls.

SIEVERS, W

(1888) Erläuterungen zur geognostischen Karte der Sierra Nevada de Santa Marta. - Zeitschr. Ges. f. Erdkunde zu Berlín, No 137, pls.

SIMPSON, G. G.

(1940) Review of the mammal-bearing Tertiary of South America. Amer. Phil. Soc. Proc., vol. 38 , pp. $649-709,4$ figs.

(1943) Notes on mammal-bearing Tertiary of South America. - Amer. Phil. Soc. Proc., vol. 86, pp. $403-404$.

SOLMS-LAUBACH, H. GRAF ZU \& STEINMANN, G.

(1899) Das Auftreten und die Flora der rhätischen Kohlenschichten von La Ternera (Chile). N. Jahrb. f. Min. etc., Beilageband 12, pp. 581-609, 2 pls., Stuttgart.

SOMMERMEIER, L.

(1913) Die Fauna des Aptien und Albien im nördlichen Peru. Teil I. - N. Jahrb. f. Min. etc., Beilageband 36, pp. $370-412,2$ pls., Stuttgart.

STAINFORTH, R. M.

(1960) Current status of transatlantic Oligo-Miocene correlation by means of planctonic Foramini- fera. - Revue de Micropaleont., vol. 2, $\mathrm{N}^{\circ} 4$, pp. 175-180, París.

STEHLIN, H. G.

(1939) Ein Nager aus dem Miozän von Columbien. Ecl. Geol. Helv., vol. 32, pp. 179-183.

STEINMANN, G.

(1906) Uber Diluvium in Südamerika. - Monatsber. Deutsch. Geol. Ges., Jahrg. 1906, Nos. 8-10, pp. 1-16.

(1929) Geologie von Peru. - 448 pp., 271 figs., Heidelberg.

STILLE, H.

(1907) Geologische Studien im Gebiete des rio Mag dalena. - Festschr. Adolf von Koenen, pp 278-358, 8 figs., 1 pl.

(1940) Einführung in den Bau Amerikas. - 717 pp., figs., Bornträger Berlín.

STIRTON, R. A.

(1946 a) The first Lower Oligocene Vertebrate fauna from northern South America. - Compil. Estud. Geol. Ofic. Colombia, vol. 7, pp. 325 340, 3 pls., Bogotá.

(1946 b) A rodent and a peccary from the Cenocoic of Colombia. - Compil. Estud. Geol. Ofic. Colombia. Vol. VII, pp. 317-324, 1 pl., Bogotá.

(1953) Vertebrate paleontology and continental stratigraphy in Colombia. - Bull. Geol. Soc. Amer., vol. 64, No 6, pp. 603-622, 13 figs.

STIRTON, R. A. \& SAVAGE, D. E.

(1951) A new monkey from the La Venta Miocene of Colombia. - Compil. Estud. Geol. Ofic. Colombia, vol. 8, pp. 347-356, 7 pls., Bogotá.

STUTZER, O.

(1926 a) Ubber einige Ergebnisse meiner geologischen Reisen in Kolumbien. - Ber. Freiberger Geol. Ges., vol. 11, pp. 50-54.

(1926 b) Geologische Beobachtungen und Gedanken bei einer zweimaligen Durchquerung der kolumbianischen Mittel-Kordillere. - N. Jahrb. f. Min. etc., Beilageband 56, pp. 135 . 151, 1 fig., 1 pl., Stuttgart.

(1927) Zur Geologie der Umgegend von Gachalá im Osten der Ost-Kordillere. - N. Jahrb. f. Min. etc., Beilageband 57, p. 157, Stuttgart.

(1928) Zur Geologie der Goajira-Halbinsel. - N Jahrb. f. Min. etc., Beilageband 59, pp. 304-326, fotos, 1 mapa, Stuttgart. Traducido en español en 1934, Compil. Estud. Geol. Ofic. Colombia, vol. 2, pp. 211-243, 13 figs.

(1934) Acerca de algunos rastros de glaciación diluvial en la cordillera próxima a Bogotá. Compil. Estud. Geol. Ofic. Colombia, vol. 2, pp. 7-15, 5 figs., Bogotá.

SUAREZ HOYOS, V.

(1945) Reconocimiento de la región del río Guavio, Gachalá (Cundinamarca). - Compil. Estud. Geol. Ofic. Colombia, vol. 6, pp. 147-192, 2 pls., Bogotá.

TERMIER, H. \& G.

(1952) Histoire Géologique de la Biosphère. - 721 pp., 6 tabls. 105 figs., 4 pls., Masson \& Cie., París.

THENIUS, E.

(1959) Wirbeltierfaunen. - En F. LOTZE, Handbuch der Stratigraphischen Geologie, 3. Band 2. Teil, 328 pp., 32 tabls., 12 figs., 10 pls., Enke Stuttgart. 
THENIUS, E. \& BURGL, $\mathrm{H}$.

(1957) Los mamíferos suramericanos en perspectiva histórica. - Rev. Acad. Colomb. Cienc. Exact., Fís.Quím. y Natur., vol. 10, No 39, pp. 123130, 3 figs., Bogotá.

THOMPSON, M. L. \& MILLER, A. K.

(1949) Permian Fusulinids and Cephalopods from the vicinity of the Maracaibo Basin in Northern South America. - Journ. Paleont., vol. 23, No 1, pp. 1-24, 8 pls., 1 fig.

TOLMACHOFF, I. P.

(1934) A miocene microfauna and flora from the Atrato River, Colombia. - Carnegie Mus., Ann., vol. 23, pp. 275-356, figs., Pittbourgh.

TORRES, J. A.

(1959) Mapa Geológico de la República de Colombia, plancha N8 "Neiva", 1:200.000. - Serv. Geol. Nal.

TRUMPY, D.

(1943) Pre-Cretaceous of Colombia. - Bull. Geol. Soc. America, vol. 54, pp. 1281-1304, 1 pl., 6 figs.
WALTHER, I.

(1924) Das Gesetz der Wüstenbildung. - 421 pp., 203 figs., Quelle \& Mayer, Leipzig.

WEEKS, L. G.

(1947) Paleogeography of South America. - Bull. Amer. Ass. Petr. Geol., vol. 31, No 7, pp. 1194-1241, 17 figs.

(1959) Geologic architecture of circum-pacific. Bull. Amer. Ass. Petr. Geol., vol. 43, № 2, pp. $350-380,8$ figs.

WEISBORD, N. E.

(1926) Venezuelan Devonian Fossils. - Bull. Amer. Paleont., vol. $11, N^{\circ} 46$, pp. $220-272,7$ pls., Ithaca, N. Y.

WERENFELS, A.

(1926) A stratigraphical section through the Tertiary of Tuloviejo, Colombia. - Ecl. Geol. Helv. vol. 20, No 1, pp. 79-83, 2 figs., Basel.

WHEELER, O. C.

(1935) Tertiary stratigraphy of the Middle Magdalena Valley. - Proc. Acad. Nat. Sci. Philadelphia, vol. 87 , pp. 21-39.

\section{CONTENIDO}

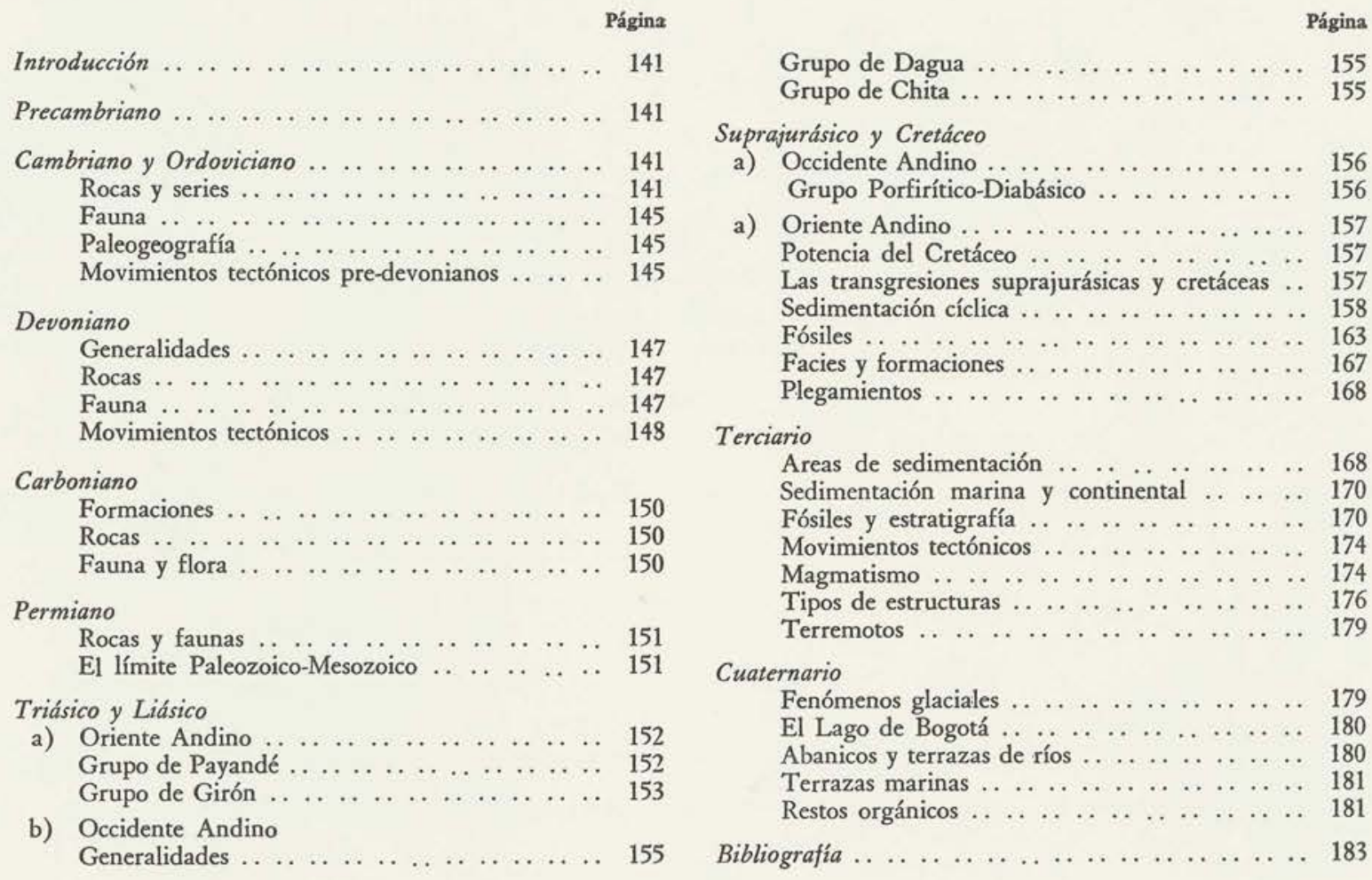

